
Historic, archived document

Do not assume content reflects current scientific knowledge, policies, or practices. 


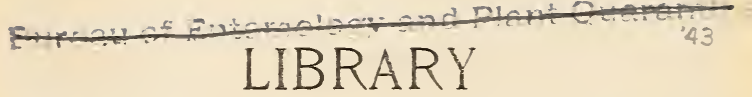

352261

OF THE

UNITED STATES

DEPARTMENT OF AGRICULTURE

Class

$\&-1577$

Book EN \&23 




U. S. DEPARTMENT OF AGRICULTURE, BUREAU OF ENTOMOLOGY-BULLETIN No. 90.

L. O. HOWARD, Entomologist and Chief of Bureau.

\section{HYDROCYANIC-ACID GAS FUMIGATION IN CALIFORNIA.}

I. FUMIGATION OF CITRUS TREES.

$$
\begin{aligned}
& \text { U. S. Departmant of Agricuitur, } \\
& \text { Washingron, U. C. }
\end{aligned}
$$

By R. S. WOGLUM, M. S. A.. Special Field Agent.

II. THE VALUE OF SODIUII CYANID FOR FUMIGATION PURP0SES. By R. S. WOGLUM, M. S. A., Special Field Agent.

III. CHEMISTRY OF FUMIGATION WITH HYDROCYANIC-ACID GAS.

By C. C. McDONNELL, Chief, Insecticide and Fungicide Laboratory, Miscellaneous Division, Bureau of Chemistry.

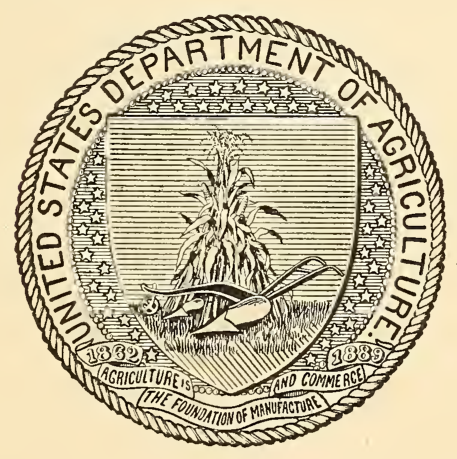

WASHINGTON:

GOVERNMEN'T PRINTING OFFICE.

1912. 


\section{BUREAU OF ENTOMOLOGY.}

L. O. Howard, Entomologist and Chief of Bureau.

C. L. Marlatt, Entomologist and Acting Chief in Absence of Chief.

R. S. Clifton, Executive Assistant.

W. F. Tastet, Chief Clerk.

F. H. Chittenden, in charge of truck crop and stored product insect investigations.

A. D. HopkINs, in charge of forest insect investigations.

W. D. Hunter, in charge of southern field crop insect investigations.

F. M. WeBster, in charge of cercal and forage insect investigations.

A. L. QuatnTance, in charge of deciduous fruit insect investigations.

F. F. Phillips, in charge of bee culture.

D. M. Rogers, in charge of preventing spread of moths, field work.

Rolla P. Currie, in charge of editorial "'ork.

MABEL ColCORD, in charge of library.

\section{Citrus Fruit Insect Investigations.}

C. L. Marlatt, in charge.

R. S. Woglum, W. W. Yothers, E. R. Sasscer, J. R. Horton, P. H. Thmberlake, C. E. Pemberton, H. L. Sanford, entomological assistants.

J. G. SANDERS, collaborator. 


\section{1.}

\section{LETTER OF TRANSMITTAL}

United States Department of Agriculture,

Bureau of Entomology, Washington, D. C., September 11, 1912.

SIR: I have the honor to transmit herewith, for publication as Bulletin No. 90 of this bureau, three papers comprising a report on an investigation of hydrocyanic-acid gas fumigation of citrus orchards in southern California. The preliminary report on the subject was published as Bulletin No. 79 of this bureau under the title "Fumigation Investigations in California." The present final report is divided into three parts, which were published separately on May 10 and 13, 1911: I, entitled "Fumigation of Citrus Trees," by R. S. Woglum, a special field agent of this bureau, containing the main report on the field investigations and discussing the various details of fumigation procedure; II, a paper by Mr. Woglum, "The Value of Sodium Cyanid for Fumigation Purposes"; and, III, one by Mr. C. C. McDonnell, Chief of the Insecticide and Fungicide Laboratory, Bureau of Chemistry, "Chemistry of Fumigation with Hydrocyanicacid Gas."

Respectfully,

L. O. Howard, Entomologist and Chief of Bureau.

Hon. James Wilson, Secretary of Agriculture. 



\section{PREFACE.}

An investigation into the methods of fumigating citrus trees with hydrocyanic-acid gas was commenced by the Bureau of Entomology, United States Department of Agriculture, during the summer of 1907, and for a period of three years has been carried on in California by the writer under the direction of Mr. C. L. Marlatt, assistant chief of the bureau. This work was undertaken in response to urgent requests from the horticultural commissions of the principal citrusfruit-producing counties of southern California and of many active fruit growers. Prominent in this movement was Mr. J. W. Jeffrey, former secretary of the Los Angeles County horticultural commission, and now State commissioner of horticulture-a man entirely familiar with the unsettled condition of fumigation practice at that time and with the need of placing it on a more scientific basis. At the commencement, the writer spent from three to four months in a thorough field investigation to acquaint himself with the conditions of citrus culture throughout southern California, the distribution of the different citrus pests and the damage caused by them, the existing methods for their control, and the methods of fumigation practiced in the various citrus districts.

During the early part of November, 1907, active experimental field work was commenced at Orange, Cal., using an outfit belonging to this bureau, consisting of four tents and the other paraphernalia necessary for practical fumigation. Field work of this character has been continued throughout, it being the writer's effort to conduct the investigation on as nearly a commercial basis as possible so that the conditions and results would be those normal to the ordinary care of citrus groves. During the work there have arisen many problems of a laboratory nature, the solution of which would have been most interesting, but these problems for the most part have been set aside except in those cases where they had a direct economic bearing on practical work in the field.

The results of this investigation have very little of the nature of original discoveries, although there has been acquired a vast amount of exact information never before thoroughly understood. The advance is largely the result of correcting, correlating, systematizing, and placing upon a more scientific as well as a more practical basis methods which had been practiced in California or elsewhere for many years. 
All information, as acquired, of direct bearing on the fumigation practice has been giren freely to the public as soon as its economic value was established, largely by means of addresses, demonstrations, and printed reports.

In the present bulletin an attempt has been made to present a * succinct account of the completed results of this fumigation investigation as well as a brief treatment of the salient features of fumigation as practiced in California at the present time. It is of the nature of a handbook on the most up-to-date equipment, methods, and directions in orchard fumigation. Full advantage has been taken of the results of other inrestigators in fumigation; yet in such cases due credit is given to the proper source. The information given in Bulletin 79 of this bureau, which is a preliminary report on this investigation, has been largely included in the present bulletin in summarized form.

The writer desires to acknowledge his indebtedness to the many people who have assisted him during this investigation and facilitated the progress which has been made. To Mr. C. L. Marlatt, Assistant Chief of the Bureau of Entomology, he is especially indebted for valuable assistance and adrice. Acknowledgment is also due to Mr. Frederick Maskew, who most capably assisted him in the performance of many of his experiments during the period from December, 1907, to August, 1909. Taluable assistance was rendered by Mr. E. R. Sasscer during the months of August, September, and October, 1909. Mr. W. W. Yothers was engaged in the work during Norember, 1909. To the Hon. J. W. Jeffrey, State commissioner of horticulture of California, credit is due not only for his activity in paving the way for this investigation, but also for the able support given by him since field work was commenced. To Mr. William Wood, of Whittier, Cal., the writer acknowledges his indebtedness for assistance in introducing the improred system of fumigation in the region adjacent to Whittier, as well as for practical advice with regard to citrus insects and their control, a subject about which Mr. Wood is especially well informed. This occasion is also taken to thank the various horticultural officers of southern California, packing-house managers, and the many citrus growers who have assisted and supported this inrestigation.

The cooperation of the Bureau of Chemistry of the United States Department of Agriculture has been an important adjunct of this investigation, and to MIr. J. K. Haywood, Chief of the Miscellaneous Division of that bureau, and his assistants the writer is indebted for the carrying out of all the chemical analyses and laboratory tests of materials and products necessary to the working out of the field experiments.

R. S. W. 


\section{CONTENTS:}

Fumigation of citrus trees.

R. S. Woglum.

Page.

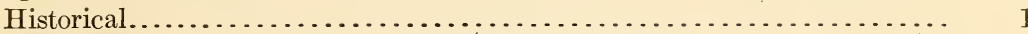

Recent renewal of interest in fumigation in California................ 2

Extent to which fumigation is practiced in California.............. 3

The various systems of fumigation........................... 4

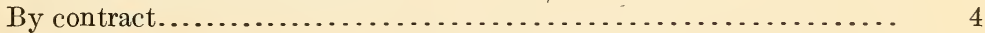

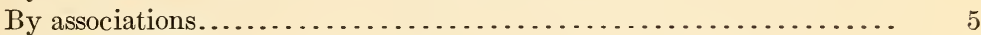

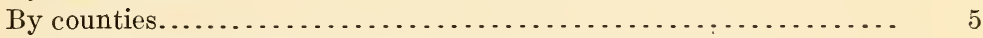

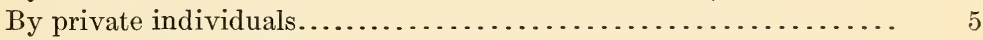

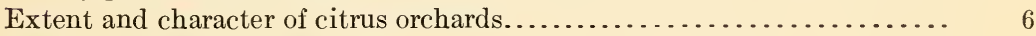

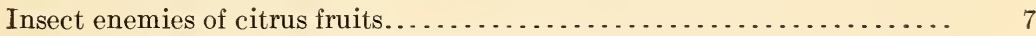

The purple scale (Lepidosaphes beckii Newm.)................. 8

The black scale (Saissetia oleæ Bern.)...................... . 8

The red scale (Chrysomphalus aurantii Mask.)................. 9

The yellow scale (Chrysomphalus citrinus Coq.)............... 10

The mealy-bug (Pseudococcus citri Risso)................... 10

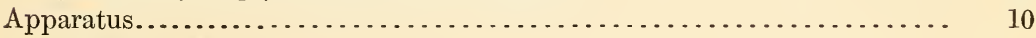

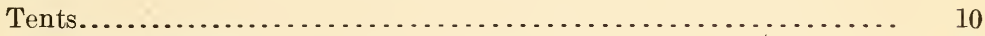

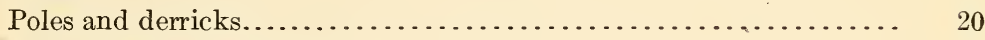

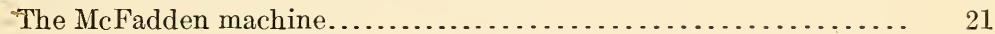

Supply cart and supply wagon.......................... 22

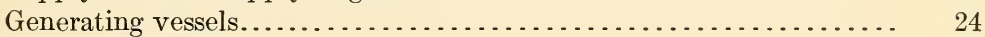

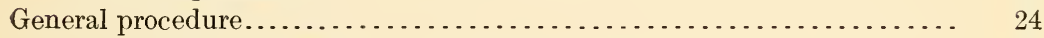

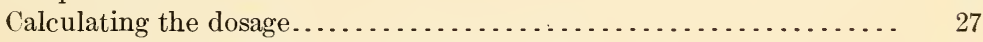

Securing the measurements around and over............... 28

The old method of procedure.......................... 30

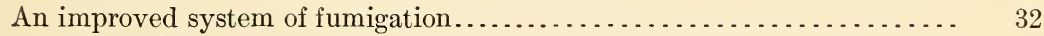

Leakage of gas. . . . . . . . . . . . . . . . . . . . . . . . 33

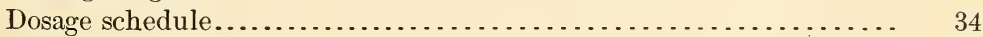

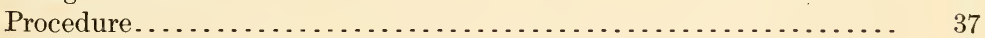

Advantages under this system.............................. 37

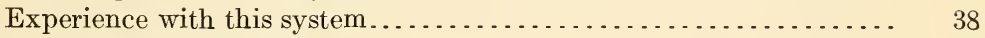

The chemicals in fumigation........................... 40

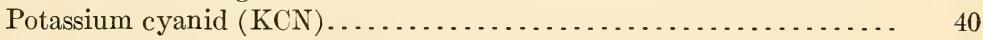

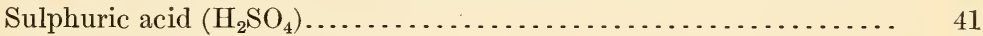

Water as a factor in fumigation............................. 44

The most economical proportion of chemicals to use........... 47

The amount of chemicals in very small dosages............... 48

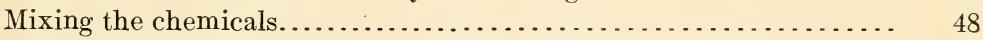

Effect of the presence of sodium chlorid on the amount of gas given off. $\quad 49$

Nature of the residue............................... 50

Dosages for various scale pests. . . . . . . . . . . . 51

Factors which affect the dosage............................. 52

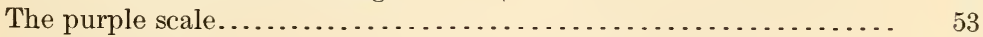

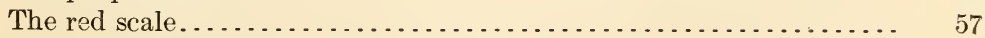

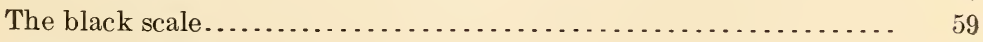

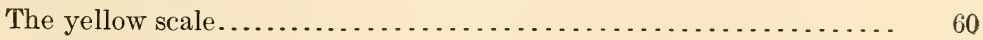

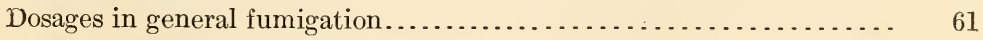

1 The three papers constituting this bulletin were issued, the first on May 13, 1911, and the last two on May 10, 1911. 
Fumigation of citrus trees-Continued.

Page.

Time of the year for fumigation $. . \ldots \ldots \ldots \ldots \ldots \ldots \ldots \ldots \ldots \ldots . .61$

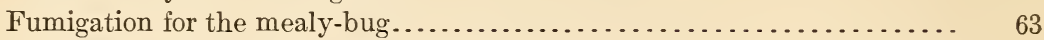

Fumigation during the blossoming period..................... 64

Fumigation while the fruit is of small size.................... 65

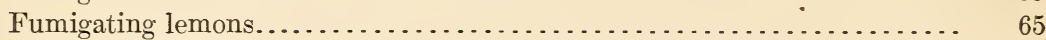

Effects of fumigation on unhealthy trees....................... 66

Greater susceptibility to injury of some varieties than others........... $\quad 67$

The distribution of gas within a tent.......................... 67

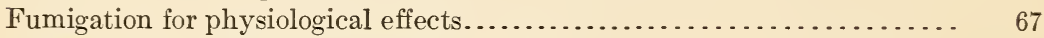

Effects of meteorological elements on fumigation................... 68

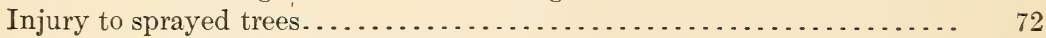

The appearance of fumigated trees............................ 73

The presence of old scales on fumigated trees.................... 74

A device for covering fumigation generators...................... 74

The effect of climatic conditions on scale insects................. $\quad 76$

The effect of fumigation on ladybirds (Coccinellidæ) and Scutellista cyanea

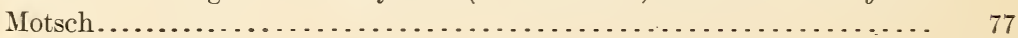

The cost of fumigation....................................... 78

General cautions........................................... 80

List of the writer's published articles and addresses on the fumigation

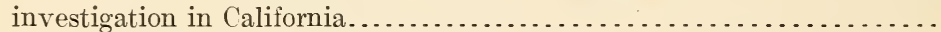

The value of sodium cyanid for fumigation purposes......... R. S. Woglum..

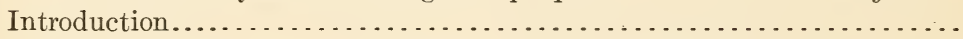

Strength of sodium cyanid expressed in terms of potassium cyanid.......

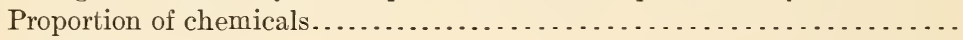

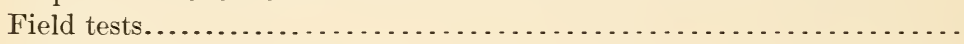

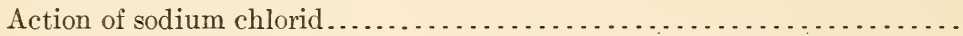

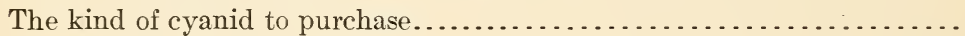

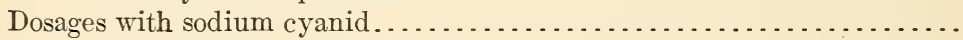

Dosages recommended for scale pests. . . . . . . . . . . . . . . . . . . . .

Comparison of sodium cyanid and potassium cyanid for general fumigation.

Chemistry of fumigation with hydrocyanic-acid gas.......C. C. McDonnell..

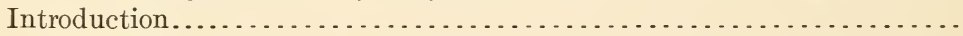

I. Analyses of chemicals used for the production of hydrocyanic-acid gas.

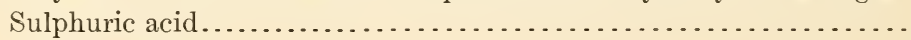

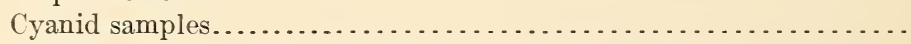

II. Proportion of cyanid, sulphuric acid, and water for best yield of gas. .

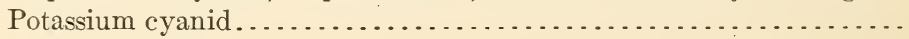

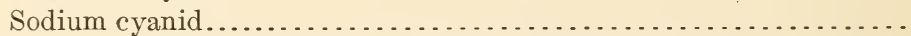

III. Action of mineral acids on cyanids and hydrocyanic acid.......... Action of sulphuric acid on hydrocyanic acid................... Action of hydrochloric acid on hydrocyanic acid..................

Effect of the presence of sodium chlorid in cyanids on the yield of hydro-

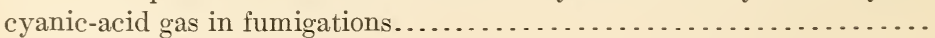

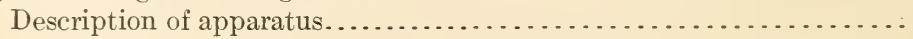

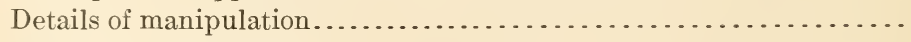

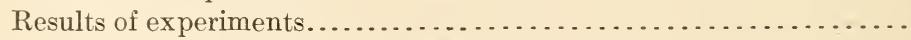

Ammonia formed from the decomposition of the cyanid..............

Effect of the presence of sodium nitrate in cyanids on the yield of hydro-

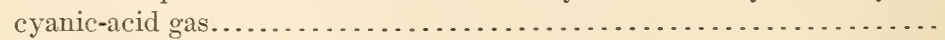

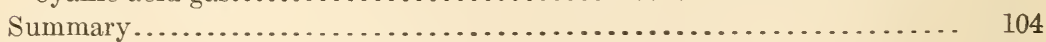

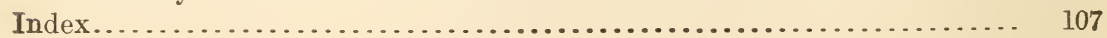




\section{ILLUSTRATIONS.}

\section{PLATES.}

Plate I. Method of covering small tree with bell or hoop tent...........

II. Fig. 1.--Brick furnace, tank, and derrick used in the tannin treatment for mildew, San Bernardino County, Cal. Fig. 2.-Machine for covering trees with sheet tents.

III. Fig. 1.-Method of attaching tent to hoisting pole by a half hitch of the rope. Fig. 2.-Top of derrick, showing method of attaching pulley. Fig. 3.--Base of derrick, showing method of construct-

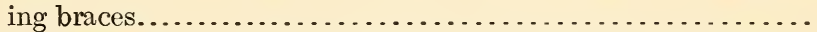

IV. Fig. 1.-Supply cart used with the improved system of fumigation. Fig. 2.-Supply wagon devised by C. E. McFadden, of Fullerton, Cal

V. Figs. 1-5.--Successive stages in placing a tent over a tree with poles. Fig. 6.-A tented tree, showing method of securing the distance around the bottom of the tent by means of a tape at-

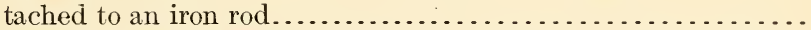

VI. Removing the tent from one tree onto another by means of poles..

VII. Placing a sheet tent over a tree by means of derricks............

VIII. Fig. 1.-A row of tented trees, with cart at one end of row, ready to commence dosing. Fig. 2.-Dosing a tree................

IX. Dosage Schedule A, for high-grade sodium cyanid............

X. Dosage Schedule $\frac{3}{4}$-A, for high-grade sodium cyanid............

TEXT FIGURES.

FIg. 1. Map showing principal localities in southern California where citrus

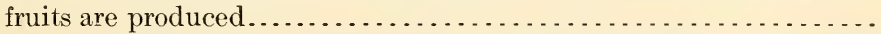

2. Plan for construction of octagonal sheet tent, 50 feet across, showing

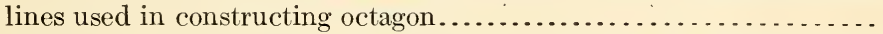

3. Method of attaching hooks to tent when covering trees with aid of der-

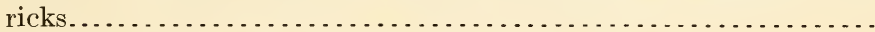

4. Ends of hoisting poles used in placing tents over trees.............

5. Earthenware acid jar with attachments for field use . . . . . . . . . . . .

6. Carboy with handles attached to facilitate pouring the acid and carrying

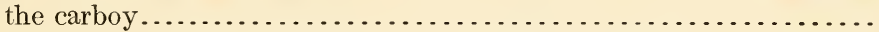

7. Outline of a sheet fumigation tent marked according to the Morrill

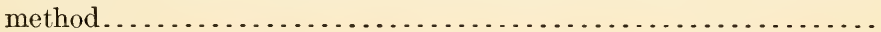

8. Man carrying tray and water bucket as practiced under the old system

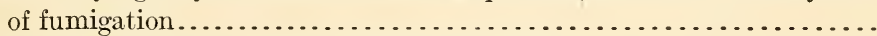

9. Dosage schedule No. 1, for potassium cyanid.....................

10. Chart showing total amount of gas evolved when different proportions

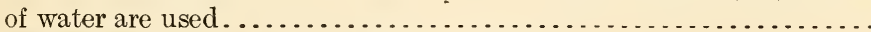

11. Dosage schedule No. $\frac{3}{4}$, for potassium cyanid....................

12. A cover device attached to a fumigation generator..................

13. Laboratory apparatus used in the decomposition of cyanids and collection of the liberated hydrocyanic-acid gas................... 



\title{
HYDROCYANIC-ACID GAS FUMIGATION IN CALIFORNIA.
}

\section{FUMIGATION OF CITRUS TREES.}

\author{
By R. S. Woglum, \\ Special Field Agent, Bureau of Entomology.
}

HISTORICAL. ${ }^{1}$

To Mr. D. W. Coquillett, of the Bureau of Entomology, United States Department of Agriculture, belongs the credit of first determining the great value of hydrocyanic-acid gas for destroying insect pests on plants. During the fall of 1886 , while a special agent of what was then the Division of Entomology, experimenting upon the cottony-cushion scale (Icerya purchasi Mask.) in orange orchards in California, he discovered this gas to be a most efficient insecticide for scale-insect pests of citrus trees, and his continued experimental work placed its use on such a practical basis that by 1890 it had commenced to be employed quite extensively in a commercial way.

The use of this gas was restricted to California until the winter of 1892-3, during which time Prof. H. A. Morgan gave it a trial on orange trees in southern Louisiana. The following year, 1893, found it on trial against the San Jose scale in Virginia and against citrus insect pests in Florida, in Montserrat, British West Indies, and in Cape Colony, South Africa. Its subsequent development and use has been rapid as well as extensive, so that to-day fumigation of citrus trees is carried on in California, Florida, Australia, Japan, and the colonies of South Africa. At the time of this writing the practice is being introduced into Spain and Porto Rico.

The great success attending the hydrocyanic-acid-gas treatment against the scale pests of citrus trees soon brought about its introduction into a broader field of activity. This gas was given its first trial on deciduous trees by Mr. D. W. Coquillett in 1894 at Char-

\footnotetext{
1 The Canadian Entomologist for 1877, volume 9, pages 139-140, contains mention of an experiment by James T. Bell in which an insect cabinet was freed from insect pests by dropping sulphuric acid on potassium cyanid. This is the first record, so far found, of the rapid development of the gas by combining sulphuric acid with lump cyanid with the objcet of killing insects. The use of cyanid, however, as a means of killing insects in collectors' bottles is very old. The gas liberated from moistened lump cyanid is the same as that generated by the action of sulphuric acid or hydrochloric acid, on the authority of Dr. J. K. Haywood, of the Bureau of Chemistry of this department. The action of the acid merely hastens the generation of the gas. It does not seem desirable or appropriate, therefore, in a discussion of the broad-scale economic use of this gas for the destruction of insects in orchards or in buildings, to consider these much earlier and minor uses of the gas by collectors for killing insects, or similar limited uses. ... C. L. M.
} 
lottesville, Ta. The same year it was first used in the treatment of nursery stock, and its development along this line has been so great and important that to-day in many States the fumigation of deciduous stock before it is planted is required by law. The use of hydrocyanic-acid gas against insects affecting greenhouse plants has been successfully carried on for a number of years. Among the other important uses to which this gas has been successfully put are the treatment of mills, various other buildings, and stored products infested with insects. The ease with which this gas may be generated as well as its destructive power, greater than that of any other known insecticide, leads the writer to believe that as soon as the various uses to which this gas may be put have been thoroughly investigated and placed on a stable basis the future development of hydrocyanicacid-gas fumigation will be quite as important and extensive as has been its past development.

\section{RECENT RENEWAL OF INTEREST IN FUMIGATION IN CALIFORNIA.}

The hydrocyanic-acid-gas treatment of citrus trees continued to become more widely used and to hold general favor with the fruit growers of southern California until about 1901, when the distillate spray was introduced. The treatment of trees with distillate was much cheaper than with hydrocyanic-acid gas. This fact, together with the fact that the distillate treatment was indorsed by many of the more prominent horticultural authorities and fruit growers led to its widespread use during the next few year's. Simultaneously the introduction from South Africa of Scutellista cyanea Motschulsky, the parasite of the black scale (Saissetia oleæ Bern.), and its subsequent splendid showing led many people to abandon treating their orchards in the hope that this beneficial insect would hold the black scale in check.

By 1903-1905 it had become very evident that the distillate spray had not only failed to keep the scales under control, but that its continued use in many cases produced an injurious effect upon the tree itself. The Scutellista also had failed to control the black scale, although even a conservative must admit that its work has been of a most praiseworthy type. Spraying rapidly sank into disuse during 1905 and 1906, until at the present time it has almost entirely giren way to fumigation. The experience of the prominent fruit growers with the distillate spray has thoroughly satisfied them of the great superiority of the hydrocyanic-acid-gas treatment to that with a spray for scale insects on citrus trees.

In the winter of 1903-4, Dr. G. Harold Powell, then of the Bureau of Plant Industry, United States Department of Agriculture, commenced an investigation of the decay of oranges while in transit 
from California. His efforts resulted in determining that the decay was almost entirely the outcome of mechanical injury to the skin of the fruit during its picking and handling in the packing house. Oranges are washed primarily to remove the sooty-mold fungus that grows in the so-called honeydew excreted by the black scale. Dr. Powell demonstrated that the decay in washed fruit is much greater than in unwashed fruit. This led the fruit growers to understand that the necessity of washing fruit should be avoided by controlling the scale in the orchard.

As a direct result of Dr. Powell's investigations, and knowing from past experience that the distillate spray and the Scutellista parasite were inadequate to control the scale, fruit growers took a renewed interest in fumigation. This led to a demand for an investigation of this process, to be conducted by the United States Department of Agriculture, and the following year, 1907, the writer was detailed to this field. The fumigation practice was then in a very chaotic condition as the outgrowth of years of use without any special effort to have the process standardized. Indeed, it was a favorite pose of many professional fumigators to veil their operations in mystery in order to secure the reputation of being authorities in a practice which they made to appear complicated and difficult of understanding. Consequently the growers, for the most part, although arranging to have their orchards fumigated, took no interest in a procedure which they little understood.

In the face of this situation the first reports of this investigation given out in 1908 attracted the immediate attention of the fruit growers. After gaining a general understanding of the process of orchard fumigation the growers in many localities have become much interested and subsequently have adopted or have caused to be adopted the more important recommendations of this investigation. This adoption of better methods has led to more satisfactory work generally. The grower has immediately seen the advantage of better methods, with the result that where formerly many were with difficulty induced to have their trees fumigated, to-day the successful orchardist needs no inducement whatever, but, on the contrary, requires that his trees be treated whenever their condition appears to demand it. This public interest in fumigation has made it one of the very live topics in the horticultural field in southern California to-day.

\section{EXTENT TO WHICH FUMIGATION IS PRACTICED IN CALIFORNIA.}

Commercial fumigation of citrus trees is confined to six counties of southern California, viz, Ventura, Los Angeles, Orange, Riverside, San Bernardino, and San Diego. In these counties about 85 different 
parties, including contractors, associations, county horticultural commissions, and private individuals, owned approximately 5,150 tents on June 1, 1910, the date on which the securing of these data was completed.

In order to ascertain the extent to which fumigation is now practiced, as well as the tax which this procedure annually places on citrus fruit growers, a careful canvass of the different parties operating tents has been made. This canvass has resulted in showing that approximately 36,000 acres were treated during the year from July, 1909, to July, 1910. Many fumigators gave the number of trees which they treated; others the acreage alone. The average orchard will approximate 90 trees to the acre, and in those cases in which estimates were returned in acreage alone, this number has been considered to comprise an acre. Wherever not known, the cost of fumigating a tree has been placed at 30 cents, which price approximates very closely the cost of fumigating the arerage-sized citrus tree in California. Calculated on this basis, the cost of fumigation of the citrus orchards of southern California during the season 1909-1910 approximated $\$ 1,000,000$.

\section{THE VARIOUS SYSTEMS OF FUMIGATION.}

Each of the citrus-fruit-producing counties of southern California has a board of horticultural commissioners consisting of three members whose duties are to supervise the destruction of insect pests, plant diseases, and noxious weeds within their respective counties. In the three greatest citrus-fruit-producing counties-Los Angeles, Riverside, and San Bernardino-numerous inspectors are also employed to assist in carrying on this important work. As a matter of convenience the counties are usually divided into three districts, each of which is supervised by one of the commissioners. If inspectors are employed, usually each is allotted a limited portion of one of these districts, and is held responsible for the proper control of pests therein. He advises when the trees shall be fumigated, and, after arranging for the execution of the work, is supposed to see that it is properly carried out. There are several different systems under which the work may be done.

\section{BY CONTRACT.}

The larger part of fumigation is carried out under the contract system. Individuals or firms that possess complete equipment for commercial fumigation and practice fumigation as a business, enter into an agreement with the grower, who desires to have his orchard treated, to do the work for a certain sum. The rate is seldom uniform but varies with such factors as the character of the ground, the acreage, and the size and arrangement of trees. Usually the cyanid 
acid are furnished by the contractor at a certain price per pound, sugh sometimes the grower himself supplies them. In the latter the sole consideration is the cost of covering per tree.

\section{BY ASSOCIATIONS.}

A citrus association is composed of a large number of growers from the same district organized for the purpose of cooperation in the handling of their fruit. Some of these associations own fumigating outfits which are utilized in the treatment of orchards belonging to its members. The manager of the association looks after the purchasing of chemicals and supplies, and also selects competent men to run the outfits. The inspector of the district usually directs the movements of the outfit from one orchard to another. Under this system the chemicals and labor are supplied at actual cost, plus a slight allowance for the purchase as well as wear and tear of equipment. In short, this system is supposed to be merely self-supporting.

\section{BY COUNTIES.}

Each of the county boards of horticulture owns a greater or smaller number of fumigation tents. In San Bernardino County this system has reached its greatest development, for here the horticultural commission owns fully 500 tents and carries on more work annually than all other systems combined. This fumigation is under the personal direction of a county horticultural officer. 'The cost to the grower of treatment by these outfits is usually what it actually costs the county to perform the work. An important consideration in favor of the system of county owned tents is that it readily enables the treatment of trees on city lots and in small orchards in out-of-theway places which otherwise would in all probability be neglected.

\section{BY PRIVATE INDIVIDUALS.}

Many citrus fruit growers who control a considerable acreage have fumigation outfits for their own work. In a few cases two or three growers in a locality combine in owning an outfit. The private ownership of tents is rapidly gaining in favor and well merits this increased popularity, as it possesses decided advantages.

Excepting private ownership, it would be scarcely possible to say which of these systems is superior. Each has its advantages. While one system may prove superior in one locality it might prove less successful in another. The reason for success or failure lies not in the system itself but largely in the personal element directing and conducting the procedure. A reckless, uneconomical, or unreliable director of any one system will achieve inferior results and give less satisfaction than a careful, economical, and perfectly reliable one 
under any of the others. This is mainly due to the fact that directors of the former class are likely to employ field men of inferior qualifications. Efficient fumigation at the present time means, for the most part, that the men in the field performing the operations are careful, conscientious, and reliable. Otherwise the work is likely to be performed in a slipshod, hasty manner, along lines of least resistance. Work of this character, combined with the element of guesswork in deciding the dosages and proportions of chemicals to be used, has been responsible for most of the unsuccessful results. If perfectly reliable men are employed to carry on the actual work in the field, using the most approved methods, success will be as marked with one system as with another.

The recent horticultural ordinances of Los Angeles, San Bernardino, and Riverside Counties requiring fumigators to be licensed are a step in the direction of more efficient results. Such ordinances offer a means of debarring outfits which perform unsatisfactory work.

\section{EXTENT AND CHARACTER OF CITRUS ORCHARDS.}

The production of citrus fruits in southern California is confined to the narrow stretch of land south and west of the Sierra Madre Range, extending from Santa Barbara on the north to the Mexican border. Although citrus plantings are located here and there throughout this territory, in reality only a small proportion of the land capable of cultivation is deroted to this industry. The most prominent centers of production (see fig. 1) are in the foothills region and lower land of the San Gabriel Valley; the corresponding regions of the San Bernardino Valley, including the Redlands-Highland, Riverside, and Corona districts, and the coast region of Orange and Los Angeles Counties. Regions of smaller production are found in southern Santa Barbara and Ventura Counties, in the San Fernando Talley, and in western San Diego County.

The groves vary in size, the majority probably areraging between 5 and 15 acres. Some fruit growers have from 50 to 100 acres or more, while a few fruit companies control from several hundred up to about 3,000 acres. The trees for the most part are budded rarieties which arerage less than 20 feet in height. In some districts a few grores of seedling trees 30 to 35 feet in height still exist. The trees in most of the grores, especially those of more recent planting, áre regularly arranged, averaging from about 22 to 24 feet apart. Some of the older groves are less uniform, either because they were not arranged after the "block" system, or, if so, additional alternate rows of trees were interset, which broke up the continuous open space between two rows of regularly set trees, thus rendering it confusing as well as difficult to work freely therein. 
The land on which the orchards occur is for the most part flat or only gently sloping, and in a state of frequent tillage-conditions which obtain because of the necessity of irrigating during much of the year. At Redlands, in San Bernardino County, a considerable acreage of oranges is found on terraced land. Fumigation of such trees is slow and difficult, but, fortunately, they comprise a very small percentage of the groves in that county requiring treatment.

\section{INSECT ENEMIES OF CITRUS FRUITS. ${ }^{1}$}

The larger number of pests most injurious to citrus fruits in southern California belongs to the Coccidæ, a group of insects popularly

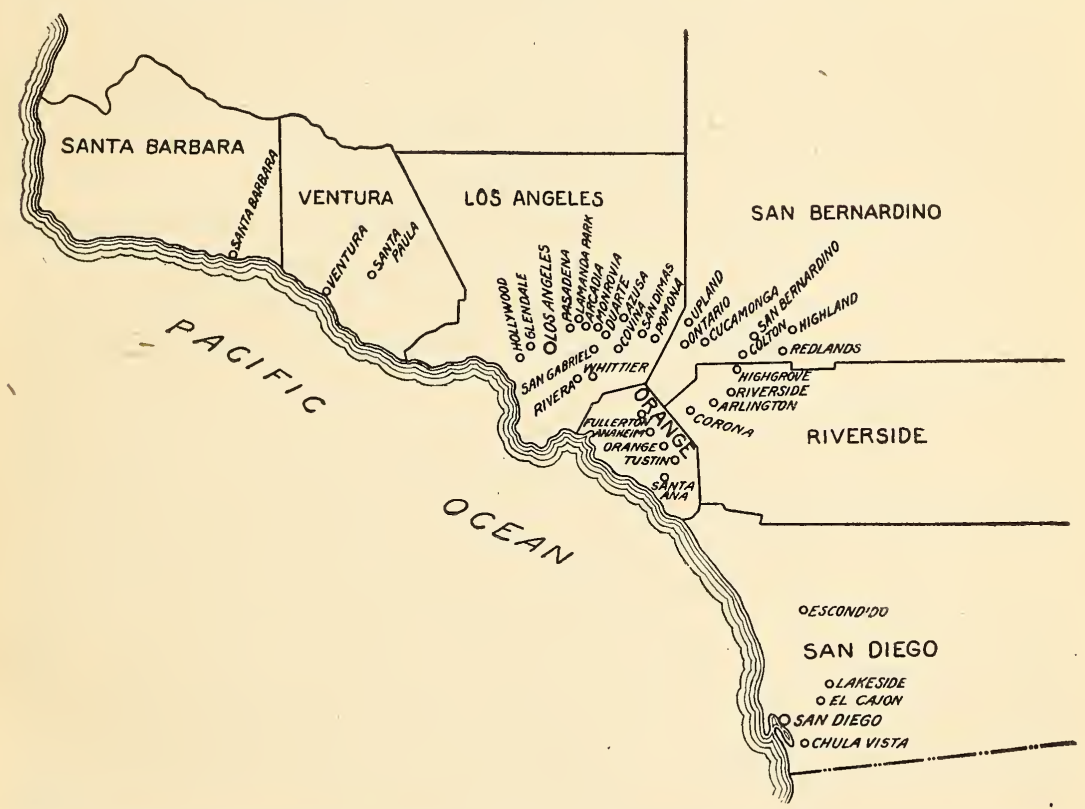

FIG. 1.-Map showing principal localities in southern California where citrus fruits are produced. (Author's illustration.)

known as scale insects. Among the scale insects which are generally so destructive as to require extended efforts for their control are the purple scale (Lepidosaphes beckii Newm.), the red scale (Chrysomphalus aurantii Mask.), and the black scale (Saissetia oleæ Bern.). The yellow scale (Chrysomphalus citrinus Coq.), considered a variety of the red scale, is much less destructive generally, though sufficiently troublesome in some localities to be considered a pest of primary importance. The citrus mealy bug (Pseudococcus citri Risso) has recently been very injurious in certain sections. Other insect pests attack citrus trees to a greater or less extent, but those just mentioned are generally the most injurious, and the principal method of their control is fumigation with hydrocyanic-acid gas. 
THE PURPLE SCALE.

(Lepidosaphes beckii Newm.)

The purple scale appears to prefer the more moist regions in the vicinity of the ocean, as its distribution is confined largely to this part of the citrus belt. This insect confines its attacks to citrus trees, infesting not only the leaves and branches but also the fruit. Much injury results. The young purple scale insects hatch from eggs deposited by the adult. The number of broods of this insect in southern California has never been exactly determined. Prof. H. J. Quayle, of the University of California, is at present investigating the life history of this, as well as the other injurious citrus scale pests. In a climate like that of southern California, which is never severe at any time of the year, there is much overlapping of broods, so that scales in all stages of development can be found at almost any time of the year. The writer's own observations in the field have shown that there are two very noticeable general broods, one appearing in the early spring during March or April, the other in the fall, usually about October. These broods are much earlier some years than others, depending on the nature of the weather. The fall brood of the scale is the most injurious, as shown by the fact that trees which at a distance may appear entirely healthy one month may have the leaves of a large area, or even an entire side, turn yellow and drop off the next month. The orchardists speak of this as "firing." It is due to the attacks of the enormous number of young insects which, on hatching, have spread about and settled down on those branches immediately adjoining the ones previously infested. Trees infested with the purple scale seldom present a diseased appearance on all sides. The habit of this insect is to frequent the inner and shadier portions of the tree, so that sometimes severely infested trees may present no visible appearance of this condition on the outside. In the majority of cases where the infestation appears on the outside of the tree it will be found that it is at or near the northwest corner, which is the shadiest part during the day. The attacks are also confined largely to the lower part rather than the top of the tree. In long and seriously infested trees the insects may spread throughout.

\section{THE BLACK SCALE.}

(Saissetia oleæ Bern.)

The black scale is found more or less throughout southern California, yet matures more freely and causes more injury in the region adjacent to the ocean than in the hot interior valleys. It occurs on a wide range of hosts, including trees, shrubs, and herbaceous plants. The commercial importance of the black scale arises largely from 
its habit of secreting honeydew, which spreads over the leaves, fruit, and branches, furnishing a growing medium for a black or sooty mold fungus, resulting in a black coating throughout the tree. This coating is removed from the fruit by washing, or in light attacks by brushing. In the investigations by Dr. G. Harold Powell ${ }^{1}$ of the causes of decay of oranges while in transit from California, it was shown that the decay was greater in washed than in unwashed fruit. To avoid the washing of fruit it is necessary to destroy the scale in the orchards. The black scale appears generally to have little effect on the vitality of the tree. Its attacks are confined mainly to the branches, yet it is commonly found on the leaves during its earlier stages of development, and sometimes it matures in this situation. Seldom does it mature on the fruit. The young of the black scale insects hatch from eggs deposited by the adult. They can be readily destroyed by fumigation in the early stages of development. Approaching maturity they become tough and leathery, and in this condition they are capable of resisting very heavy dosages of gas. The breeding of the black scale in southern California has never been closely investigated, so the exact number of broods is not known. When this has been done undoubtedly it will be found to be very variable with different hosts, or even on the same host. The scales on "sucker" shoots will mature much more rapidly than those on other parts of the tree. There is one noticeable general brood which is usually largely hatched by the first part of September. In the warmer and drier parts of the citrus belt, remote from the coast, the hatching of this brood is quite distinct, so that in most instances all the insects may be found in the early stages of development at the same time. In the immediate vicinity of the coast, and especially on recently budded trees, one frequently finds the scale in all stages of development on the same tree. In these latter instances fumigation will prove less satisfactory than in the former.

THE RED SCALE.

\section{(Chrysomphalus aurantii Mask.)}

The red scale, although its injuries are more severe in some localities than in others, has the limits of its distribution very much the same as has the black scale. It can be found within a few miles of the ocean or as far inland as Redlands. This insect occurs on many host plants besides citrus trees. It attacks the fruit, leaves, and branches. In point of destructiveness it excels all other citrus scale insects in this State, destroying not only branches, but sometimes entire trees by its attacks. The young are born alive. It has at least three broods and is very prolific. 
THE YELLOW SCALE.

\section{(Chrysom phalus citrinus Coq.)}

Infestations of the rellow scale appear to be most marked in the foothills region of the San Gabriel Talley and along the Sierra Madre Range through Upland and Cucamonga. It causes considerable damage at Redlands, San Bermardino County, ret elsewhere is not regarded as a very serious pest. This insect infests the leares and fruit, seldom occurring on the branches. The young are born alive, as in the case of the red scale. to which it is closely related.

\section{THE MEALY BLG.}

\section{(Pseudococcus citri Risso.)}

The mealy bug occurs in various sections of the southern part of California. The districts of greatest injury are in southern San Diego County and at Santa Paula, in Ventura County. Little effort for its control has been made except in these two places. This insect attacks fruit, leares, and branches. secreting a honeyder, which is followed by a black fungus. as in the case of the black scale. Its injury is much greater than that of the black scale because it discolors and weakens the rind of the fruit at those places where it extracts the juice. The cottony secretion in which the eggs are deposited is difficult to remore. The serere washing which this fruit requires. combined with its weakened rind in certain places. produces a heary decay in such fruits as are treated in this manner. The mealy bug occurs on sereral hosts beside citrus trees. The roung are hatched from egos deposited br the adult.

\section{APPARATUS.}

TENTS.

When hrdrocranic-acid gas was first employed in treating orchards the apparatus used in the process was of a rery cumbersome nature. ${ }^{1}$ The most popular apparatus consisted of tents more or less of a bellshaped nature manipulated by a high derrick mounted on a wagon. The wagon was drawn between the rows and the tents lowered orer or raised from the trees by means of ropes attached to the derricks. The use of such apparatus was difficult. slow, and costly.

\section{SHEET TENTS.}

During 1592 Mr. C. W. Finch, a fumigator at Riverside, Cal., devised a much simpler and cheaper apparatus than those theretofore used, which consisted of flat sheet tents. octagonal in outline. (Fig. 7 . ]. 29.) This simplified tent was rapidly adopted. and now sheet 
tents are exclusively (parts of two outfits excepted) used in southern California. A tent of this character is easy to construct, easy to repair, and its manipulation has been so perfected by years of use that it is very easily handled in the field by intelligent workmen.

Sizes.-The standard sizes of sheet tents are 17, 24, 30, 36, 41, 43, $45,48,52,55$, and 64 feet, but larger ones up to 72 and 84 feet have been employed. The size of this style of tent is properly based on the distance between parallel sides, not on the distance between opposite corners.

Materials used.-The materials now generally used for'sheet tents in southern California are $6 \frac{1}{2}$-ounce or 7 -ounce special drills and 8-ounce special army duck, though 10-ounce army duck is sometimes used in very large tents. These cloths are spoken of in ounces, meaning such a weight per yard 30 inches wide. Drills are used as freely as ducks. In some other countries where fumigation is practiced, notably South Africa, even heavier than 10-ounce cloth is sometimes used. This is largely because of its strength and tightness of texture. The tendency in California has been to sacrifice tightness in favor of lightness, as the lighter tents are so much more easily manipulated in the field. The main reason for this tendency is probably that the practice has been largely in the hands of contract fumigators rather than in the hands of the growers themselves. The concerns furnishing the fumigation tents apparently have made no special effort to supply the very tightest goods available on the market, probably because the profits on these goods would be smaller than on the cheaper and more porous cloths. Several of these firms have special goods which they recommend for fumigation use. For the most part these goods are about on a par as regards the requirements for fumigation. Only one grade distinctly superior to the others has been seen; it is used solely by private outfits, and is slightly more expensive than the other grades. The results secured depend directly on the tightness of the cloth; in fact, this consideration of tightness of tenting is one of the most important factors in the entire fumigation procedure. On it depends not only the efficacy of the treatment but also to some extent the cost of the operation. A dosage recommended as securing certain results with tents of a given degree of tightness will not produce the same results with tents of less closely woven material. Even though the initial cost is greater, tightly woven material is the most economical in the long run.

New tenting material.-Considerable attention has been given during this investigation to the character of cloth used in fumigating tents, and an attempt has been made to secure the most suitable material possible. The leading manufacturers and dealers in cotton ducks and drills in the United States were consulted and samples of their tightest cloths secured. Many of the nearly two hundred sam- 
ples secured were rerr superior in tightness to the grades now generally supplied in California for the fumigation trade. Although this collection contained samples of the rerr tightest ducks and drills manufactured. it was decided to accept the offer of one of the largest cotton-goods concerns to carry on special experiments in wearing for the benefit of this inrestigation. As a result of these experiments samples of 6-ounce. $i$-ounce, and $S$-ounce drills were furnished. These are easily the most tightly woren drills the writer has erer seen and some local cloth experts are of the same opinion. Each of these samples was made rerr tight by forcing in more threads than are found in the tightest drills on the market.

Experiments with new tent material.-Tents were made of each of these $\bar{i}$-ounce and S-ounce special drills and tested in the field. Part of an orange orchard of trees from 10 to 15 feet tall which were sererely infested with the purple scale was fumigated during September, 1909. The point was to determine at what strength eradication would occur with these new tents. Both potassium cranid and sodium cranid were used. On examining the results with these new tents it was found that schedule No. 1 (see p. 34) with potassium cranid produced eradication, whereas with the ordinary fumigation tents a $1 \frac{1}{2}$ schedule was required to secure the same results. With the sodium cranid it was found that the equiralencr of between a three-fourths schedule and a No. 1 schedule produced eradication, whereas it requires the equiralent of, a $1 \frac{1}{t}$ schedule with ordinary tents to reach the same degree of efficiencr. These results with both potassium cranid and sodium cranid show that this new tenting material requires at least one-fourth less of these chemicals than the regular tents now largely used. This would mean a saring of fully 25 per cent on the amount of cranid required in field work if the tighter tents are used.

What cloth to use.-Cranid is the most expensire element in fumigation work. A saring of 25 per cent on this article means a materially lessened cost for the process. This better and tighter special tenting material mar be somewhat more expensire than the present inferior goods used. ret the amount of cranid sared as well as the superior results secured from its use will in the long run many times offset the additional initial cost. The writer would advise either a 7-ounce or an S-ounce weight of these new goods for commercial fumigation as superior to any cloth he has erer seen. There appears to be little difference in tightness between the two weights. By reason of its greater weight the s-ounce drill might prove more durable, whereas on the other hand the 7 -ounce weight is easier of manipulation in the field. This special grade of drill adrised by this inrestigation can be purchased at ans of the dealers in fumigation tents, in Los Angeles, Cal. Anrone making an inrestment of the amount 
necessary in the purchasing of a fumigation outfit usually is better satisfied if he has exercised, or had the opportunity to exercise, his own judgment in the selection of the cloth, even if experience has proved one particular kind to be superior to all others. To satisfy this demand of independent people it is suggested that anyone contemplating the purchase of a fumigation outfit procure as many samples as possible of $6 \frac{1}{2}$-ounce to 8 -ounce drills and 8 -ounce ducks and compare the tightness of these samples with that of samples of the 7-ounce and 8-ounce special drills recommended by this investigation. This can be done by holding the various samples at different angles between the eye and the sun, noting the comparative number of light rays penetrating the different samples.

Construction.-In California the demand for fumigation tents is so great that several concerns make a special business of meeting it. The man contemplating the purchase of an outfit visits one or all of these different dealers, and, having selected the cloth which meets with his approval, places his order for the number of tents of the size desired. These are shipped to him ready for use. A method of constructing tents will be explained, however, for the benefit of people more distant from the sources of supply than are the people of' southern California. As previously explained, the tents are flat sheets, octagonal in shape. The ducks and drills are usually 30 inches wide, although sometimes they measure 29 or $29 \frac{1}{2}$ inches. The sides of the strips are sewed together so that the strips all run in a parallel direction. Before attempting to cut the cloth for a tent it is well to construct a diagram having therein an exact representation of the number of strips required as well as their length and shape. Such a diagram is shown in figure 2 (p. 14), and was originally presented by Dr. A. W. Morrill, ${ }^{1}$ who was engaged in fumigation work against citrus pests in Florida from 1907 to 1909. Each side of the tent or octagon, when constructed, will be equal, approximately, to two-fifths of the distance between the parallel sides. In explaining the construction Dr. Morrill states:

The strips when cut should be overlapped three-eighths or one-half inch and double stitched, and all raw edges should be hemmed. In calculating the number and length of strips the overlapping will reduce the width of the cloth from three-fourths inch to 1 inch. As an illustration of the method of calculating the length of the - strips used in making an octagonal tent of 8-ounce duck, 50 feet may be taken as the desired size. This is equal to 600 inches and the width of the cloth, if 29.5 inches, will be reduced to 28.5 if overlapped one-half inch at the seams. By dividing 28.5 inches into 600 inches the nearest multiple is found to be 598.5 inches, or 49 feet $10 \frac{1}{2}$ inches, which is sufficiently close to the desired width for practical purposes. The number of strips in a tent 598.5 inches wide is 21 . The middle section B [fig. 2] is approximately two-fifths the entire width, or 239.5 inches. Deducting this from 598.5 inches, the entire width, the remainder, 359 , equals the sum of the widths of sections $\mathrm{A}$ and $\mathrm{C}$. These sections being equal, the width of each is 179.5 inches. 
The number of strips in each section can now be readily calculated. The 21 strips should be numbered on the diagram from left to right. Section A requires six strips and 8.5 inches of the seventh. Similarly, section $\mathrm{C}$ requires six strips beginning at the right (twenty-first to sixteenth, inclusive) and 8.5 inches of the fifteenth. Section $\mathrm{B}$ requires the remaining 20 inches of strip No. 7, 20 inches of strip No. 15, and seven entire widths, thus making the total of 21 strips required.

The cutting of the cloth can be done without waste if the details of construction are well planned. In the above tent seven strips 50 feet long (49 feet $10 \frac{1}{2}$ inches) should first be cut out for section B. Strips Nos. 7 and 15 are next cut and the outside corners cut at an angle of 45 degrees, as indicated in the diagram. Each strip for sections $\mathrm{A}$ and $\mathrm{C}$ is cut shorter by its own width outside at each end than the strip

E

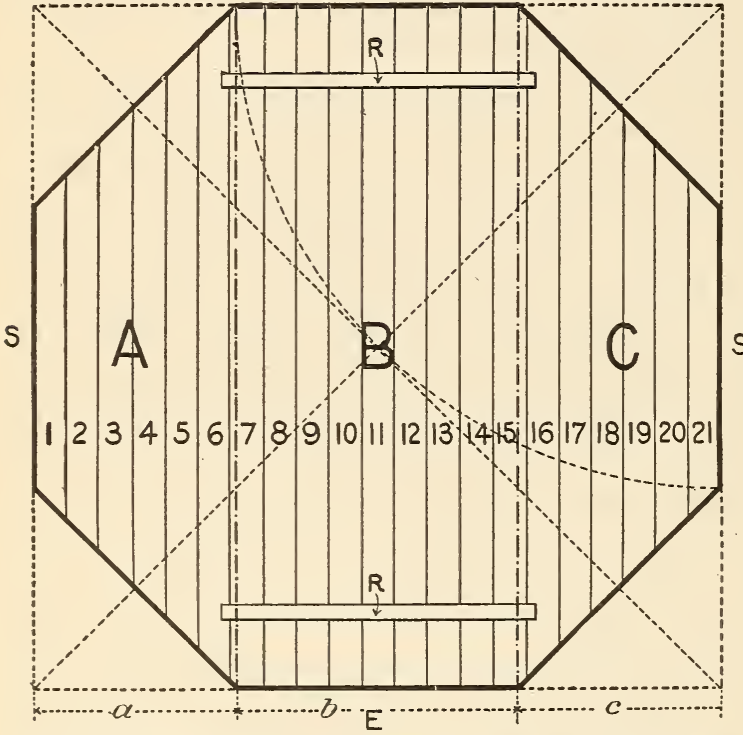

FIG. 2.-Plan for construction of octagonal sheet tent 50 feet across, showing lines used in constructing octagon: $A, C$, side sections; $B$, central section of full-length strips; $E, E$, so-called "ends" of tent; $S, S$, so-called "sides" of tent; $R, R$, reinforcements; 1-21, strips of duck $29 \frac{x}{2}$ inches wide orerlapped $\frac{1}{2}$ an inch at the seams. (From Morrill.) preceding it. Thus the required lengths of the side strips are found by matching the inner edge of the new one to the outer edge of the one before it. It is desirable to have the central section, $B$, made up entirely of full-length strips so that the stress will not be $S$ across seams. The stress is so slight, comparatively, in the side sections $\mathrm{A}$ and $\mathrm{C}$ that this is not an important point.

Such is the construction of a 50 -foot tent. The method of constructing a tent of any other size is similar. Tents up to 45 -foot size are constructed throughout of either of the drills or of S-ounce duck.

Larger size tents should have the full length strips of S-ounce duck, while the shorter side strips, or "skirts," as they are sometimes called, are made of a light drill. The main strain and wear falls on the middle, heavier and stouter, long strips; hence the use of the lighter material for the "skirts" decreases the weight of the tent without affecting its durability. The duck used in such tents should be of the very tightest grade available, while the $6 \frac{1}{2}$-ounce or 7 -ounce special drill previously recommended is most suitable for the "skirts."

Amount of cloth required for different-sized tents. - It is very essential in constructing tents to know the amount of cloth required for the size which it is intended to make. The writer has calculated this for the regular sizes and gives below the results. Calculations are based 
on cloth 30 inches wide, and represent the number of linear yards of such cloth required-not square yards. Allowance of an inch to each strip has been made for overlapping edges. These figures are based on the assumption that the cloth is cut without waste.

\begin{tabular}{|c|c|c|c|}
\hline Size of tent. & $\begin{array}{c}\text { Cloth } \\
\text { required. } \\
\text { (30 inches } \\
\text { wide.) }\end{array}$ & Size of tent. & $\begin{array}{l}\text { Cloth } \\
\text { required. } \\
\text { (30 inches } \\
\text { wide.) }\end{array}$ \\
\hline 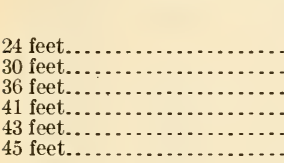 & $\begin{array}{r}\text { Yards. } \\
70 \\
105 \\
155 \\
195 \\
215 \\
235\end{array}$ & 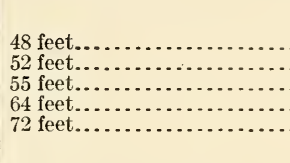 & $\begin{array}{r}\text { Yards. } \\
265 \\
315 \\
345 \\
470 \\
590\end{array}$ \\
\hline
\end{tabular}

Size to purchase.-Most of the tents in southern California are of either the $36,41,43$, or 45 foot sizes. Few tents of less than 36foot size are constructed. Outfits or parts of outfits having tents of $48,50,52$, and various other sizes as high as 84 -foot are known. The number, however, is comparatively small. The size of tent required depends on the size of trees in the orchard or orchards to be fumigated. The tents should be large enough to cover the tallest trees. An easy method of accomplishing this, as suggested by Morrill, is by throwing a tape attached to a reel over the top of the tallest tree and measuring from ground to ground. Although the weight of the tent reduces the height of the tree to some extent, nevertheless it is policy to add from 2 to 4 feet to the distance measured by the tape so as to be assured of having the edges of the tent rest well on the ground. If an outfit is to be procured for use in a young orchard, the tents purchased should be large enough to allow for 5 or 6 years extra growth. The average age of a fumigation outfit is from 3 to 5 years, depending, of course, on the amount and character of usage which it has undergone. A well-cared-for outfit used only by a private grower in covering his own orchard should last through 5 or 6 seasons of work.

Ring attachments and reenforcements.-Small iron rings are sometimes attached to tents as catch places for the poles or derrick hooks used in throwing them over trees. These ring attachments are most convenient on tents above 45 feet in diameter, but unnecessary on smaller sizes. An easy and satisfactory method of attaching rings to the cloth, as proved by many years of experience in California and elsewhere, is shown in figure 3. It consists in gathering the cloth of the tent about some object or material, binding the same in place by a stout cord, which also passes through the ring. A tightly rolled wad of some cloth such as burlap is commonly used. Another method well worth mentioning is by means of a piece of manila rope from 
3 to 4 feet long sewed to the tent in the form of a right angle, as shown in figure 7 , page 29. As fumigation tents should be pulled onto or off the trees in the direction in which the strips of cloth run, the rings should be so placed as to make this method of manipulation possible. This is accomplished br having two rings at either end of the tent and apart by about the width of the arerage-size tree treated. Ther should be placed from 3 to 5 feet back from the edge, the distance depending on the size of the tent. A small link of chain called a "jingler" is usually attached to the ring, the sole purpose of which is to direct the operator to its location. By merely giving the sheet a shake this simple device enables the tent pullers to

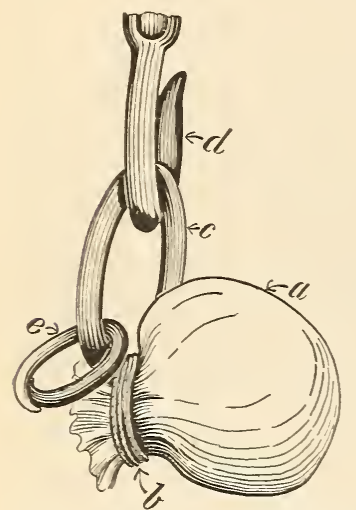

FIG. 3.-Method of attaching hooks to tent when corernig trees with aid of derricks: $a$, Tent gathered around ball of burlap or other suitable object; $b$, stout cord for attaching ring; $c$, catch ring; $d$, hook on pulley block; $e$, lap link or "jingler." (From Morrill.) easily locate the rings on the darkest nights. Such a great strain is localized at the place where the rings are attached that it is well to have this part reenforced by stitching on an extra thickness of cloth. The same material of which the tent is constructed is rery suitable. The strip used should be 3 or 4 feet long.

\section{BELL TENTS.}

Originally the bell, or hoop, tent was the kind in use in California, and eren now it enjors a limited use in some countries. This tent is dome shaped, having the mouth held open by a circle of $\frac{3}{4}$-inch gas pipe. It is suited only for corering small trees. Plate I illustrates the character of this tent and the method of its manipulation. Experiments in California have resulted in the disuse of bell tents in faror of sheet tents, the latter style being not only easier of construction and manipulation, but also more easily kept in repair.

\section{GAS-PROOFING.}

The treatment of covers with various substances to increase their tightness has been in practice to a greater or less extent since the beginning of fumigation. Linseed oil was one of the first tried. It renders the tents perfectly tight but greatly increases their weight. Experience has proved that tents so treated are liable to burning and rotting under the conditions to which they are subjected in the field. Treating tents with the mucilaginous concoction resulting from soaking the common cactus (Opuntia engetmanni) in water for two to four days was practiced to some extent during the nineties. Numerous other methods have been tried, such as painting with a flexible paint: treating with glue dissolved in water; treating with 

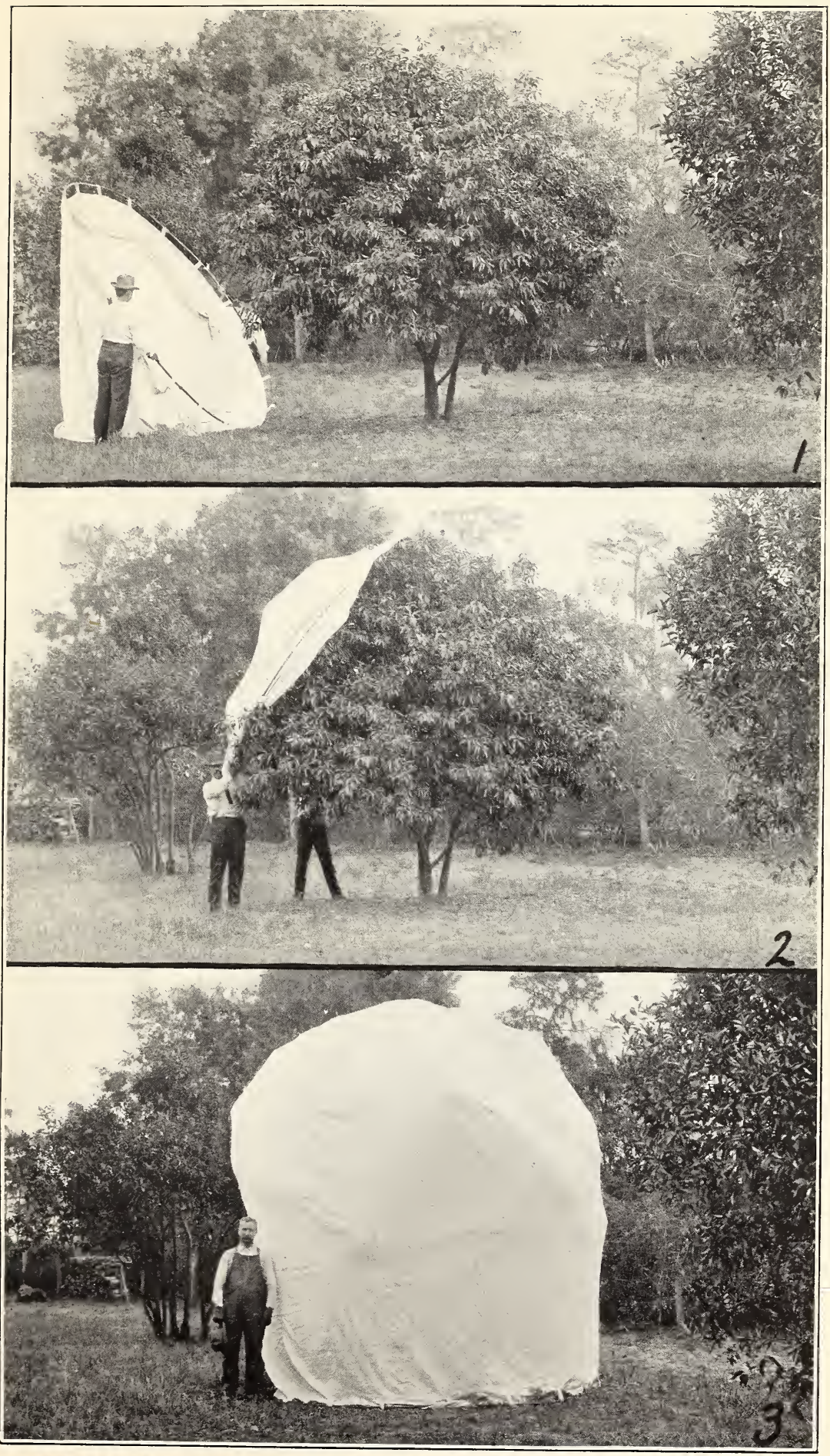

Figs. 1-3.-Method of Covering Small Tree With Bell or hoop Tent. (From MORRILL.) 

sactus juice combined with linseed oil, or glue, or tannin, etc. Experience with these many substances has resulted in discarding all of them in this State, so that to-day no effort is made to render tents gas-tight by the use of any liquid substance.

It is well known that a decidedly smaller dosage would be required with gas-tight covers than is nesessary with tents of the present character. This has led many writers on fumigation to advise the treatment of the cloth with some of the substances just mentioned to accomplish that end. Had these writers undergone a considerable experience in the actual handling of tents in the field their expressions on this particular subject might have been somewhat modified. Tents treated by some of these methods will be rendered gas-tight, or nearly so, but for certain practical reasons they are not now used and never will be used on a large commercial scale.

Experiments have been made with many different substances in attempting to render cloth gas-tight, and several samples of gas-tight or almost gas-tight cloth have been received from dealers. This experience in all cases has shown that to render a cloth very much more nearly gas-tight than is possible in weaving, some treatment must be used which materially increases the weight of the tent as well as rendering it somewhat stiff. Both of these conditions should be avoided as much as possible. Heavy tents are not only difficult to manipulate, but also destroy fruit and break branches while being hauled over trees. Stiff tents will not lie close to the ground, thus allowing the escape of gas. Tents must be constantly overhauled to mend the holes which result from acid burns as well as other causes. The mending of such treated cloth is so difficult as to be impracticable, especially in large-sized tents.

After considering both sides of the question experience leads to the conclusion that the economy of gas resulting from gas-tight tents is more than offset by the many difficulties experienced in the use of such stiff heavy covers in the field. The writer advises the purchase of the most closely woven untreated cloth obtainable, of the character and weight previously mentioned (p. 12), believing such to be superior for orchard work to cloths which have undergone a treatment to render them gas-tight.

Small tents used in treating nursery stock, and especially covers of cloth made over a framework in the shape of a box having one end open so as to be easily placed over nursery trees or such small plants, can be rendered gas-tight without experiencing some of the more serious objections to their practical use that exist in the case of large covers in orchard work. Linseed oil is very suitable for this purpose. The preparation and application of a linseed-oil varnish, which is used by the War Department in the treatment of cloth for balloon purposes, is quoted below. It renders the cloth gas-tight and at the 
same time leaves it more pliable than any other gas-tight treatment experienced. The Acting Secretary of War has described this method as follows:

In order to render the cloth gas-tight a linseed-oil varnish is applied. The varnish is made in proportion of 100 pounds pure linseed oil, 4 pounds litharge, and 1 pound of umber. This should be heated to a temperature of $130^{\circ}$ to $200^{\circ} \mathrm{C}$. for six or seven hours and constantly stirred during that time. A sponge or wad of cloth is ordinarily used for applying the varnish, which should be put on in very thin coats and well rubbed in by hand. The addition of one coat of this varnish about once a year will be found of great value in preserving the impermeability of the material.

One coat of this oil on each side of the tenting will prove adequate with most cloths. Treated cloth should be hung up to dry for about two weeks, and if not entirely tight at the end of that time a second coat should be applied. The cloth should be thoroughly dry before it is used.

MILDEW-PROOFING.

The treatment of tents with substances to render them próf against mildew is practiced to some extent. In San Bernardino and Riverside Counties probably the majority of tents are dipped in a solution of tannin, while in Los Angeles and Orange Counties, which are much nearer the coast and consequently have a more generally moist climate, tents for the most part are used without any treatment whatever. This localizing of treatment to the dryer sections demonstrates that for a climate like that of southern California the mildewproofing of tents is not absolutely essential. The covers used in this investigation have been in use mostly in the more moist coastal region for three seasons, yet they have never been affected with mildew. Neither has any mildew injury to other tents been seen or heard of meanwhile. The life of untreated tents in this State appears to be as long as that of those which have been mildew-proofed-at least this is the case with tents that are properly cared for in the field as well as in storage.

Long-used tents are now cast aside, not because of weakness die to deterioration of cloth from mildew, but largely from weakness due to extensive mending of holes, resulting principally from acid burns, but to some extent also from use on trees containing dead branches. This necessary patching, combined with general wear, limits the life of the average fumigating tent to 3 or 4 years. Judging from the experience of California fumigators, as well as from that of the writer himself, it appears unnecessary in California to treat tents for mildew if proper precautions are taken for drying them. Wet tents should be spread out during the day on the ground between the trees, so that the sun may reach them as much as possible. At the end of a season's work they should be thoroughly dried, rolled up, and stored in a dry room. 
In places like Florida, as well as in tropical countries where tents become wet every night, treatment to prevent mildew would seem advisable. Even in California it will act as a guarantee to those fumigators who exercise little care in the drying of their outfit. The dipping and boiling of tents in a solution of tannin is the only method now practiced there to render them proof against mildew. This tannin treatment has been in use for a long time, and is very satisfactory. Contrary to the belief of many, tannin does not render the tents any tighter. It merely shrinks them, which can be as well accomplished by dipping in water, or a few nights' exposure to heavy dews will produce the same results. The tannin treatment, as practiced by Mr. S. A. Pease, horticultural commissioner of San Bernardino County, is as follows:

A brick furnace [Plate II, fig. 1] is constructed so that the upper half partially incloses a tank, 3 by 10 feet and 3 feet deep, made of No. 16 galvanized iron. This is filled with water to within 8 inches of the top, which would be about 500 gallons, and about 200 pounds of extract of oak bark is added. This mixture is raised to a temperature as high as the hands of the operators will stand. A tent stretched out in as loosened a condition as possible (not in a wad) is then introduced into the vat. It is stirred around and kept submerged by means of wooden paddles manipulated by the crew. After 20 or 30 minutes of this treatment the tent is raised to the top of a derrick above the tank and suspended for a few minutes until well drained, after which it is lowered on a rack, moved away, and spread out on the ground to dry. Twenty-five gallons of water and 20 pounds of extract are now added to the tank before another tent is introduced, and this is repeated for each succeeding one.

The above recommendations are for 45-foot tents. Larger tents require more material and smaller ones less. Oak-bark extract costs about 10 cents per pound by the barrel.

\section{MARKING.}

On pages 29-30 of this bulletin is explained a method of marking tents, which is used in the most improved fumigation procedure. Tents should have been thoroughly wet at least once before being marked, as new cloth is subject to considerable shrinkage, and if marked before shrinkage the measurements will be erroneous. Measurements made of several tents of $6 \frac{1}{2}$-ounce drill, before and after shrinkage, showed that 45-foot covers shrink about 3 feet lengthwise of the strips of cloth. The crosswise shrinkage is much less. A convenient method of shrinking untreated tents is to spread them out on the lawn and wet with a hose or sprinkler. After being dried they are ready for marking. Tents treated with tannin should be marked after the treatment.

The best method for marking tents is to place them on a smooth floor. If this is not possible, spread them out on the smoothest ground available. A tapeline, brush, and marking fluid are required. Printer's ink, diluted, is the best marking material, although some 
have used lampblack and turpentine, or a soft, flexible paint, with satisfaction. The first line marked should be the one running through the center of the tent. When many tents are to be prepared, the use of a stencil large enough to include a complete line of figures on one side will facilitate the operation. The numerals 'should be not less than 5 or 6 inches long.

\section{POLES AND DERRICKS.}

Two wooden poles or derricks are used in placing tents over trees. No absolute statement- can be made as to when poles should be employed or when derricks. The practice is to use poles when-
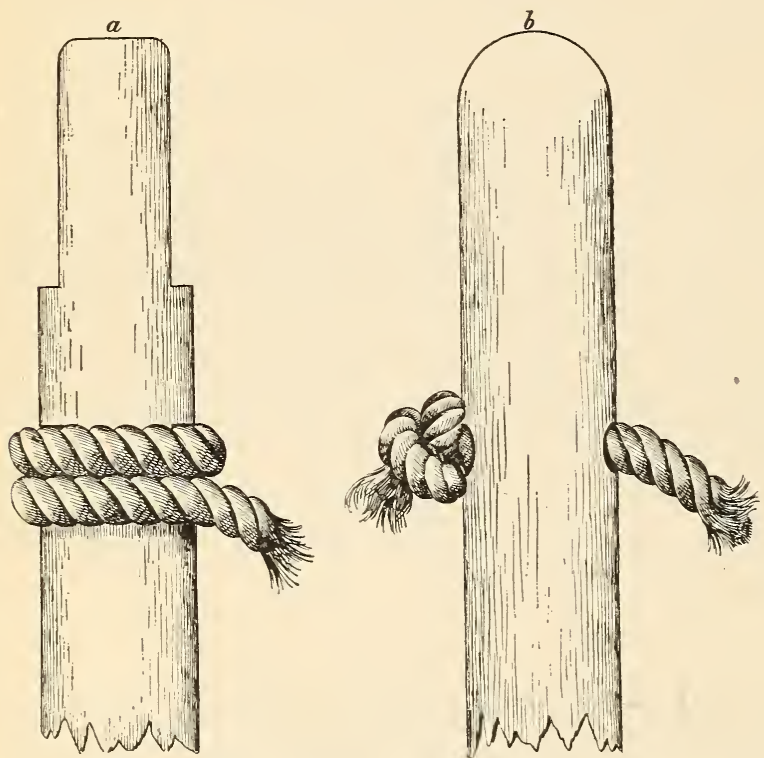

FIG. 4.-Ends of hoisting poles used in placing tents over trees: $a$, Used with tents where rings are present: $z$, used with tents having no rings. (Original.) ever possible. This has resulted, in general, in the use of poles with tents up to 45 feet in size and of derricks with the larger sizes. Sometimes poles are used with tents of 48-foot or 50-foot sizes, but this is difficult, especially if the trees are tall and narrow rather than low and broad. Preferably the poles should be 6 inches to a foot longer than the height of the trees. The two

lengths of poles in most common use are 14 feet and 16 feet. Twentyfoot poles are occasionally required. These poles average from 2 inches to $2 \frac{1}{2}$ inches in diameter, are rounded, and made of straight-grained Oregon pine. The lower end is slightly sharpened to secure a ready hold in the ground. The upper end, to which a rope is attached for erecting the poles, preferably is also bluntly narrowed after one of the methods shown in figure 4. This figure also shows two convenient methods of attaching the rope. The end of $a$ is narrowed about onehalf inch on all sides for 3 or 4 inches. This allows it to slip easily through the rings in tents. The rope is tied in a shallow furrow 6 or 7 inches distant from the end. In $b$ the end of the pole is merely rounded, while the rope occupies an auger hole through the center 


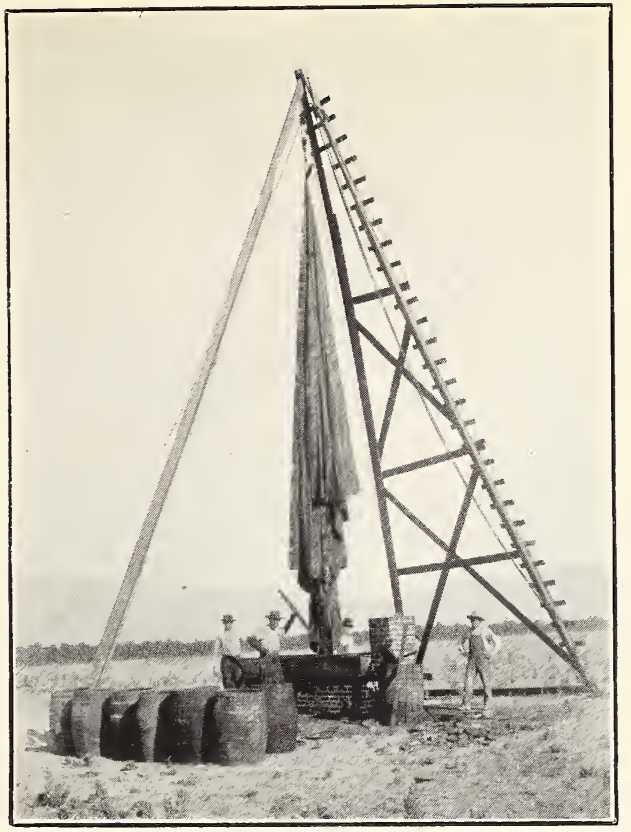

FIg. 1.-Brick Furnace, TANK, AND DeRrick USED IN THE TanNin TREatment of Tents to PReVEnt Mildew, San Bernardino County, Cal. (Original.)

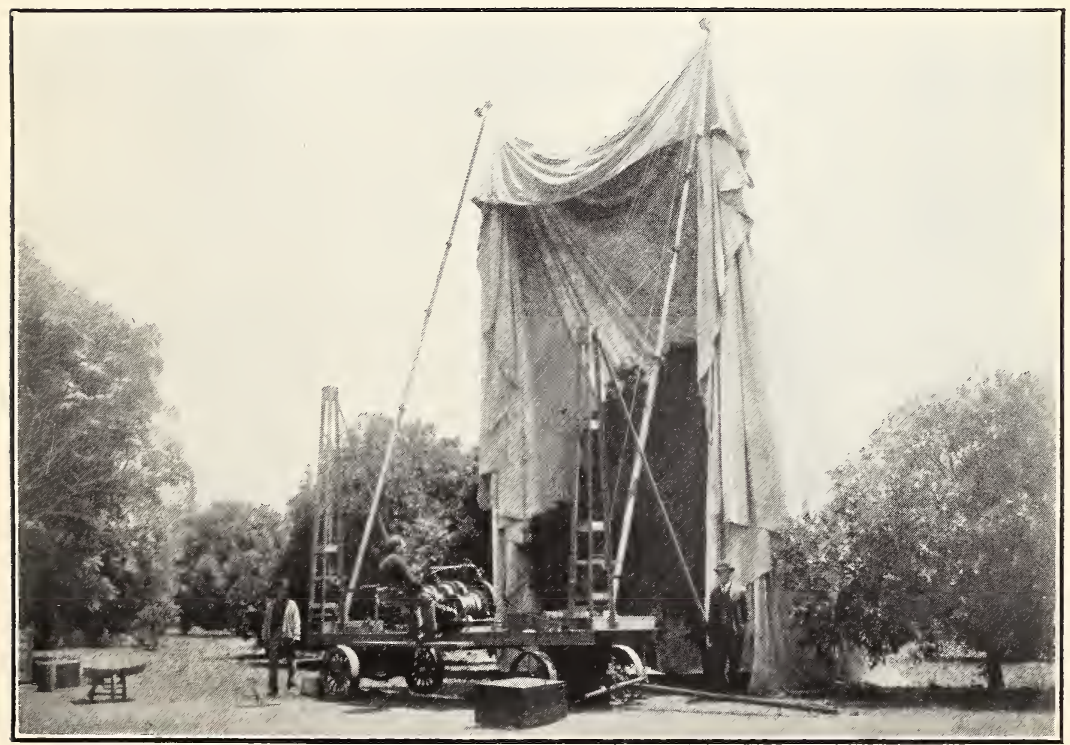

Fig. 2.-Machine for Covering Tree with Sheet Tents. Devised by C. E. MCFadDEN, of Fullerton, Cal. (Original.) 

of the pole and at the same distance from the end as is the furrow in $a$. A knot at the end of the rope prevents its removal from the hole.

Most of the wear on the rope falls on the first 2 or 3 feet adjacent to the pole, for this part is half-hitched each time over the tent. (See Pl. III, fig. 1.) Some fumigators substitute a stout piece of rawhide about 3 feet long to occupy this region between the end of the rope and the pole. The rope should be $\frac{1}{2}$-inch or $\frac{5}{8}$-inch, and about 3 feet longer than the pole.

Derricks are necessary for very tall trees, which can not be covered conveniently with poles. They consist of long poles having a framework attached to the bottom by which to prevent slipping, as well as to confine their movement to either of two directions while standing erect. There is a rope and pulley arrangement at the top for raising the tent. The length of the uprights depends on the height of the trees to be fumigated. They should be fully a foot higher than the tallest trees. In California derricks average between 25 and 35 feet tall, having the top $2 \frac{1}{2}$ to $3 \frac{1}{2}$ inches and the bottom $3 \frac{1}{2}$ to $4 \frac{1}{2}$ inches in diameter. Straight-grained Oregon pine is used. Their construction is well shown in Plate III, figures 2 and 3 . The framework at the bottom (Pl. III, fig. 3) is held together by bolts. The tackle attached to the derrick in part consists of a pulley block fixed to the top of the pole as shown in Plate III, figure 2. A $\frac{1}{2}$-inch to $\frac{5}{8}$-inch rope is attached to this pulley, passing through another pulley block which is free, and thence back through the fixed one (see Pl. VII). The rope used should be about three times the length of the pole. When the derrick is to be moved from one tree to another the free pulley should be hooked to a rope or ring on the standard, the rope pulled taut, and the free end tied temporarily, as shown in Plate III, figure 3. This will prevent the rope from becoming twisted. The movable pulley should have a hook at the bottom by which it can be attached to a ring on the tent. A guy rope several feet longer than the derrick is fastened at the top of each upright and is used in its manipulation.

\section{THE M'FADDEN MACHINE.}

Mr. C. E. McFadden, of Fullerton, Cal., has devised an elaborate and ingenious machine for placing tents on trees. A picture of this machine is shown in Plate II, figure 2. In brief it consists of an iron framework mounted on a pair of trucks. At the center of either end of the framework is attached a long arm made of iron tubing. These arms are comparable to a pair of long hoisting poles. Each of these arms is raised or lowered by a system of steel cables passing through pulleys attached to the arms and two high iron standards. These cables are manipulated by a gasoline engine, which also operates another pair of cables used to raise or lower the tents to or from 
the end of the poles. When ready to throw a cover, the machine is drawn opposite the tree, the arms are lowered until their ends are suspended beyond the outer edge of the tree, cables are then let down from the end pulleys and run through two series of rings in the tent, after which the tent is raised to the end of the derricks. These rings are so placed that when the cable is raised about one-third of the tent is gathered up in a series of folds. The derricks are then erected and the tent cables released, when the tent will fall over the tree.

This operation is quite rapid as well as less wearing to the trees and tents than the use of poles or derricks. Although slower and more expensive than the use of poles in covering small trees, it is easily superior to derricks in covering large ones, such as seedlings, especially where so closely set that the branches interlace.

\section{SUPPLY CART AND SUPPLY WAGON.}

An apparatus of some sort is required in carrying from tree to tree the chemicals necessary in fumigation. The idea of using a twowheeled pushcart originated with the San Bernardino County outfits, where this method has been used for several years. Observation of its use convinced the writer that in most places the employment of a properly equipped handcart is the most practical method available for carrying the chemicals. Extended effort has been made to equip such a cart in a manner suitable for convenient use in the field. The result of this effort is shown in Plate IV, figure 1, the make-up of which has been so improved over the original as to resemble it but little. As purchased, the cart-bed consists of a plain box fitted with a two-shaft handle. This handle is removed, and is replaced by a tongue having an enlarged link-shaped iron about a foot long firmly attached-at the end. This link-shaped handle is very convenient in field work. The scales for weighing the chemicals are placed on a platform above the center of the box. The ordinary kind having a free scoop and using weights is most convenient; $1,2,4,8$, and 16 ounce weights are required. The cyanid is contained in a tin-lined box in the rear half of the cart, while the acid and water are placed in the front end. A 10-gallon keg firmly attached in a horizontal position to the bed of the cart is a very convenient receptacle for the water. A galvanized-iron basin, like that shown above the keg, having an opening at the bottom fitting into the bung of the keg, makes a very satisfactory funnel for filling the latter. The acid may be held in an earthenware jar or a lead-lined tank, with cover firmly attached to prevent slopping.

By way of a cover for the earthenware jar, a lead-lined lid (fig. 5) which fits tightly within the top has been used. At the center of this lid is an opening about 6 inches in diameter, around the circumference of which is attached a leaden tube which extends downward several 


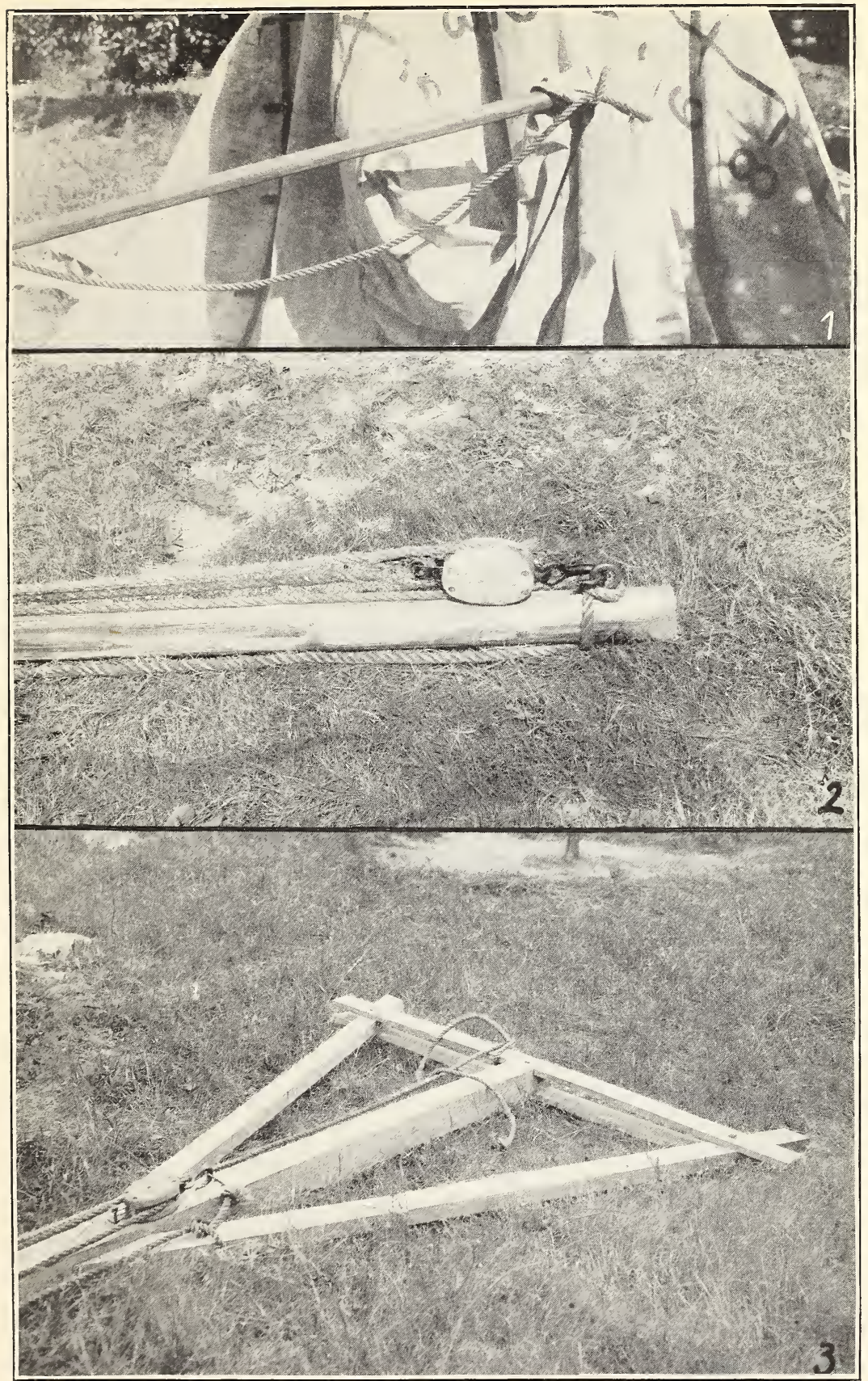

Fig. 1.-Method of Attaching Tent to Hoisting Pole by a Half Hitch of the

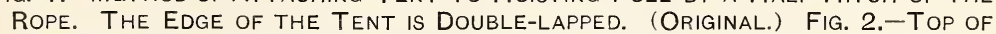
Derrick, Showing Method of Attaching Pulley and Guy Rope. Fig. 3.-Base of Derrick, Showing Method of Constructing Braces. (From Morrill.) 


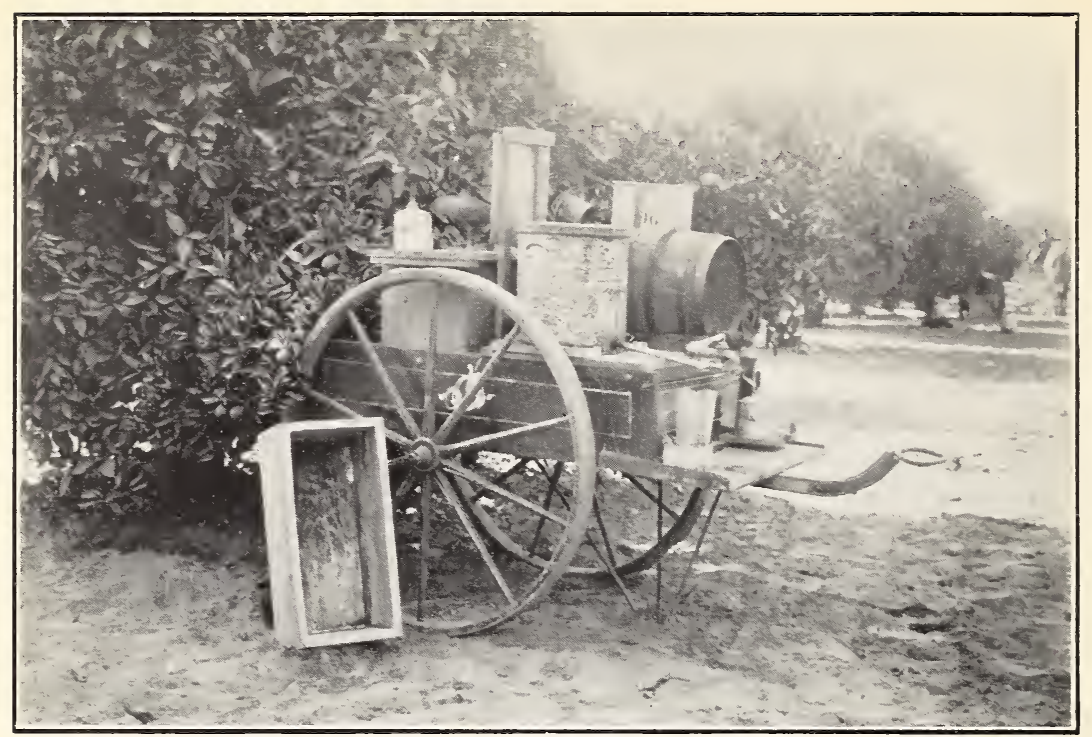

Fig. 1.-Supply CART USEd With THE IMPROVEd System of Fumigation. (Author'S ILLUSTRATION.)

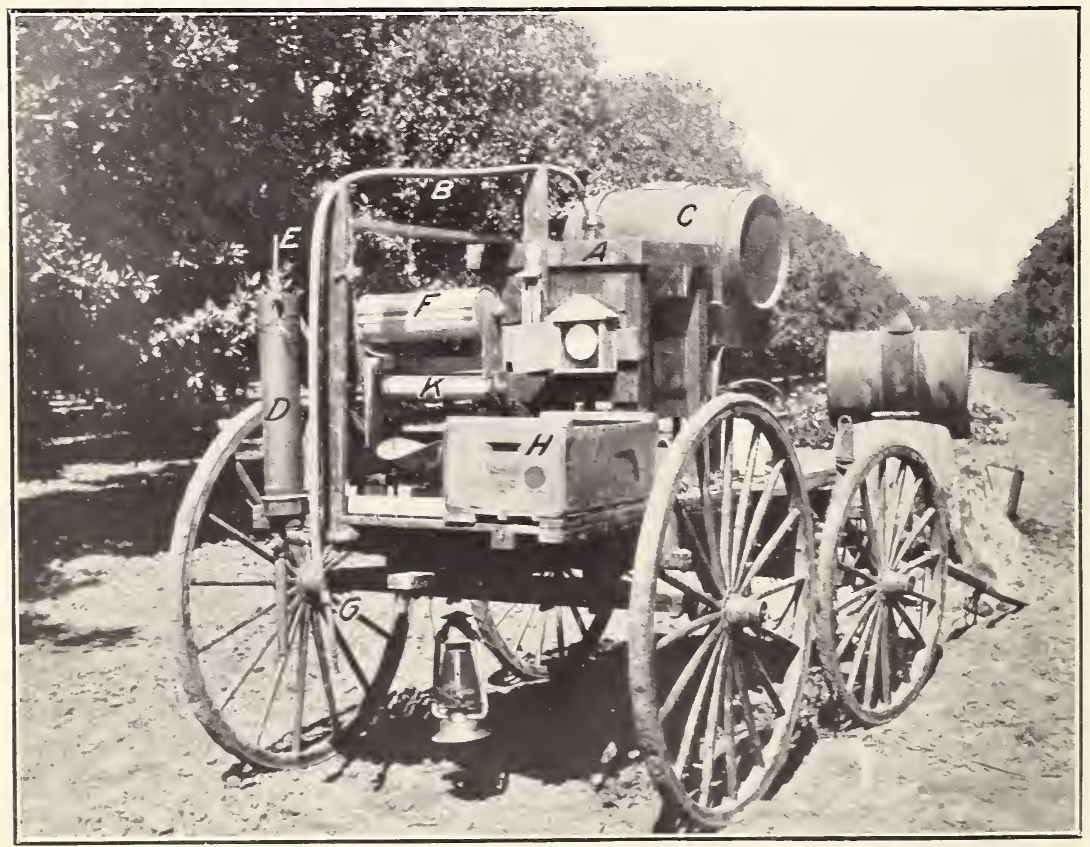

Fig. 2.-Supply Wagon devised by C. E. mcFadden, of Fullerton, Cal. (Original.) 
inches and prevents the slopping of acid through the hole. A leadlined cover fits into the top of this tube. This opening in the cover is for use in filling the jar. Very few metals will withstand sulphuric acid without corroding. For this reason all the common types of faucets are practically worthless for drawing acid. In fact there is no faucet on the market that is altogether satisfactory for this purpose. A manufacturing firm on the Pacific coast has experimented extensively along this line, but without any marked success. This difficulty has been met in an entirely practical manner by attaching a three-quarter-inch copper or iron pipe to the lower side of the jar and regulating the flow of acid by means of a large pinchcock placed on a short piece of rubber tubing at the end of the pipe (fig. $5,1,4$, and 5 ). The flow of acid is rapid and easy to control. Pure rubber is most satisfactory, and a fresh piece should be substituted about every other night.

The water is drawn from a faucet. In order that this may be drawn on the same side of the cart as the acid, an elbow pipe of the character shown in Plate IV, figure 1, is required. The faucet should have an opening of about three-fourths inch to allow a heavy flow, and should be of such a type that a half-turn will give it a full opening.

As fumigation is usually conducted at night, a torch is placed on the front of the cart to furnish a light by which to measure the acid and water; another, on the elevated platform, is convenient for the man weighing the cyanid.
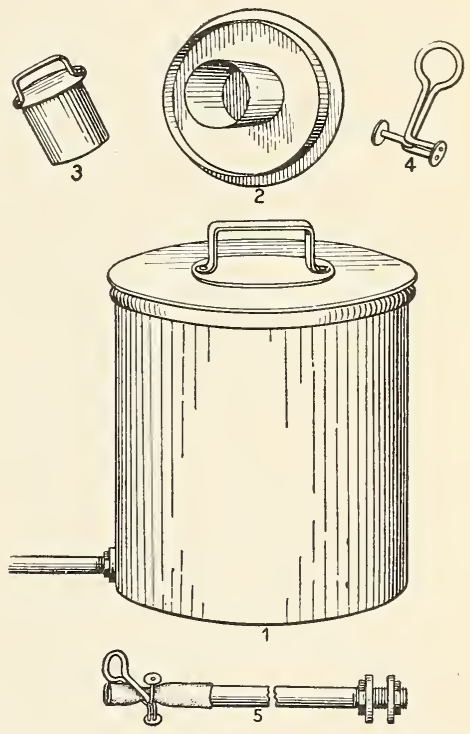

FIG. 5.-Earthenware acid jar with attachments for field use; 1 , Jar complete; 2, inside view of lead-lined cover showing tube at center; 3, copper top for opening in cover; 4 , pinchcock; 5 , method of attaching, iron pipe to jar, and rubber tube on end of pipe with pinchcock attached. (Author's illustration.)

This style of cart is entirely practicable for almost all fumigation work. The chemicals can be measured quickly and accurately without any slopping of acid or water. A glass graduate with a capacity of 16 or 32 ounces, preferably the latter, is essential for measuring acid and water. A kind having elevated rings in the glass has been found most satisfactory for night work. The man handling the acid should wear rubber gloves. Cotton gloves are convenient for handling cyanid.

Some fumigators have preferred to use a horse-drawn wagon equipped for carrying the chemicals rather than a handcart. This has resulted in a number of very original combinations. The most $67330^{\circ}-$ Bull. $90-12-3$ 
elaborately equipped of these recent innorations was devised by Mr. C. E. McFadden, of Fullerton, Cal., and is shown in Plate IV, figure 2. Some of its devices are very ingenious and well worthy of mention. The large box (a) in the middle of the wagon contains an acid carboy whose neck can be seen projecting abore and into which is inserted a rubber hose $(b)$ which leads backward and downward to the rear of the wagon. Pieces of lead pipe are attached to the ends of this hose, the free end of which $(g)$ is equipped with a piece of rubber tubing and cut-off for regulating the flow of acid. The water is contained in the barrel (c) at the front of the wagon. A hose leads from the bottom of this back to the large vertical cylindrical object $(d)$ to the left of the acid hose and adjacent to the wagon wheel. This cylinder is the graduate used for measuring water. The slender iron rod $(e)$ seen projecting from the top of this cylinder is attached to a movable float. This rod is graduated so that each graduation is equivalent to 3 ounces of water. The turning of a valve at the bottom of this cylinder allows the water to flow in, raising up the movable float. When the graduation on the iron rod shows that the cylinder contains the required amount this valve is closed and another opened which directs the water through a downward-projecting pipe into the generator placed beneath. The cyanid is contained in the box $(h)$ at the rear of the wagon. The wagon is also equipped with a thermometer and hydrometer. The upper and larger $(f)$ of the two horizontal cylinders above the scales is a rotary device for reading the dosage schedule. The lower cylinder $(k)$ contains a sheet of paper on which a record of the dosages used is kept.

GENERATING VESSELS.

In California earthenware ressels of the type shown in figure 12 (p. 75) are made especially for, and are almost exclusively used in, generating the gas. They are sold without a cover. The average capacity is 2 gallons, although a $1 \frac{1}{2}$-gallon size is sometimes used for small trees and a 3 -gallon size for very large ones. A $1 \frac{1}{2}$-gallon generator will serve for a dosage of about 15 ounces of cyanid without boiling orer, a 2-gallon generator for approximately 20 ounces, and a 3 -gallon one for about 30 ounces, provided the cyanid is in average-sized lumps and not powdered. Where dosages larger than 30 ounces are required, use two generators, or three if necessary.

\section{GENERAL PROCEDURE.}

The process of fumigation consists of covering trees with cloth tents and grenerating beneath them a very poisonous gas called hydrocyanicacid gas. As previously mentioned, sheet tents exclusirely are used in California. After exposing a tree to the gas for a definite time, 
usually an hour or thereabouts, the tent is removed to the next tree and the process repeated. The work is carried on at night.

Let it be supposed that a man owning an orchard of several acres has made arrangements to have this fumigated. Before entering on the actual work certain preliminaries are attended to. The fumigator prefers and usually requires that the orchard shall have been cultivated recently so that the ground shall be clean and smooth. This condition of the soil is not only an advantage to the fumigator but to the grower as well, for in loose level soil the tents will lie closer to the ground and thus allow less escape of gas underneath than would be possible on weedy or roughly furrowed land. The moving of the chemical cart or wagon is also more difficult on the rougher ground.

An outfit usually consists of about 30 tents. Before placing the outfit in the field the fumigator makes a survey of the orchard in order to determine in what manner the tents can be used to best advantage. This depends on such considerations as the arrangement of the trees, the length of the rows in different directions, slope of the soil, whether irrigation furrows are present, location of water supply, and similar factors. Having decided the direction in which the tents shall be pulled, the wagon which has moved the outfit from the preceding field to the present one is driven along the first row to be fumigated and a tent and generating pot dropped off at each tree. The "commissary," or place where the supply of chemicals and water is located, should preferably be near one end of the row of tents. The location of the source of water will, of course, determine this position. If no source is bordering the field, barrels should be provided for this purpose. The acid is usually furnished in large iron drums. It is convenient to remove the acid from the drums into 10 -gallon glass carboys of the nature shown in figure 6 . These carboys are easy to handle and two or three hold enough for a full night's work.

Immediately preceding the treatment the tent-pullers unfold the tents and have them in position for covering the trees. This position should be with one end facing the tree on the side away from the direction in which they are to be moved. Covering the trees is commenced at one end of the row. Two poles of the character described on pages 20-21 are required, one for either side of the tree. If rings are in the tents the ends of the poles are attached to the rings. However, it is very much easier and more satisfactory not to use rings on tents manipulated by poles, but to double-lap the edge of the tent over the end of the pole and attach it by a half hitch of the pulling rope (Plate III, fig. 1). This is quickly done, does not subject the tent to undue wear, and prevents detaching, as sometimes occurs with rings, but the greatest advantage is that the distance between the poles can be gauged in accordance with the 
width of the tree, which frequently makes tent pulling much easier than when the poles are more broadly separated. The tent should always be mored in the direction of the strips of cloth so as to prevent pulling the seams apart.

The successive stages in the covering of a tree are shown in Plate T. In brief, they are as follows: When the tops of the two poles have been attached to the edge of the tent the width of the tree distant from each other, the bottoms are placed at the sides of the tree opposite the trunk, as shown in Plate T, figure 1. Each tent-

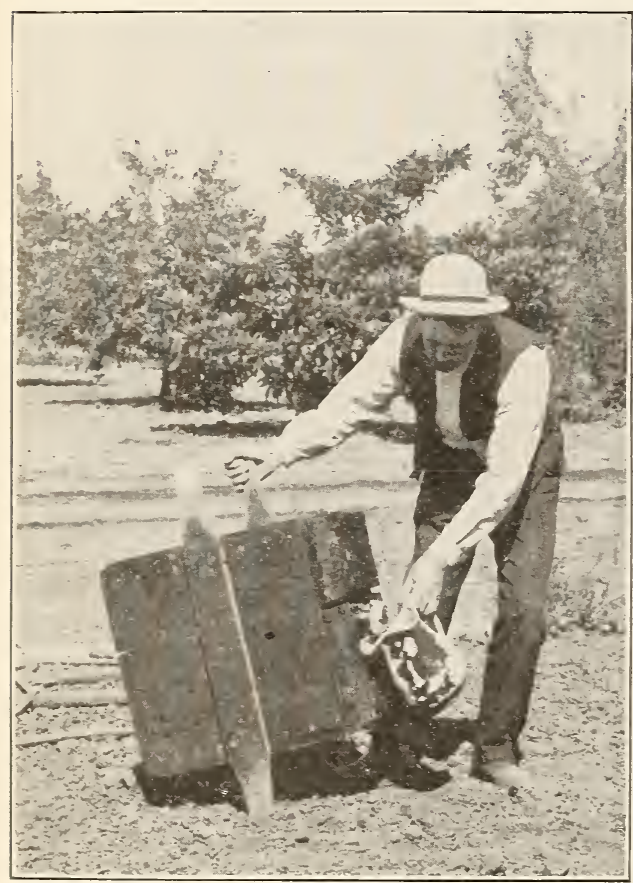

Fig. 6.-Carboy with handles attached to facilitate pouring the acid and carrying the carboy. (Author's illustration.) puller then places one foot on the end of his pole to prerent it from slipping and pulls on the gur-rope, thus raising the upper end of the pole and the tent (see Plate V, fig. 2). Then erected to such an angle that the poles no longer slip, the puller remores his foot from the bottom and runs away from the pole so as to secure a greater leverage on the rope (see Plate $\mathrm{T}$, fig. 3). The direction of the pulling should be not only forward but also somewhat to the side so as to keep the tent taut between the ends of the poles and thus prevent it from being caught in the top of the tree by sagging. After corering the tree the edges should be kicker in-

ward so that the tent hangs straight from the tree to the ground, thus preventing unnecessary space underneath and making the tent lie close to the soil.

The remoral of tents from one tree onto another is done directly without first having to pull them off onto the ground. In fact, it is easier to draw a tent off of one tree onto another than to raise it from the ground onto the tree. Attach the poles to the edge of the tent as previously explained. The poles can then be laid flat on the ground, as in Plate VI, figure 1a, or the end with the tent attached raised up and leaned against the tented tree, as shown in Plate VI, 

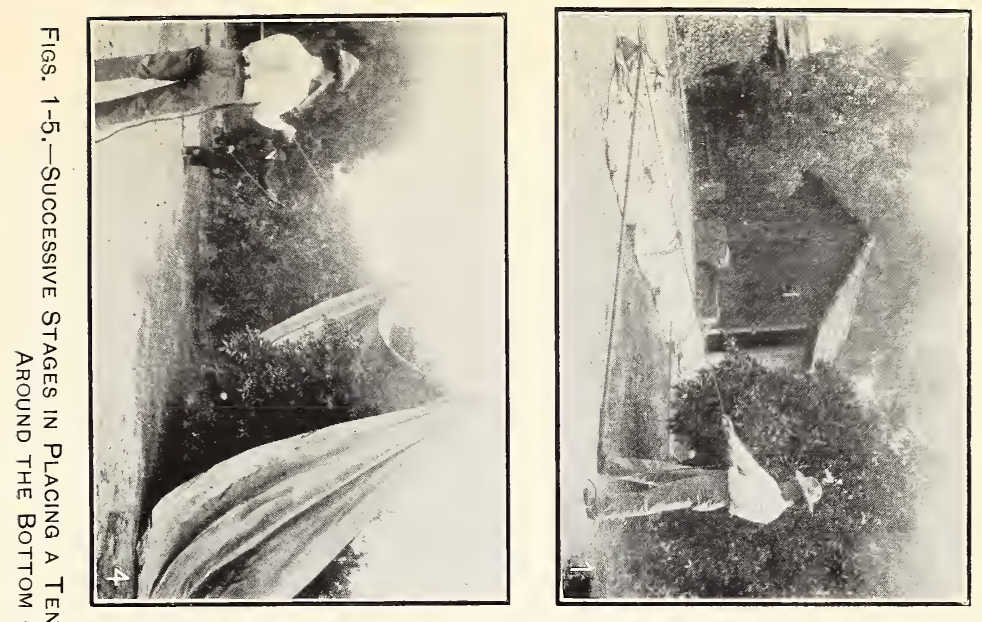

유근
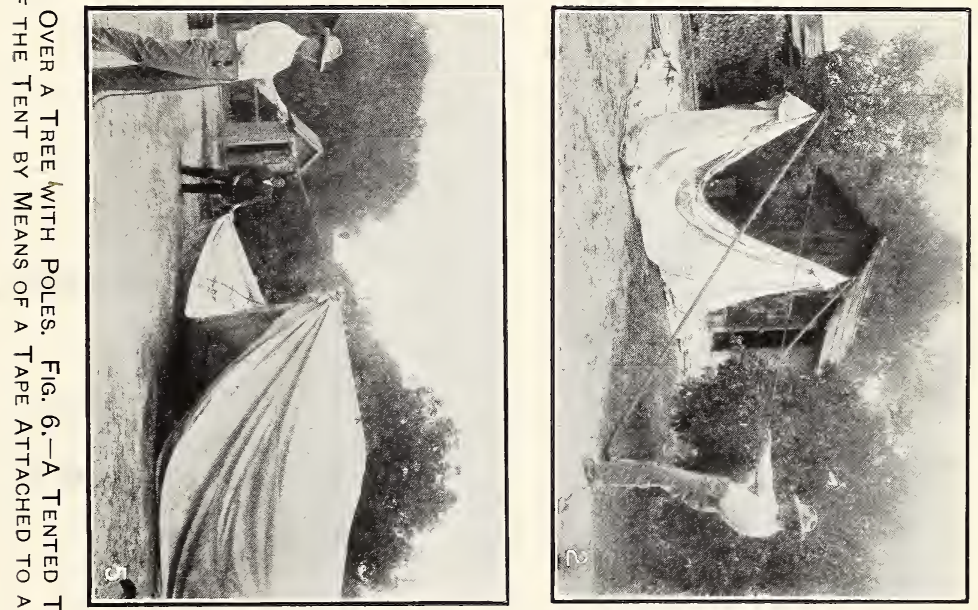

ग

일

ग

이

$\widehat{O}$

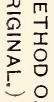

-
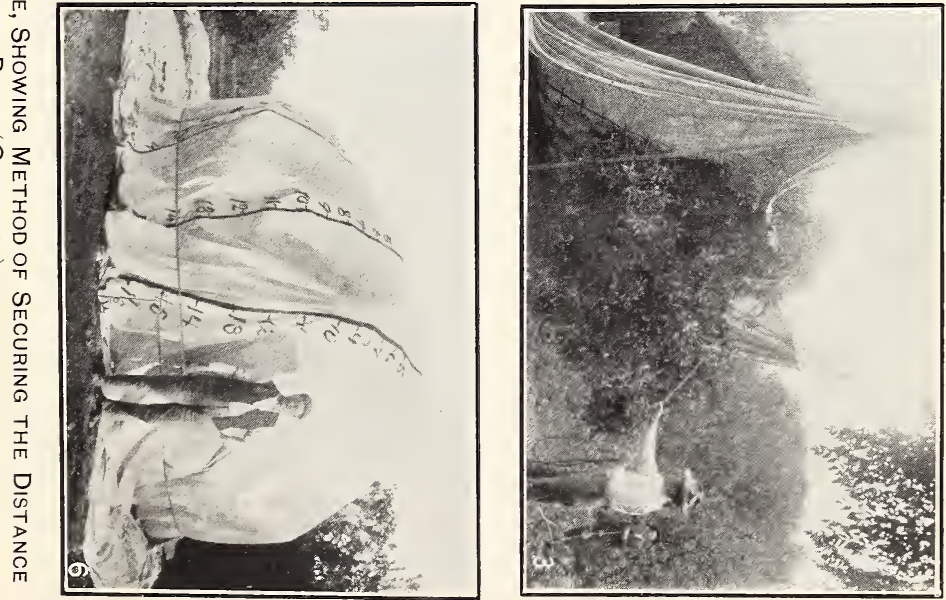

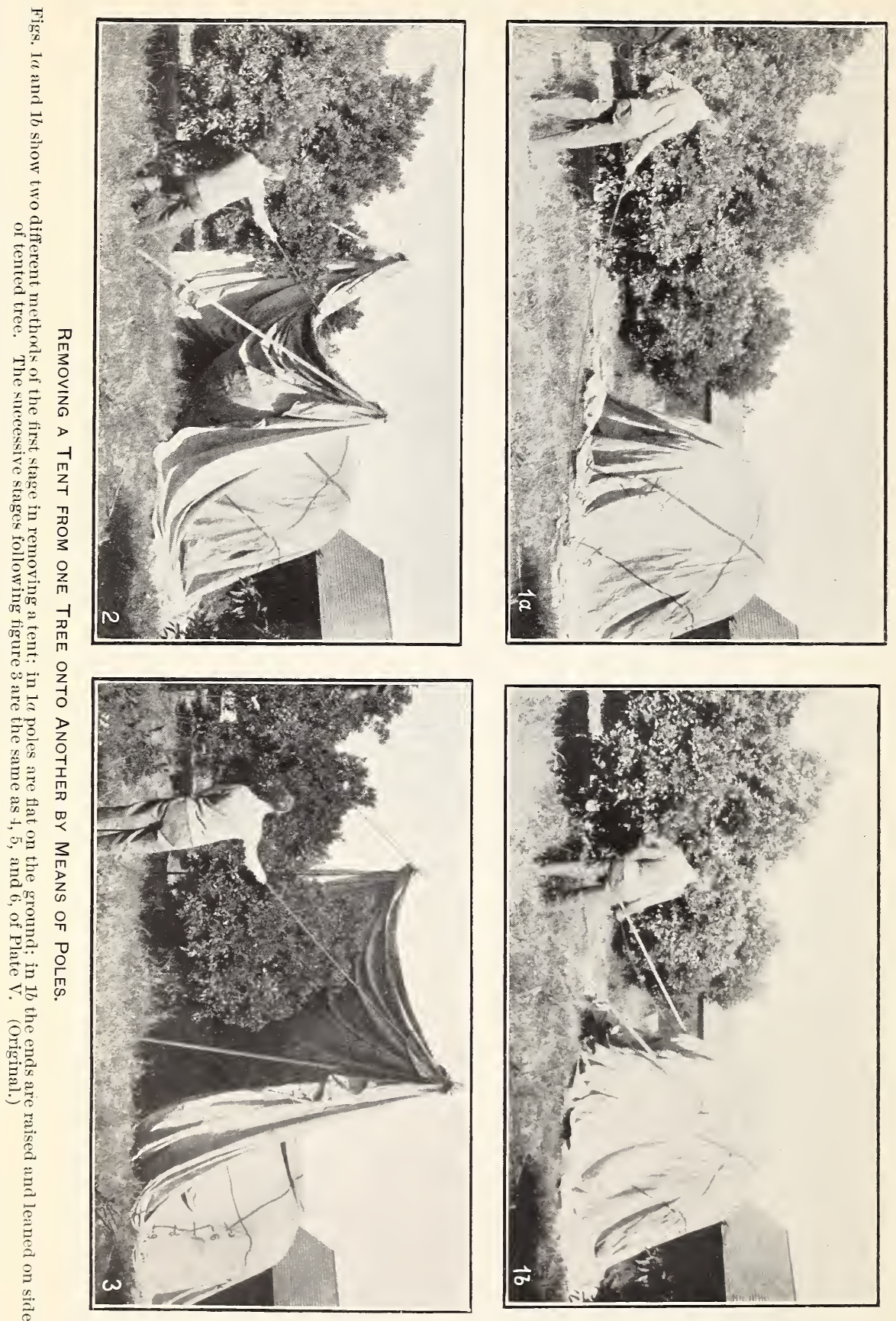
figure $1 b$. The second step in the procedure is shown in figure 2 of Plate VI, while the remaining steps are the same as in Plate V, figures 4,5 , and 6 .

In covering very large trees derricks of the nature described on page 21 are used. Four men are required for their manipulation, which is shown in Plate VII. A derrick is raised to a nearly upright position at each side of the tree (Plate VII, figs. 1-3), leaning at a slight angle backward and held in this position by the guy-rope attached to its top (Plate VII, fig. 3). The movable pulley of each derrick is then attached to a ring in the tent (Plate VII, fig. 3) and pulled up to the top of the derrick, where it is held (Plate VII, fig. 4). By pulling on the guy-rope the derrick is caused to fall forward, drawing the tent over the tree.

Calculating the DOSAge.

Having covered the trees, the next requirement is the amount of chemicals to use, or the dosage. The dosage is the most important consideration in the gas process. It varies not only with the size of the tree but also with the character of insect to be destroyed. Specific recommendations of dosage for the principal insects injurious to citrus trees in California are given elsewhere in this bulletin (pp. 51-61).

The first requirement in calculating the dosage for a tree is to compute the cubic contents inclosed by the tent when in position over the tree. Although most citrus trees possess a certain general similarity in shape, they are nevertheless somewhat irregular, no two ever being identical in all respects. This irregularity renders it impracticable to determine the contents to within a cubic foot or so of its actual volume; yet it can be approximated with a sufficient degree of accuracy for such practical work as fumigation. In order to calculate the cubic contents of an object it must be considered as shaped like some regular geometrical figure or figures. The figure which most closely approximates in shape an orange or lemon tree before it has been pruned is a cylinder surmounted by a hemisphere, and in computing the volume of citrus trees they are considered to be of this shape.

If the height and width of a tree covered with a tent is known, it is a comparatively simple matter to calculate its contents. In the past work in California the dosage has been based upon these two measurements. After a tree is covered with a tent it is a matter of some difficulty to determine its height and width. By using as factors the distance around the bottom of the tent and the longest distance over the top of the tent we arrive at a more practicable method by which to compute the cubic contents, of a given tree. Using these 
measurements as a basis the writer has invented a formula ${ }^{1}$ by means of which the cubic contents of a tree may be computed.

To aroid computation work in the field, in so far as possible, the writer has formulated a table approximating the cubic contents of trees of different dimensions, which is sufficiently extensive to include any citrus tree in southern California. During this inrestigation no tree has been found whose dimensions did not fall within the limits giren in this table. The distance around and orer a giren tree being known, the table will show the approximate cubic contents of the tented tree. The dosage can then be applied in proportion to the contents and at any strength desired.

A lemon tree, after being pruned, is flat on the top. Therefore the geometrical figure which is applicable to an orange or unpruned lemon tree can not be considered as applicable to a pruned or flattopped lemon tree. The figure which approximates the latter is a cylinder. Now it so happens that the contents of a cylinder haring certain dimensions orer its top and around its bottom are almost the same as for a figure of the same dimensions composed of a cylinder surmounted by a hemisphere. This is a great advantage, for the schedule of dosage proposed for orange trees may also be used for all lemon trees, thus obriating the necessity of preparing two different schedules.

\section{SECURING THE MEASUREMENTS AROUND AND OVER.}

The distance around the bottom of a tent is easily secured by the use of a tapeline, or by pacing. The distance orer the top, howerer, was much more difficult to determine until Dr. A. W. Morrill, ${ }^{2}$ in the course of his work for the Bureau of Entomology against the citrus white fly (Aleyrodes citri R. \& H.) in Florida, invented a method of marking tents for this purpose. The Morrill method renders the securing of the distance orer the top of the tent as easy as that around the bottom.

1 Prof. Woodworth (Bul. 152, Unir. of Cal. Agr. Exp. Sta., p. 5, 1903) was not only the first to suggest the measurements around the bottom and orer the top of tented trees, but also was the first to propose a formula for obtaining the contents of tented trees based on a knowledge of these distances. An analysis of this formula during the early part of the writer's field work proved that it was inaccurate, thus necessitating the determination of a new formula. The writer has worked out a formula based on the two measurements abore mentioned. It is as follows:

$$
\frac{\mathrm{C}^{2}}{4 \pi}\left(\frac{\mathrm{O}}{2}-\frac{\mathrm{C}(3 \pi-4)}{12 \pi}\right)
$$

In this formula $\mathrm{C}$ equals the circumference of the tree.

$\mathrm{O}$ equals the distance orer the top of the tree.

If a person works out and notes down in a chart the values of $\frac{\mathrm{C}^{2}}{4 \pi}$ and $\frac{\mathrm{C}(3 \pi-4)}{12 \pi}$ for different values of $\mathrm{C}$ of which he is apt to make common use, it is possible by its use in connection with the formula to determine the contents of trees with fair rapidity.

2 Bul. 76, Bur. Ent., U. S. Dept. Agr., pp. 31-34, 1908. 
Bul. 90, Part I, Bureau of Entomology, U. S. Dept. of Agriculture.

Plate Vil.
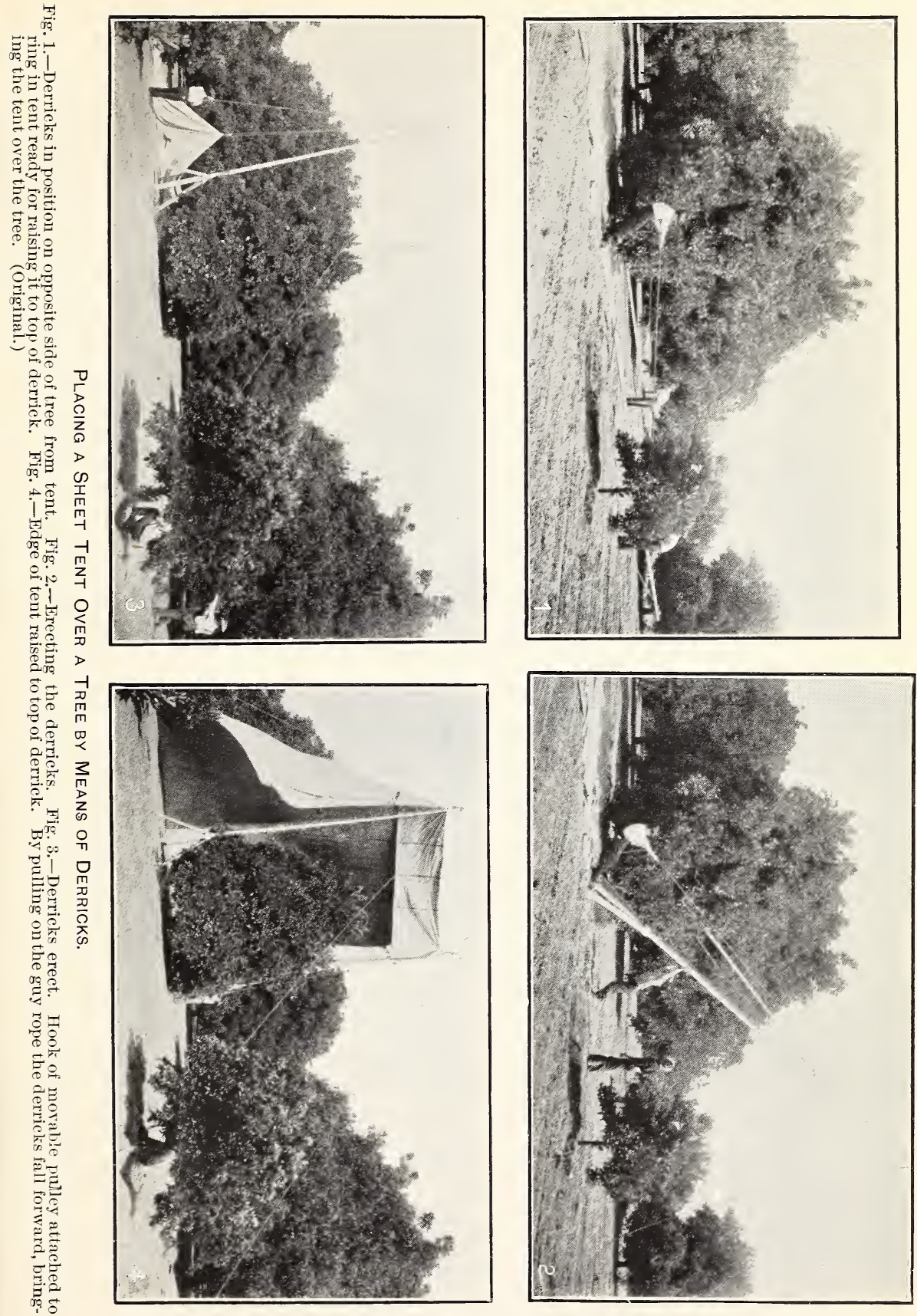

THE MORRILL METHOD.

In figure 7 is shown an outline of a regulation fumigating tent marked after the Morrill system. Three parallel lines and one line at right angles to them are indicated on the tent. The middle one of the three parallel lines passes through the central point in the tent canvas, running lengthwise of the central section or strip of which the tent is made and passing over the top of the tent from the edge

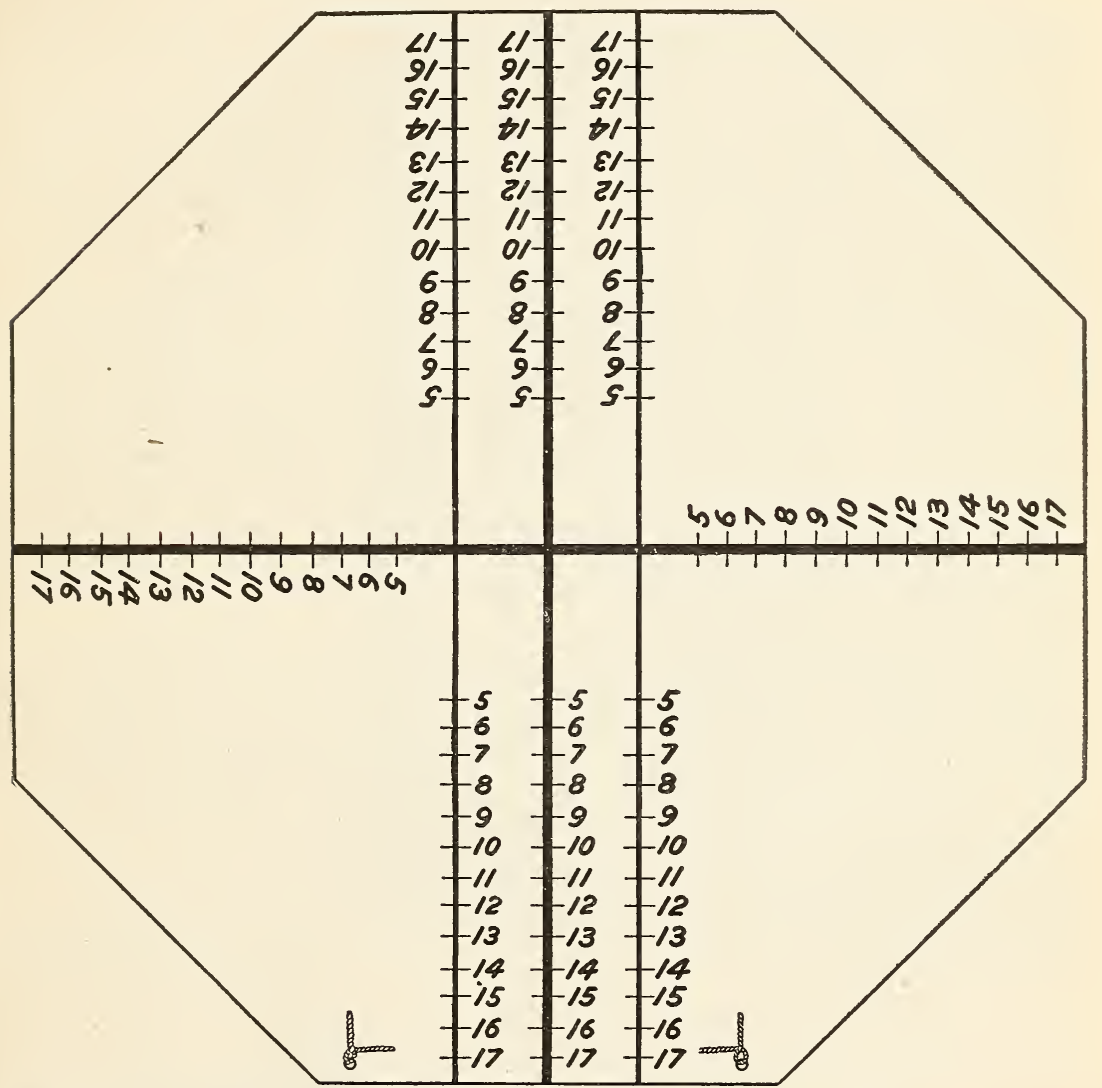

FIG. 7.-Outline of a sheet fumigation tent marked according to the Morrill method. (Author's illustration.)

on one side to the edge on the opposite side; these lines also run in the direction in which the tent should be pulled on or off a tree. Beginning at the center these lines are graduated in feet toward either edge of the tent, after the manner shown in the diagram. For tents above 36 feet (average size) it is unnecessary to commence the graduation nearer than 5 feet from the center of the canvas. When one of these lines is over the middle of the tree the distance over can be calculated by merely adding together the two numbers on the opposite sides of the tent where the edge touches the ground. 
For instance, suppose that on the line over the center of the tree 12 is nearest the ground on one side and 15 on the other. The distance over the center of this tree would be the sum of these numbers, which is 27 feet. With the lines graduated after this manner it makes little difference in determining the distance over the top of the tree whether or not the geometrical center of the tent is at the center of the tree, the single requirement being that some part of one of the graduated lines approximates the center of the tree.

The two lines running parallel to this central line should be about 4 feet distant from it in the larger fumigating tents. The reason for using these auxiliary lines is, that in practice the center of the tent is very often pulled considerably to one side, especially in covering small trees. If the middle line does not fall immediately over the center of the tree, one of the other two lines is quite likely to do so, and that one should be used in obtaining the distance over.

The cross line running at right angles to the three parallel lines also passes through the center of the tent and is marked like the others. The idea of this cross line is that in case of an irregularly shaped tree the distance over can be taken in two different directions and the average taken for use in determining the cubic contents. For experimental purposes with a few tents this line is an advantage, but in practical operations it is unnecessary and should never be placed on the tent, as measurement over the top in one direction is sufficient. The presence of so many lines tends to confuse the operator.

Having calculated the volume of a tree from the two measurements, around and over, it is possible to dose the tree at any strength per unit volume desired. When the dosage has been determined the chemicals are measured out and placed underneath the tented trees.

THE OLD METHOD OF PROCEDURE.

When this investigation was started, a system of fumigation was used exclusively in which the dosage given the trees was based entirely on guesswork. The estimator, who ordinarily is the man in charge of the outfit, starts out in an orchard equipped with a blank schedule sheet of cross-section paper. He walks between two rows of trees, jotting down in the corresponding squares of the schedule sheet the dosage which he belieres the trees should receive. This dosage is based on his eyesight supported by his past experience. If he is a careful scheduler, he will look at the trees from different sides before indicating the dosage, as trees are sometimes more compact on one side than on another. Less careful men set down the dosage for the two rows of trees while moring along as fast as they can walk. The writer has seen some schedulers walk through the orchard at a rapid pace, taking four rows at a time. 
The inaccuracy of such a method is at once apparent. Measurements made after many estimators have shown that the most careful are very irregular in their scheduling. No one has been found who does not at times vary as much as 50 per cent in dosage estimates for trees containing exactly the same cubic contents after being covered with tents. ${ }^{1}$ This variation in the scheduling of an individual fumigator is not all, but the general average dosage used by one man has frequently been one-fourth to onehalf more and sometimes even twice that used by a nother for the very same insect.

This chart of dosage for the trees in an orchard is taken into the field at night. Before dosing a row of trees the common method is to first measure out the dosages for the trees in this row into small cans and pitchers, which are placed in a hand tray, as shown in figure 8 . This tray is then carried from one tree to the next down the row.

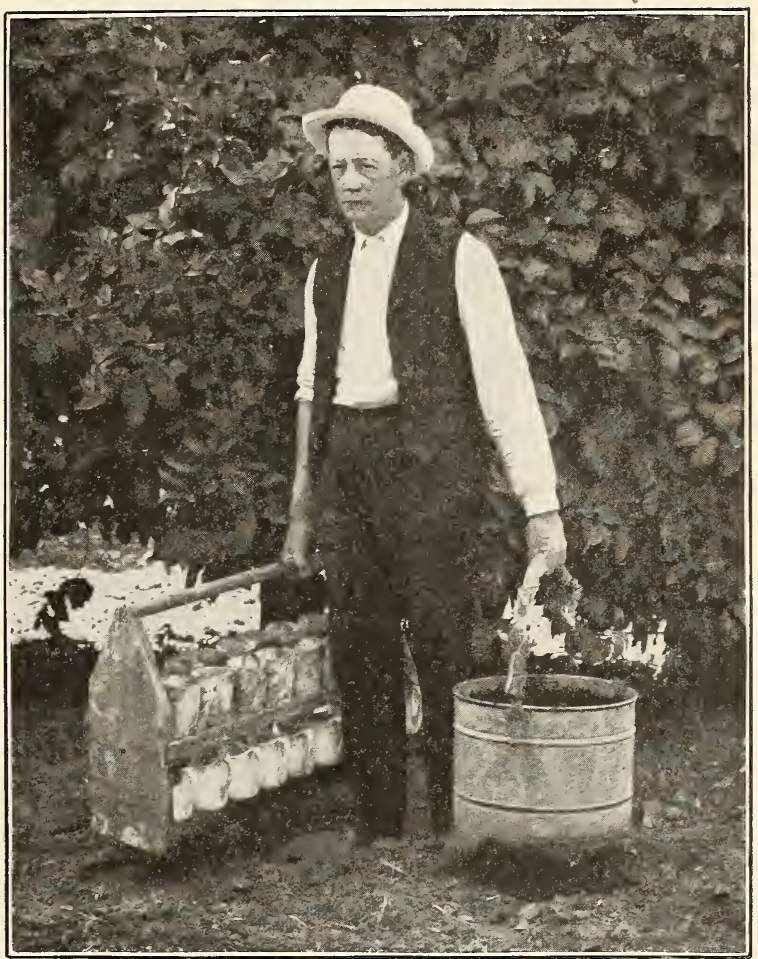

Fig. 8.-Man carrying tray and water bucket as practiced under old system of fumigation. (Author's illustration.)

The water is carried in a pail and measured at each tree. The instruments used for measuring the water have been found to vary all the way from graduated dippers to quart pitchers or old tin cans. Under this old method the general results secured by a few of the more careful and expert fumigators have been fairly good. However, the work in the majority of cases has been irregular and poor. This old system is rapidly sinking into disuse, being replaced by an improved procedure which has resulted from the present investigations. 


\section{AN IMPROVED SYSTEM OF FUMIGATION.}

After becoming acquainted with the chaotic condition of the fumigation practice as it existed at the commencement of this investigation, it was very evident that some system should be perfected which would entirely eliminate the guess features and provide for a calculation of the dosage based directly on the size of the tree. As the result of extended observation, experimentation, and devising, a system of fumigation having decided advantages over the old method was introduced into California during the month of July, 1908. This system is by no means original, but is largely the result of utilizing, correcting, correlating, systematizing, and making entirely practical the best methods and ideas which either had been in practice or had been suggested in the State before this investigation was begun. The method of procedure was copied largely after that of the San Bernardino County outfits, while the method of calculating the dosage was suggested by Prof. Woodworth, of the University of California, and made practical by the adoption of the Morrill method of marking tents. A method quite similar in general features to the California improved system was introduced into Florida by Dr. A. W. Morrill, during the winter of 1907-8. Each of these systems was in the process of evolution at the same time, yet almost entirely independent of each other. To Dr. Morrill, however, greatest credit is probably due for the present advance in procedure, as the inventing of his method of marking tents was the turning point between impractical and practical scientific field calculations.

The tents should be marked after the Morrill method described on pages 29-30. Only three parallel lines are used, the crossline being not only unnecessary but a disadvantage in practical work. This supplies an easy and rapid means of determining the distance over the top of the tree. The distance around the tented tree can be measured accurately by pacing if this is done in a careful manner. Experience with men on the outfit used in this investigation as well as on some of the practical outfits which first adopted the improved system demonstrated that after some practice in pacing around tents some men could so regulate their pace as to be sufficiently accurate for practical purposes. This resulted in at first advising the method of pacing to secure this distance. The broad adoption of this improved system, as well as the frequent changes that take place in the personnel of a crew, resulted in the pacing being assigned to various types of men, some of whom have been known to be hasty and careless. Another discouraging feature is that the tents are very often not properly kicked in around the bottom of the tree, which interferes with accurate pacing. To eliminate the possibility of irregularity due to the above causes it is now advised that pacing be discontinued 
and that the distance around the tent be secured by means of a tape. To meet this requirement, a scheme has been devised by Messrs. Griffin and Gray, of Whittier, Cal., which renders the securing of the distance around the tent not only absolutely accurate but also more rapid and easy than by pacing. The apparatus consists (1) of a straight iron rod 3 or 4 feet long and about one-half inch in diameter, having the lower end sharpened while the upper end is made in the form of a loop, and (2) a strong tapeline having a snap at one end by which it is fastened to the loop of the iron rod.

To secure the distance around a tent the iron rod is stuck into the ground at one end of the marked line on the tent which runs over the top of the tree (Pl. V, fig. 6). The operator then moves around the tree, allowing the tape to slip through his hand as he moves. When he has obtained the distance around he drops the tape, takes the iron rod, with the tape attached, to the next tree, and continues as before. In this manner the operator is required to move only once around each tree. This method is entirely practical, as proved by experience, and in having their work done the growers should demand its use. It reduces variation resulting from the work of careless operators to a minimum. From these two measurements (the distance around and the distance over) it is possible to approximate the cubic contents of the tree and thereby calculate the dosage. This might be done in the field and the trees then dosed in proportion to the contents. However, the time required for the calculation of the dosage, even after determining the cubic contents of the tree, would not only prevent rapid field work and allow an opportunity for error, but would cause a lack of uniformity in dosage from the consideration of the cubic contents alone, as wili be explained later. This difficulty has been obviated by preparing a dosage schedule from which the required dosage may be calculated without any figuring as soon as the measurements of the tree are known.

\section{LEAKAGE OF GAS. ${ }^{1}$}

One of the most important questions relating to the proper dosage in fumigation is that of leakage of gas through the tent. In fact, with the present character of tenting, where the gas has usually all escaped by the end of an hour, the dosage depends directly on the amount of this leakage. In figures which approximate a citrus tree in shape the volume decreases at a more rapid rate than does the surface. Computation shows that a tree 20 feet around by 12 , feet over has 0.86 of a square foot of tent surface for each cubic foot of gas within to escape through, whereas a tree 79 by 54 feet has only 0.22 of a square foot of tent surface for each cubic foot of gas to escape through. This would mean that there is about four times as 
great an opportunity for leakage, or that the leakage would be approximately four times as rapid in the smaller tent as in the larger one. There can be little doubt that the leakage of gas through most of the tenting materials used in this State is nearly in accordance with these figures. In order to secure uniformity of results this leakage must be taken into consideration and small trees must receive more cranid to 100 cubic feet than the larger trees. The correctness of the foregoing statement has been repeatedly demonstrated during the work in the field. Reference to the leakage of gas through tents was first

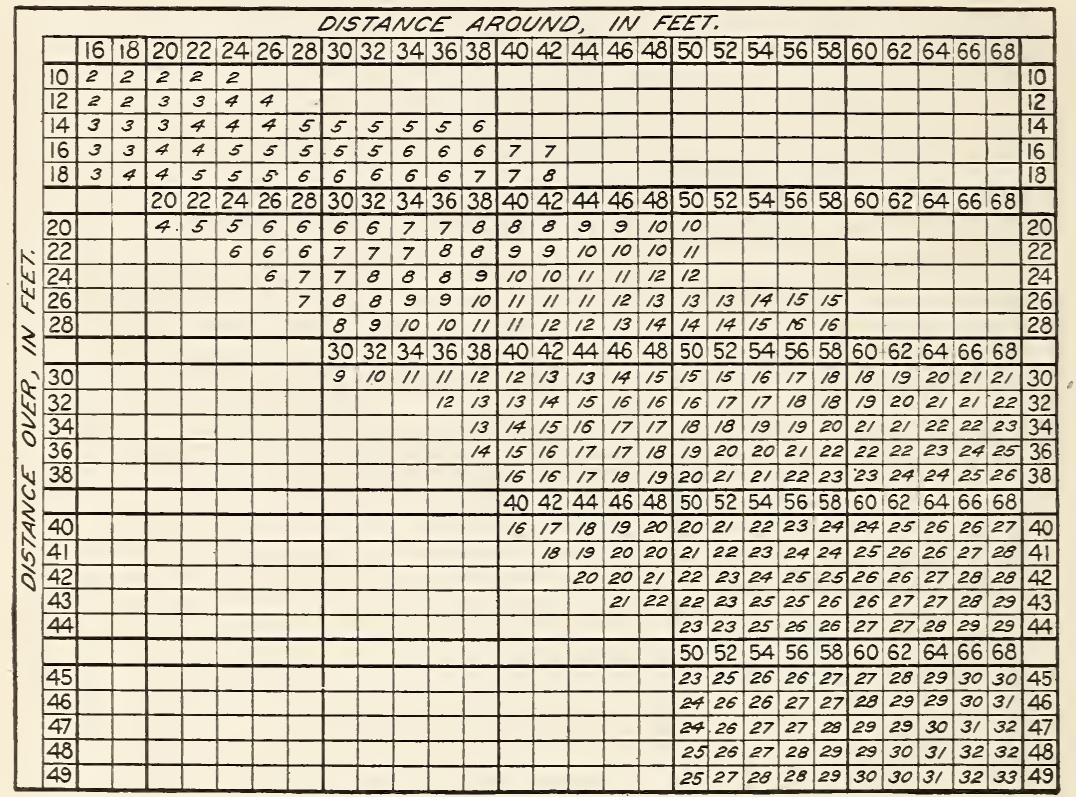

FIG. 9.-Dosage schedule No. 1, for potassium c5anid. (Original.)

made by Prof. Woodworth, ${ }^{1}$ and in a recent publication Dr. A. W. Morrill ${ }^{2}$ has given it a very thorough treatment.

DOSAGE SCHEDULE.

After haring performed a large number of experiments against the purple scale, and determined the dosage required to destroy this insect on different sized trees, the writer utilized these results in preparing a schedule of dosage to be used in fumigation. This schedule (see fig. 9) has been designated "dosage schedule No. 1." The dosages used in this schedule are entirely original with the writer, being the result of experimental work supplemented by calculations as explained in the following paragraphs. After the dosages were 
determined they were introduced into a chart of the same general form as that used by Dr. Morrill. Such a chart form has been known in scientific work for many years and was first introduced into fumigation scheduling by Prof. Woodworth. ${ }^{1}$

An average-sized orange tree, one 41 feet in circumference by 28 feet over, was taken as a basis in the preparation of the schedule. The cubic contents of the tree was determined and a dosage calculated which would give it 1 ounce to each 100 cubic feet. Trees of other dimensions, both larger and smaller, were then considered and their contents determined. In working out the dosage for these other trees not only was the cubic contents taken into consideration but also the rate of leakage as compared with that of the tree 41 by 28 feet in size. Trees which were smaller than this would have a greater proportional leakage rate while the larger ones would have less, as explained on pages 33-34. In securing the dosage for various trees, those smaller than 41 by 28 were given sufficient cyanid in excess of 1 ounce per 100 cubic feet to offset the increased leakage, while the dosages for larger trees were proportionately decreased below the 1-ounce rate. This allowance for leakage so modified the schedule that some of the smaller trees were receiving in excess of $1 \frac{1}{2}$ ounces per 100 cubic feet, while trees as large as 60 by 44 were receiving only about three-fourths of an ounce to the same space. It thus can be seen that each dosage was worked out independently and so correlated to the other dosages that when placed in schedule No. 1 the ultimate result was that of a schedule which should approximate uniform results throughout.

How to use the chart.-Referring again to figure 9, the top line of numbers, commencing at 16 and continuing up to 68 , represents the distance, in feet, around the bottom of the tent. The outer vertical columns of numbers, on either side, commencing at 10 and increasing regularly to 49 , represent the distance, in feet, over the top of the tent: The dosage of a tree of known dimensions is found in that square where the vertical column headed by the distance around the tree intersects the horizontal line of figures corresponding to the distance over. For instance, in the case of a tree 40 feet around by 28 feet over, in the top line of numbers 40 is next after the third heavy vertical line. The dosages computed for trees 40 feet around are to be found in the vertical column headed by this number, which commences with 7 and ends with 16 . Then the vertical column of large figures at either margin is followed down until 28 is reached. All dosages computed for trees 28 feet over are found in this horizontal line of figures, which commences with 8 and ends at 16. The dosage for a tree 40 by 28 feet is found at the intersection of this line with the vertical column headed with 40 , that number being 11 , the required dosage of cyanid in ounces. Before the numbers 20,30, 40, and 45 in the lines 
at the right and left margins are to be found blank spaces, and in the horizontal lines corresponding to these the numbers at the top of the chart are repeated in that part of the chart containing dosage figures. These numbers, repeated in this manner, make it easier for the eye to locate with certainty the dosage figures sought. In the chart used by the writer the figures representing distances around and orer are printed in red. The lines bounding these columns of figures are also red. All the rest of the lines and figures are black.

The writer does not maintain that this table is accurate to the minutest part of an ounce for every dosage, but that such rariations as do exist are so small that in practical work in the field the results in killing scale insects will be found uniformly satisfactory throughout. Two years of experience with the outfits belonging to this investigation, as well as with many practical outfits, in which work thousands of acres have been fumigated, have proved that this belief is well founded.

It is a common practice with tent-pullers in covering small trees to kick in the edge of the tents little if any so as to prevent as much as possible the generator as well as the escaping gas from coming in contact with the tent. This common practice leaves much more space under the tent and incidentally makes more leakage surface in small trees than was provided for in the original chart. (Bulletin No. 79, fig. 28, p. 65.) To correct this feature of the fumigation practice, the original chart has been revised by increasing the smaller dosages to the extent which in field practice has been found necessary. In this revised chart the half ounces are not used as in the original. Field experience has taught that it is desirable to have schedules as simplified as possible. The writer would now advise all fumigators to discard all old schedules and to use the revised one entirely. The dosage strength on which this schedule was based was calculated for use against the purple scale. Howerer, this does not imply that it may not be used against other insects; in fact, the greatest adrantage of it is that it can be manipulated so as to meet the requirements for use against any insect. The schedule in its original form is not recommended for use against all insects under all conditions, as many have beliered. Some of the scale pests frequenting citrus trees require a heavier dosage for their destruction than others. The first point to be determined is the strength of gas required for a particular pest under its special conditions. When this is known, then schedule No. 1 can be manipulated to meet the requirements, provided it is not already of the proper strength. This change is secured by increasing or decreasing all the dosages throughout schedule No. 1 at the same rate, i. e., $\frac{1}{2}, \frac{1}{3}, \frac{1}{4}$, etc. The resultant schedule will be one of uniformity even as is the original. So in treating an orchard the first point to determine is what species of insect has to be combated. 
Having determined this, the dosage strength to use must next be learned. On this latter point the writer has spent much time, and elsewhere in this bulletin will be found information as to what dosages should be used for most of the common scale pests.

\section{PROCEDURE.}

Five men are required to operate this system to advantage. Two men pull the tents and kick in the edges around the bottom of the tree. One man takes the measurements of the tree, and should also empty the generator to be used for that tree and have it in readiness by the time the supply cart arrives. He should empty the generator with one and the same hand at all times, and with this hand he should never touch the tent. He should also be careful not to slop any of the residue on his clothes or shoes lest it be rubbed off on the tent and thus produce acid holes. The supply cart, described on pages $22-23$, is most convenient for carrying the chemicals from tree to tree. Two men look after the chemicals - one measures the water and acid, the other weighs the cyanid. The latter then holds up the edge of the tent while the acid man places the charge beneath the tree. (See Pl. VIII, fig. 2.)

In actual field practice, after the tent-pullers have commenced removing the tents the cart is brought to one end of the row which is to be fumigated. (See Pl. VIII, fig. 1.) The estimator secures his measurements and calls them out to the cyanid weigher at the rear of the cart, who then determines the dosage from a schedule which is fastened to the raised platform. The required amount of chemicals is then measured and the tree dosed. While the handlers of cyanid and acid are thus engaged the estimator has moved on to the next tree, secured his measurements, and holds his generator in readiness when the cart is brought up. This tree is dosed in the same manner as the first, and thus the procedure continues until the entire row has been fumigated.

The above procedure is such as the writer has used in the field and as has been followed by most outfits using the improved system. In the procedures adopted by some other outfits there are marked differences in the duties of the different men.

ADVANTAGES UNDER THIS SYSTEM.

This improved system possesses decided advantages over all others. The element of guess in estimating dosage and the consequent waste of cyanid under the old method are eliminated. With the use of a known dosage strength certain definite and uniform results occur. The chemicals are measured accurately and the most economical proportion used at all times. Each tree gets the dosage scheduled for it - a result which did not always happen under the old method, owing to confusion of the cans on the tray. The tent- 
pullers seldom get more than one or two trees ahead of the cart, and thus all trees receive the same length of exposure. The work of the men who dose the trees is easier than where the heary trars are used. Another decided adrantage is that the orchardist can at any time determine what character of treatment is being giren his trees and see that the work is properly carried out. In the past many persons hare been prone to look upon fumigation as a process that is complex and more or less mysterious. In some cases fumigators of years' experience hare encouraged this widely prerailing opinion, so that they might themselves be looked upon as experts in a practice difficult to understand and only capable of being successfully performed by men of long experience and special qualifications. This is, of course, erroneous. The improred system outlined in these pages shows how simple the practice of fumigation may be made. Careful men who hare never before heard of fumigation can begin the practice of this srstem and are competent, after a few hours of instruction, to secure eren better results than were to be expected from the most expert fumigator in California under the old method. This system reduces fumigation to a matter of simple mechanical operation, entirely intelligible to the arerage man, wherein the operator, to obtain the best results, is required merely to proceed according to the formulas and directions giren. Hence, orchardists are enabled to own their own outfits and carry on their work after the most economical as well as successful manner. Ownership of tents is to be advised for sereral reasons, which are fully explained elsewhere in this bulletin. Fumigation then can be conducted at the most opportune time, good and careful work is assured, while the expense is at a minimum. An orchardist owning his own tents can keep his fruit clean at all times, which otherwise might be impossible, because the number of fumigation outfits in southern California at the present time is insufficient to cope properly with the situation.

\section{EXPERIENCE WITH THIS SYSTEM.}

The introduction of this improred system was made with two outfits of the Whittier Citrus Association, at Whittier, Cal., during the latter part of July, 1908, using dosage schedule No. 1 for the purple scale. On August 15 a demonstration was made before a meeting of fruit growers and fumigators in Los Angeles and proroked deep interest. The rery successful work against the purple scale at Whittier had begun to be evident by this time and led to the prompt adoption of the system by the orchardists thereabout. Growers from other localities, inquiring into the experience with the recent innoration at Whittier, commenced to sanction its adoption in their respective districts, so that by the end of the fumiga- 


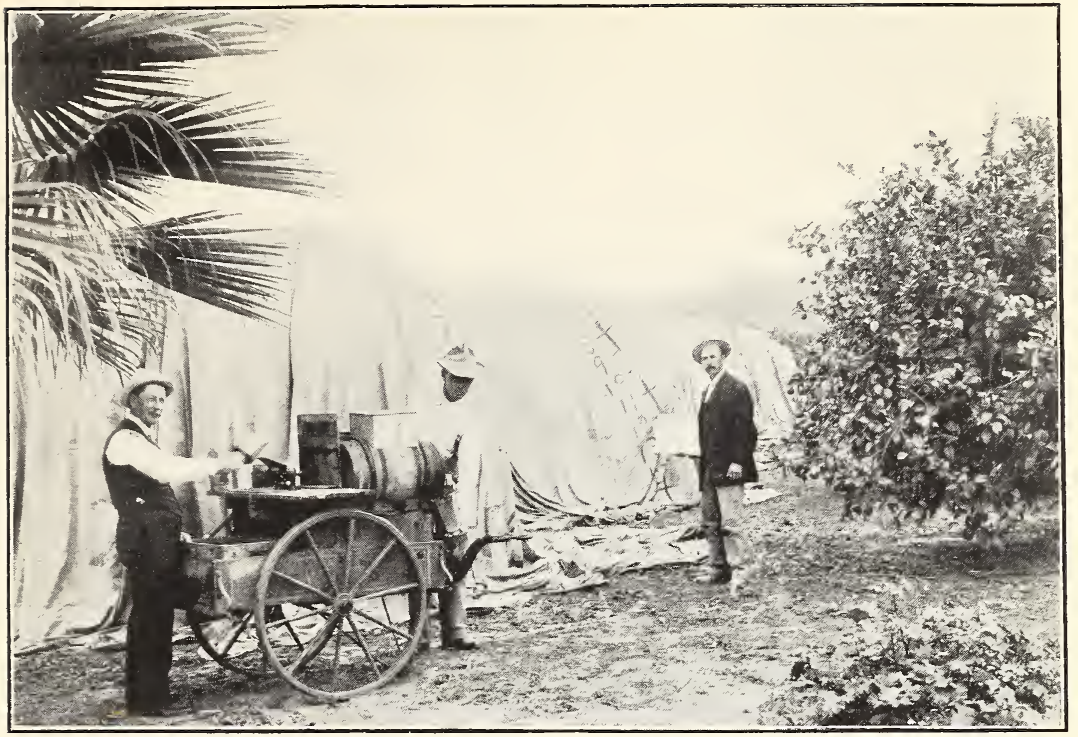

Fig. 1.-A Row of Tented Trees and Cart at one End of Row, Ready to Commence DOSING. (ORIGINAL.)

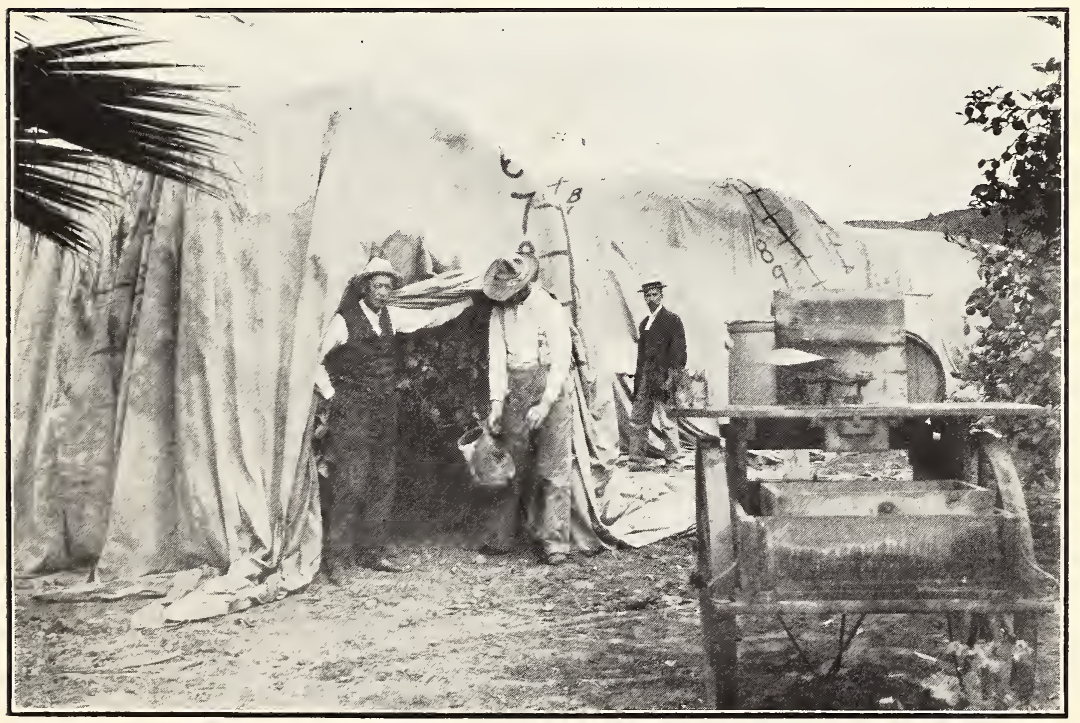

Fig. 2.-Dosing a Tree. This View Also Shows the Scheduler Securing the measurements of the Next Tree in thé Row. (Original.) 

tion season of 1908 fully a dozen outfits in various parts of Los Angeles and Orange Counties were using the new method in preference to the old. The experience of the first season has led to the rapid and successful introduction of the new system quite generally, so that it now has been adopted by many outfits in Los Angeles, Orange, Ventura, and Riverside Counties, while in San Bernardino County it is used almost exclusively.

Naturally there was considerable opposition, at the commencement of this investigation, on the part of the professional fumigators. Their prejudice has been overcome to a large extent by demonstrations and personal cooperation, and many of them are now endorsing the new methods. The chief means of exploitation have been lectures, demonstrations, and personal contact with the fruit growers. In this educational campaign the assistance of many county horticultural officers and managers of citrus associations has made success far easier than it otherwise would have been.

The rapid and general adoption of the new method indicates its practical economy, for new ideas are not adopted by California horticulturists merely for the sake of novelty. The primary question before the grower is whether in the long run the new system of fumigation is more economical than the old one. The new system. nas been used in and about Whittier for nearly two years. Having been located in that region, the writer has been able to keep in touch with the condition of fumigation thereabouts.

A year ago almost all fumigation in the Whittier and Rivera districts was carried on under the new method. Packinghouse statistics of last year's crop at the Whittier and Rivera Citrus Associations, which handle most of the fruit from this section of several thousand. acres, showed that a considerably smaller percentage of fruit was discarded because of being infested with scale than during any season when the old method of fumigation was practiced. Such. statistics are conclusive and their significance is plain.

One of the writer's early contentions was that, after one or two successive thorough treatments under the new method, using the proper dosage, most orchards would be in such a clean condition that they could go without treatment at least every other year. Indicating the correctness of this belief, Mr. William Wood, the very efficient former horticultural officer for the Whittier district, states that many more orchards in his district which were treated during 1908 under the new system were sufficiently clean not to need fumigation the following season than has been the case under the old method at any time within his experience. To show the general attitude of the growers it is only necessary to say that they are so satisfied as to refuse to have their orchards treated except under the new procedure. This condition at Whittier is illustrative of what is taking $67330^{\circ}-$ Bull. $90-12-4$ 
place in many other districts in southern C'alifornia. In short, the experience with this new method of fumigation has been so successful throughout the southern fruit-growing sections that it is only a matter of time when it necessarily must entirely supplant the old methods.

\section{THE CHEMICALS IN FUMIGATION.}

For the generation of hydrocyanic-acid gas in fumigation potassium cyanid, ${ }^{1}$ sulphuric acid, and water are necessary. The hydrocyanic-acid gas is produced by the action of the sulphuric acid on the cranid of potassium. Under the early methods of generating hydrocyanic-acid gas the cyanid was dissolved in water before being used. At the present time cyanid is used entirely in the crystal form. The water is first measured and poured into the generating ressel. The required amount of acid is then added to the water, producing a great increase of the temperature of the mixture. While the mixture is hot it should be placed beneath the tree and the cyanid added. If permitted to cool before the cyanid is added, the generation of gas will not only be slower than with the heated mixture, but the amount of arailable gas will be decreased, thus making the operation more expensive, and necessarily less efficient.

\section{POTASSILA CYANID ( $\mathrm{KCN}$ ).}

An imported potassium cranid designated as 98 to 99 per cent pure is used almost exclusirely for fumigation purposes in southern California. This imported potassium cyanid has been employed throughout the field investigations of this bureau and is referred to in this bulletin whenerer cyanid is mentioned, unless specific mention of another grade is giren. Analyses of seren samples taken promiscuously in the field during this investigation areraged 9S.1 per cent pure, the poorest sample being 97.2S per cent. The general fumigation experience with such a high grade of potassium cyanid has been rery satisfactory. This cranid is purchased in cases containing approximately 200 pounds.

The potassium cyanid most frequently used in California for fumigation purposes is commonly spoken of as "German" cranid, it being generally known that this chemical is imported from Germany. This term "German" has been used in distinguishing the regular potassium cyanid from another kind popularly known as "American" cyanid, which has had a very limited and unsatisfactory usage for a number of years. This "American" cyanid was known to be of a generally much harder composition and slower in generation. Because this latter cranid is made in America the general belief has prevailed among fumigators that it is impossible to manu- 
facture as suitable a grade of fumigating cyanid in this country as in Germany. Such a belief is, of course, erroneous. Chemical analysis of this so-called "American" cyanid has shown it to be not potassium cyanid but sodium cyanid, which is a very different article. No potassium cyanid is manufactured in this country.

A potassium cyanid ${ }^{1}$ guaranteed to be $98-99$ per cent pure should be used, as experience gained during this investigation, as well as that from commercial operations, has proved this grade of cyanid to be uniformly successful. Moreover, such a high-grade article is quite free of sodium chlorid (common salt), the detrimental action of which is explained later.

Cyanid should be exposed to damp air as little as possible, as it is decomposed by moisture. Analysis of a sample exposed to the air for a few months showed it to be several per cent less pure than originally. Such a cyanid, or even one which has become moistened by only a few days' exposure to the weather, is slower in generating its gas, and this is an objectionable feature in fumigation. After opening in the field, the case of cyanid should be protected by a tight cover which will ward off the action of dew or rain.

SULPHURIC ACID $\left(\mathrm{H}_{2} \mathrm{SO}_{4}\right)$.

A commercial sulphuric acid $\left(\mathrm{H}_{2} \mathrm{SO}_{4}\right), 66^{\circ}$ Baumé, which is approximately 93 per cent pure, should be used. Sulphur is the basic ingredient in the manufacture of sulphuric acid. Generally speaking, an acid in which the sulphur is obtained from brimstone is preferable to one made from iron pyrites. The reason is that those which are made from a brimstone base usually contain fewer impurities than those made from iron pyrites. If the impurities be eliminated, however, the sulphuric acid made from the one is as satisfactory in fumigation as that made from the other.

The commonest impurity in sulphuric acid is sulphate of iron $\left(\mathrm{FeSO}_{4}\right)$. This often occurs in acids made from pyrites, and sometimes to a very great extent. It adds a milky appearance to the acid. The action of acid on long-used iron drums also causes the formation of sulphate of iron, evidenced by the whitish appearance of the "settlings" or the acid at the bottom of the drum. The writer has used acid containing considerable sulphate of iron without any apparent injury to citrus trees or fruit. Nevertheless acid con-

1 Experimentation during this investigation has shown that a high grade of sodium cyanid will produce exactly as satisfactory results as a high-grade potassium cyanid. No sodium cyanid less than 126-130 per cent pure (as reckoned in terms of a potassium cyanid) should be used. If a suitable potassium cyanid is not available then purchase a sodium cyanid of the purity mentioned. $\mathrm{A}$ pound of this sodium cyanid contains approximately one-fourth more available gas than a pound of potassium cyanid. Hence, if used, the dosages employed should be one-fourth less than those mentioned in this bulletin. The proportion of chemicals is also different. A $1-1 \frac{1}{2}-2$ formula is advised; that is, to each ounce (average) of $126-130$ per cent sodium cyanid use $1_{3}^{1}$ ounces (liquid measure) of sulphuric acid and 2 ounces of water.

For a thorough treatment of sodium cyanid in relation to fumigation see Part 11 of this Bulletin. 
taining large quantities of sulphate of iron should be avoided for the same reasons that cyanid containing large quantities of impurities should be aroided, even though the impurities are apparently harmless.

Traces of nitric acid $\left(\mathrm{HNO}_{3}\right)$ are sometimes present in sulphuric acid. For several years an opinion has been current in California that nitric acid when present in sulphuric acid used in fumigation would result in the burning of fruit. Burning of fruit has occurred to a greater or less extent throughout the history of fumigation, yet in recent years, because this damage has sometimes taken place when an acid made from pyrites was being used, and in which a trace of nitric acid was sometimes present, the belief has berome quite general among fumigators that such an acid was unsafe. The theory proposed as the cause was that the heat produced in generating the hydrocyanic-acid gas drove off the nitric acid in the form of a vapor, which, coming in contact with the cooler surface of the fruit, condensed, resulting in a burn or pit. Cáreful experiments were recently carried out in order to decide this point. Eight orange and lemon trees well laden with fruit were treated on three different. nights, using sulphuric acid containing from 1 to 10 per cent of pure nitric acid. Dosage schedule No. 1 was followed. The exposure was one hour. No pitting or burning resulted with any of the strengths used. As these amounts of nitric acid are far in excess of the quantities ever found in commercial sulphuric acid it can be safely concluded that there is no danger of burning as a result of the presence of nitric acid in the commercial sulphuric acid.

Traces of arsenic, lead, or zinc are sometimes found in commercial sulphuric acid, yet in all samples of acid analyzed during this investigation the quantity, when present, has been so small as to demand no consideration as a source of injury.

Sulphuric acid is purchased largely in iron drums containing from 1,500 to 2,000 pounds. Glass carboys of about $10^{\circ}$ gallons' capacity are sometimes used. The drums, because of their great weight, are seldom taken into the field. A common and conrenient method is to roll the drums onto an elerated platform at the source of supplies. The acid is then remored into glass carboys or some other receptacle for carriage into the field. Two or thiee carboys usually will contain enough acid for one night's run of an outfit of tents.

Care should be observed in handling this acid. Rubber gloves are adrisable. If some acid accidentally reaches the flesh hasten to wash the affected parts with water.

THE AMOUNT OF SULPHURIC ACID NECESSARY.

Chemical combinations take place with definiteness under the same conditions; that is, given the same conditions, when one chemical acts upon another in the production of a third substance, 
the proportion between the first two chemicals is practically the same. Such is the case when sulphuric acid acts upon potassium cyanid in producing hydrocyanic-acid gas. A given amount of cyanid requires a given amount of sulphuric acid of a fixed degree of purity in order to thoroughly utilize the quantity of cyanid employed, evolving the maximum amount of gas, and carrying the reaction to completion. A quotation from a letter received from Dr. J. K. Haywood, of the Bureau of Chemistry, of this department, illustrates this point:

In the action of sulphuric acid on potassium cyanid approximately four-fifths of an ounce (avoirdupois) of 93 per cent acid is used up for every ounce of 98 per cent cyanid. ${ }^{1}$

Expressed in fluid ounces four-fifths of an ounce avoirdupois equals about 0.42 of a fluid ounce. We may say that theoretically 1 ounce avoirdupois of 98 per cent potassium cyanid needs 0.42 of a fluid ounce of ordinary commercial sulphuric acid (93 per cent) to convert it entirely to hydrocyanic acid. Since it is always best to have some excess of the acid to carry the reaction to completion, it is probable that three-fourths of a fluid ounce of commercial sulphuric acid is ample in practice to convert 1 ounce avoirdupois of 98 per cent potassium cyanid to hydrocyanic acid. If 1 fluid ounce of the commercial sulphuric acid is used it will certainly leave a considerable excess of sulphuric acid. It is perfectly possible, however, that this excess of sulphuric acid is of value in heating up the mixture so that more of the hydrocyanic acid is liberated and not absorbed by the liquid.

Two series of field experiments were performed which were identical in all respects except that in the first 1 ounce of sulphuric acid was used while in the other $1 \frac{1}{4}$ ounces were used to each ounce of potassium cyanid. Analysis of the residue by the Bureau of Chemistry, of this department, showed that the reaction was as perfect with the smaller proportion of acid as with the larger. The addition of a great excess of acid might even result in an impediment to rapid work in the field. As an explanation of this condition it might be stated that the residue always contains a substance which is soluble in water alone, but the presence of a large excess of sulphuric acid will cause it to crystallize and solidify. This latter condition will frequently occur if more than equal parts of acid to cyanid are used, especially so with the smaller dosages. The removal of solidified residue necessitates loss of time.

Summing up, it may be said that 1 fluid ounce of commercial sulphuric acid (93 per cent) to 1 ounce (avoirdupois) of 98 per cent potassium cyanid is certainly enough to carry the reaction to completion in the liberation of hydrocyanic-acid gas and is perhaps an unnecessarily large amount. In practical field work, where dosages of varying sizes are constantly being used, it is very convenient to reckon the acid in the same number of parts as the cyanid. The use of 1 part (fluid measure) of acid to each part ( 1 ounce avoirdupois) of cyanid is therefore recommended. 


\section{WATER AS A FACTOR IS FUMIGATION.}

There are sereral reasons why water should always be emploved in fumigation. It is rery useful in dissolving the potassium cranid and hastening and completing the chemical reaction with the acid. A piece of cyanid thrown into a mixture of acid and water immediatelygires up a portion of its mass in solution. Scarcely has the cranid dissolved when it is partially converted into gas. The heat liberated during this process assists in forcing the solution of more cyanid which is also partially converted into gas. This continues until the chemicals are exhausted and the reaction ceases.

Potassium sulphate, a solid, is the br-product resulting from the reaction by which hydroctanic-acid gas is produced. Water dissolves the potassium sulphate as it forms and prerents it from coating the cyanid not yet in solution. In the presence of an insufficient amount of water, the potassium sulphate is not completely dissolved, but forms a coating on the pieces of cyanid, preventing the sulphuric acid from penetrating to it, and thereby retarding, or even in part preventing, the reaction. In such cases this undissolved potassium sulphate usually solidifies, causing the pots to "freeze." This phenomenon always occurs where the formula is 1-1-1, or where the same amounts of water, acid, and cranid are used. On agitating the residue by stirring, it is almost always possible to find small pieces of undissolred cyanid enreloped in a coating of the potassium sulphate. Ordinarily, when the residue is stirred the particles of cranid are remored, to some extent, from this envelope of potassium sulphate, allowing some of the unused acid to reach them, and thus evolving a small amount of gas without the addition of more acid. Under these conditions, howerer, the reaction is nerer complete, and it is highly desirable, therefore, to add sufficient water at the beginning to dissolve all the potassium sulphate.

Recalling the statements made in discussing the amount of sulphuric acid to use, it is seen that the "congealing" or "freezing" of the residue in the generating jars is due to either or both of two conditions: (1) An insufficient amount of water to completely dissolve the sulphate of potassium, or (2) a large excess of sulphuric acid, whereby the water is rendered less capable of taking into solution the same amount of sulphate as it otherwise would.

Another very important function of the water in the reaction is the heat produced by the union of the sulphuric acid and water. Potassium cyanid introduced into this heated mixture gires off hydrocyanic-acid gas much more quickly and thoroughly than at a lower temperature, and in field work rapid generation of gas is essential.

The action of pure or highly concentrated sulphuric acid on potassium cyanid results in a rery different chemical reaction than when 
the acid has been diluted with water. With very dilute sulphuric acid and up to a strength of 1 part acid to 1 part of water, which is as concentrated a mixture as is ever used in fumigation work, nearly pure hydrocyanic-acid gas is given oif. By decreasing the proportion of water used below 1 part, the amount of hydrocyanic-acid gas resulting is also decreased until, when concentrated sulphuric acid acts on a cyanid, hydrocyanic-acid gas is not given off, but rather an entirely different gas called carbon monoxid. ${ }^{1}$

THE EFFECT OF DIFFERENT PROPORTIONS OF WATER.

On iemperature of gas.-Anyone who has watched the escaping gas and steam from the reaction of potassium cyanid and sulphuric acid wherein different proportions of water were used could not fail to notice that the violence with which the generation starts and the gas is given off is apparently greatest with the smaller proportions of water. Experiments carried on by this investigation showed that

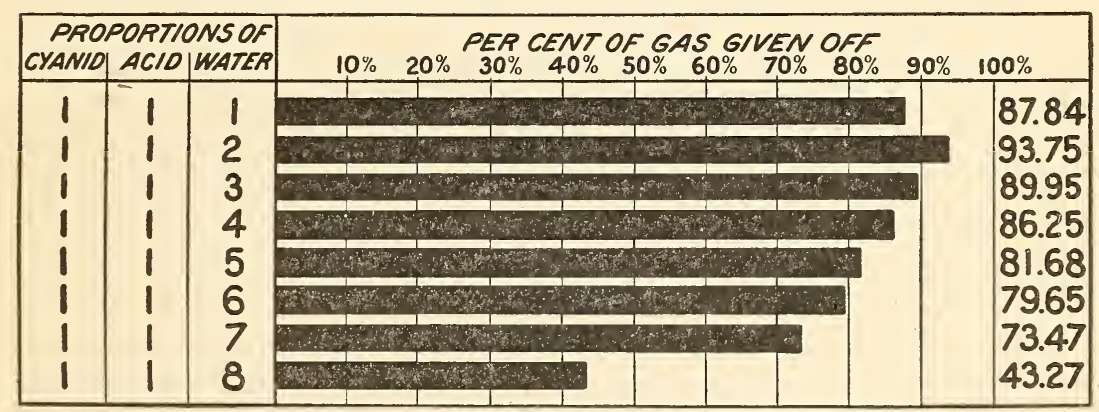

FIG. 10.-Chart showing total amount of gas evolved when different proportions of water are used. (Author's illustration.)

the temperature of the escaping gas was considerably higher with smaller proportions of water than with the larger proportions. In one experiment the highest temperature of the escaping gas was $124^{\circ} \mathrm{F}$. with 1 part of water, but only $90^{\circ} \mathrm{F}$. with 8 parts. The temperature was approximately uniform with from 1 to 4 parts of water.

On amount of available gas.-The Bureau of Chemistry of this department, at the request of the Bureau of Entomology, performed an experiment to determine the amount of hydrocyanic-acid gas available when generated with proportions of water varying from 1 to 8 parts. The results have been incorporated in the accompanying chart (fig. 10).

In these experiments commercial sulphuric acid $66^{\circ}$ Baumé, analyzing 92.77 per cent pure, and potassium cyanid 97.12 per cent pure were used. Three ounces (fluid) of sulphuric acid and 3 ounces 
(avoirdupois) of potassium cyanid were employed in each experiment, and $3,6,9,12,15,18,21$, and 24 ounces, respectively, of water were used in the different experiments.

From this chart it is evident that with the grades of acid and cyanid mentioned the largest amount of gas is arailable from 2 parts of water. As the proportion of water is increased above 2 parts the available gas is decreased, until with 8 parts of water we obtain only about 43 per cent of gas, or less than one-half as much as with 2 parts. In other words, 1 ounce of cyanid and 1 ounce of acid in combination with 2 ounces of water will produce much more available gas than 2 ounces of cyanid and 2 ounces of acid with 16 ounces of water.

The cause for the smaller amount of gas with 1 part of water has been explained on page 44. One of the principal reasons for the decrease of the amount of gas as we go above 2 parts of water is that the temperature of the acid-water mixture decreases as the proportion of water increases. With dosages of 5 ounces of cranid the temperature was found to be $190^{\circ} \mathrm{F}$. where two parts of water were used, but only $125^{\circ} \mathrm{F}$. with 8 parts of water. The hotter the acidwater mixture the quicker and more violent the reaction with the cyanid will be. Secondly, hydrocyanic-acid gas is rery soluble in water. As the cyanid is immersed during the reaction, the gas has to rise through the liquid in order to escape. Less gas will be absorbed by rapid evolution through a small amount of water than by slower rise through a large amount.

The proportion of water used by different fumigators under the old system has raried all the way from 2 to 8 parts, some men eren varying widely in their individual work. In brief, the method followed by the "generator" man in dosing has been that on coming to a tree he first looks at his can of cyanid for that tree and then makes a guess as to how many ounces it contains. If he is using 2 parts of water he will use twice the amount that he thinks there is cyanid in the can; if $\delta$ parts, then $\delta$ times the amount of cyanid he thinks there is in the can. A very few outfits have measured the water in graduated beakers; the majority of receptacles used have raried all the war from half-pint dippers to quart dippers, quart pitchers, or even old tin cans. Think of measuring with accuracy the amount of water for a tree requiring 4 ounces of cranid with a quart pitcher! The writer has frequently seen fumigators, in measuring the water for a tree, first measure out what they thought to be the proper amount, then hesitate as to whether it was enough, and finally dip out a second or eren a third portion. Those second and third dips meant less arailable gas, and the common multifold guessing in the measure of water under the old system has been directly responsible for irregular results. 
It has been a common practice among fumigators to increase the dosage when fumigating a tree severely infested with scale. It also has been a common practice - in fact so common as to be almost universal - to increase the proportion of water when using such heavy dosages. It was believed that this extra water reduced the temperature of the gas, thereby preventing the burning of the foliage. Very naturally, the use of extra water might produce less injury, but this would not be due to the reduction of temperature, as has been believed, but to the decrease of the amount of gas given off. This practice has caused a great waste of cyanid and wide disparity in results. Indeed, the writer believes that no one factor has had more to do with the wide variation in results secured in fumigating citrus trees than has this erratic use of water.

THE CORRECT PROPORTION OF WATER.

It has been shown that 2 parts of water to 1 part each of cyanid and sulphuric acid will produce the maximum amount of available gas. It is impractical, however, to use 2 parts of water in field work because with this proportion the residue, especially when small dosages are used, will frequently solidify within one hour's time, which is the usual period for leaving tents on the trees. Although this proportion of water apparently is sufficient to dissolve the sulphate at first so that a complete reaction takes place, it appears unable to hold the sulphate in solution long enough afterwards to prevent "freezing." This phenomenon is an impediment to rapid field work, for some little time is required to remove this congealed residue from the constricted-neck generating pots in common use. It is evident in this instance that a "frozen" generator does not imply an incomplete generation, although in some other cases the residue left may be congealed and the generation incomplete. With 3 parts of water the residue seldom congeals and this is the proportion recommended by and used in all the field work of the writer. With dosages of 12 ounces of cyanid or above, a $2 \frac{1}{2}$-ounce ratio of water can be used without danger of "freezing." The water should be measured carefully with a glass or dipper graduated to ounces.

THE MOST ECONOMICAL PROPORTION OF CHEMICALS TO USE.

In the preceding. discussion it has been shown that for various reasons 1 fluid ounce of commercial sulphuric acid and 1 ounce (avoirdupois) of 96 to 100 per cent potassium cyanid in combination with 3 fluid ounces of water give a complete reaction. Thus the 1-1-3 formula, hitherto recommended by the Bureau of Entomology, is fully indorsed for fumigation work in the field.

A review of the use of hydrocyanic-acid gas for fumigation, both in California and elsewhere, shows frequent divergence from the more 
economical and satisfactory proportion of chemicals indicated abore. However, since the results of this investigation have been given out the former erratic methods of measuring water have almost entirely disappeared. The usual practice now is to use 3 parts of water which is generally measured in graduated receptacles. The systematizing of the use of water has been one of the greatest accomplishments of the present investigation.

In such special treatments as that of nursery stock, mills, houses, and the like, where the extra time required to remove the congealed residue would in no way interfere with the rapid and economical progress of the work, 2 parts (ounces) of water to each part (ounce) of cyanid is recommended.

\section{THE AMOUNT OF CHEMICALS IN VERY SMALL DOSAGES.}

The results in the fumigation of small trees requiring from 1 to 3 or 4 ounces of cyanid have generally been much less satisfactory than for the larger sizes. If the amounts of chemicals used for such small dosages in large generating pots are always in proportion to the 1-1-3 formula the reaction will sometimes be slow and incomplete. This is especially the case if pieces of cyanid of such size as to project above the surface of the liquid are used. In order that the cyanid may be entirely covered by the liquid the entire dosage should be not in one piece but preferably in two or more smaller pieces. It is also advisable to increase the amount of the acid-water mixture to a slight extent in such cases. An extra ounce of acid and 3 extra ounces of water will usually suffice.

\section{MIXING THE CHEMICALS.}

It is preferable to pour the water into the generator first and then add the acid. The pouring of the water onto the acid is more likely to cause splashing of the acid from the jar onto the fumigator. When the acid and water are in readiness for generating the gas the fumigator adds the pieces of cyanid to the mixture and hastily retreats. As already stated, the cyanid should be added while the mixture of water and acid is hot. Other investigators ${ }^{1}$ have called attention to this, while experiments performed by the Bureau of Chemistry of this department show that the reaction with a cool solution is very inferior to one when the heat is great. Potassium cyanid added to the mixture of acid and water when hot lost $10.6 \mathrm{~S}$ per cent of hydrocyanic-acid gas, while the same cyanid added to a mixture of acid and water while cold lost 23.25 per cent, a difference of more than 12 per cent. The cyanid should never be placed in the water before the acid is added. If the acid is added to the cyanid in solution, a very violent reaction takes place, which will sometimes throw 
much of the liquid from the vessel. In one instance about 1 pound of cyanid was dissolved in water in a 2-gallon generator. Acid was then added, producing a disturbance so violent as to throw some of the liquid almost to the top of a 2 -story barn.

The cyanid should be in pieces anywhere from the size of an English walnut to that of a good-sized lemon. The smaller pieces should be used in the small dosages. Powdered cyanid should be avoided in so far as possible. Where purchased in large boxes there is always a considerable quantity of fine material at the bottom. Entire dosages for a tree should never be composed entirely of this character of cyanid or a violent reaction will take place, blowing much of the fine particles out of the generator and endangering the tent as well as the operator. This fine cyanid is most economically and satisfactorily disposed of by using it in small quantities along with lumps.

The generation of gas has practically ceased at the expiration of from three to five minutes.

Many writers on fumigation recommend the use of paper bags for holding each dosage when placed in the generating pot. These bags are used largely to retard the reaction so that the operator may retreat to some distance before the generation commences or else to prevent slopping. The writer's own experience, as well as some principles previously mentioned in this chemical discussion, would lead to advising against the use of paper bags. The retardation of generation is so marked in the case of small dosages in heavy paper bags that the amount of gas resulting must be considerably less than if the cyanid had been introduced in a free state. ${ }^{1}$ By the exercising of a slight amount of care in introducing cyanid in the free state into a generating vessel there is no danger of the operator being affected by the gas or of the acid being slopped out. Neither will the generating pots boil over if the amounts scheduled on page 24 are used. Fine or powdered cyanid should never be used in houses. In household work sheets of heavy paper should be placed underneath the generators.

EFFECT OF THE PRESENCE OF SODIUM CHLORID ON THE AMOUNT OF GAS GIVEN OFF.

Practically all commercial cyanid contains more or less common salt, technically known as sodium chlorid. The action of this salt in connection with fumigation demands consideration. It has been found, when sodium chlorid is present in the reaction of sulphuric acid on a cyanid in the production of hydrocyanic-acid gas, that this chlorid salt produces a secondary reaction which liberates an acid called hydrochloric acid, and that this liberated hydrochloric acid

1 If paper sacks are employed, they should be of thin paper, or slit to allow the free action of the acid on the cyanid.-C. L. M. 
immediately attacks the hydrocyanic-acid gas and decomposes it to a great extent. Hence, as the presence of sodium chlorid in a cyanid produces a partial decomposition of the hydrocyanic-acid gas when liberated, the ultimate result is that less gas is given off than from a cyanid of the same degree of strength which is free of it. ${ }^{1}$ Extensive experiments carried out by the Bureau of Chemistry of this department showed that the presence of sodium chlorid in a reaction causes a very marked decomposition of the hydrocyanic acid. Experiments with two different cyanids each of which has had a limited usage in California showed that the amount of sodium chlorid in one caused a decomposition of 9.76 per cent of the total hydrocyanic acid, the other of 34.07 per cent. An experiment performed with a cyanid having a very large quantity of sodium chlorid in the reaction resulted in a decomposition of over 92 per cent of the total amount of gas, only a little over 7 per cent being evolved.

The results of these experiments bring to our attention a second requirement in the purchasing of a cyanid. That it be of a certain degree of purity is no longer the only consideration. It is of equal importance that the cyanid be practically free of sodium chlorid. Possibly extensive and expensive refining would be necessary to eliminate all traces of sodium chlorid from a cyanid. Such a condition would be preferable but can not be demanded at the risk of increased cost. We can, however, reasonably expect a high degree of purity, and the writer would condemn as unsuitable for use in fumigation any cyanid containing in excess of 1 per cent of sodium chlorid. This does not mean that every cyanid used should be examined to determine if it contains in excess of this quantity of sodium chlorid. A potassium cyanid 98-99 per cent pure has such a small margin for impurities that it will not contain any objectionable quantity. A potassium cyanid guaranteed as 98-99 per cent pure can be used with entire safety provided its purity measures up with the guarantee.

NATURE OF THE RESIDUE.

The residue resulting from the generation of hydrocyanic-acid gas is usually a bluish or greenish colored liquid consisting for the most part of water. It also contains sulphate of potassium, more or less sulphuric acid, and some hydrocyanic acid held in solution. This combination of substances is of a rery poisonous nature. Nevertheless, some writers on fumigation, considering the plant-food elements which this residue contains, have advised that the residue was of much importance as a fertilizer and should be spread over the ground for such a purpose. This is an instance of the too frequent tendency

1 The decomposing action of sodium chlorid on cyanid used in fumigation was first mentioned oy Newell in Bulletin 15, Georgia State Board of Entomology, 1905. 
of many writers to advise a practice based on theory alone. The writer has seen vegetation destroyed by the action of this residue, especially where the amount of residue was large. Its injurious efect on cover crops has been called to his attention by one orchardist. One of the most striking examples of its injurious efiect that the writer has ever seen was in an orchard of large trees on light sancly soil. The residue was emptied at the trunks of the trees, with the result that portions of the root systems of some trees were destroyed. These examples go to show that the residue produces an immediate injurious effect on vegetation wherever it may come into contact with the same.

The residue should never be emptied near the base of the tree, but out in the middle of the row. It should be so placed that the tents do not come into contact with it while being moved from one tree to another. The common practice in California is to empty it midway between the two rows of trees in the opposite direction from which the tents are being moverl. This prevents their being dragged over the residue.

\section{DOSAGES FOR VARIOUS SCALE PESTS.}

It has been stated previously in this bulletin that the purple, black, red, and yellow scales were the insect pests of citrus trees against which fumigation was generally practiced. In some instances this treatment has been tried against the mealy-bug. The distribution of these insects is such that in one locality the purple scale might be the principal problem of control, whereas in another it might be the black scale, red scale, or yellow scale. Usually a single species will predominate in any one orchard, yet sometimes two or even all require attention at the same time.

The tendency of citrus-fruit growers is to overlook the fact that this problem of control is one wherein different species of insects are concerned and to believe that whatever treatment the fumigator applies should accomplish the same results in all cases. Only the treatment itself is considered, not the strength of dosage, and this has led many orchardists to complain because fumigation by the outfits owned by associations or counties sometimes costs as much or even a little more than that by contractors. If one party performs the work much cheaper than another, the real basis of this cheapness is that less cyanid is used. The desired results can not be accomplished unless the correct dosage requirements are met.

Many dosage tables for the different scale pests of citrus trees have been published in California and elsewhere, based on a consideration of the height and width of the trees. These dosage tables for the most part are very erratic, being calculated largely from hearsay 
rather than from actual experience in the field. ${ }^{1}$ The practice among commercial fumigators has been to absolutely ignore these tables, depending, instead, on their own judgment. The result is that their scheduling differs markedly from that of the published schedules.

\section{FACTORS WHICH AFFECT THE DOSAGE.}

Although citrus-fruit growing in southern California is restricted to a limited area the climatic conditions are not uniform in all sections. The region adjacent to the coast generally is cooler and much damper at night than in the interior valleys. This situation has led to a diversity of opinion among fumigators as to the comparative dosage for the two sections. Some hold that a heavier dosage is required near the coast on the ground that the gas is absorbed by the dampness; others, that the drier and lighter air in the interior valleys allows a more rapid escape of gas through the tent, which necessitates more cyanid than for the lieavier air of the coast. Setting aside these opinions and examining the situation as it actually is, we find that the general dosage strength for a particular insect is approximately the same throughout southern California regardless of nearness to or remoteness from the ocean. Of course, there are a few striking individual variations from this general statement, but these variations are as noticeable in one place as in another.

Personal experience in all sections has taught the writer that the leakage of gas is for the most part noticeably greater in the dryer and warmer interior sections than near the coast. Despite this condition any given dosage appears to be as efficient in one place as in another. This marked efficiency in the dryer and warmer sections regardless of the greater leakage might possibly be due to the fact that the scale insects are more susceptible to the gas in the higher temperatures general there than in the cooler temperatures of the coast. It is known among entomologists that insects are active at high temperatures but become dormant at low temperatures and in the latter condition are more difficult to destroy. Prof. Woodworth, of the University of California, has informed the writer that laboratory experiments performed by him have shown this condition to exist among scale insects and that the temperature at which they become dormant is relatively high. This interrelation of temperature and activity has a very important bearing on the fumigation treatment and demands much further experimentation in the field as well as in the laboratory.

The old conception that an increase of dosage was required near the coast to offset the loss of gas from absorption by moisture is also no longer tenable. Experience has shown that the results during 
damp nights near the coast are exactly as satisfactory as on dry ones. Even if the gas is absorbed by moisture the tents become so much tighter from being moist that any negative effect from the dampness is offset.

The character of the tenting material used directly affects the dosage required. Most of the ducks and drills now used in California (see p. 11) are about equally gas-tight. The recommendations of dosage given in this bulletin are for these tenting materials. With the special new drill experimented with during these investigations (see pp. 11-12) one-fourth less dosage is required. Any tenting tighter than the cloth commonly used for this purpose in California will also require less dosage.

THE PURPLE SCALE.

Preliminary experiments to determine the dosage required for the destruction of the purple scale were undertaken at Orange, Cal, during the month of November, 1907. Orange trees severely infested with the purple scale in all stages of development were treated with dosage rates varying from three-fourths of an ounce of cyanid per 100 cubic feet up to $2 \frac{1}{2}$ ounces per 100 cubic feet. The cubic contents of the trees varied but little, the trees ranging from 11 to 14 feet in height. The 1-1-3 formula was followed. Exposure lasted one hour. After a period of about two months an examination of the results of this experiment was made. To show the care with which the examination was conducted in this as well as all other experinents against the purple scale it might be mentioned that in each case the scales were overturned and examined with a high-power hand lens. In those instances in which the entire contents of the scale were not at once revealed, the delicate ventral scale was ruptured and the contents scraped out. Through this method not a single egg could escape observation.

As a result of this experiment it was found that all insects were destroyed on the leaves and branches by a $\frac{3}{4}$-ounce dosage rate, that all insects and over 99 per cent of the eggs were destroyed at a 1-ounce dosage rate, and that all eggs on the leaves and branches were destroyed at a $1 \frac{1}{2}$-ounce dosage rate. Very littlefruit was on the trees, yet, where present, normal eggs were found on the fruit after a dosage as high as a $1 \frac{3}{4}$-ounce rate.

In another experiment in which the trees were considerably smaller, some being not more than 7 feet tall, it required a 2-ounce rate to eradicate the eggs on the leaves and branches, even though the length of exposure was one and one-half hours. This condition shows that smaller trees require a much heavier dosage proportionally than large trees to offset the leakage of gas, as explained on pages $33-34$.

During July, 1908, an orange orchard near Whittier, consisting of about two acres of trees averaging about 7 to 9 feet tall which were 
sererely infested with purple scale, was fumigated with the 1-1-3 formula with an exposure of one hour. Dosages varring from $1 \frac{1}{2}$ to $2 \frac{1}{4}$ ounces per 100 cubic feet were used. The result was that eradication occurred on the leares and branches at a rate of 2 ounces per 100 cubic feet, thus corroborating the work on such small trees previously carried on at Orange.

Eradication of an insect would be preferable, ret experience during these experiments just mentioned demonstrated that the dosage required for eradication might result in injury to the fruit. A rate of 1 ounce per 100 cubic feet for trees about 11 to 12 feet high was safe under almost all conditions and such a rate was adopted for general work. Dosage schedule No. 1, based on such a strength of gas, was prepared at this time.

This schedule No. 1 was used during the autumn of $190 \mathrm{~S}$ br sereral practical outfits in the ricinity of Whittier, and has since been followed in other sections in which the purple scale occurs. Thousands of acres hare been fumigated after this schedule. The general result, when the work has been carefully done, has corroborated the writer: own experiments in that all live insects and in excess of 99 per cent of the egos were destrored on the leares and branches. Such a killing is entirely satisfactory. In some cases a slight amount of pitting of fruit has occurred, especially in the top of the trees, and has caused some growers to complain. This slight amount of pitting can be orerlooked by reason of the superior killing which has resulted. To use a dosage sufficient to control the scale and at the same time entirely aroid pitting throughout a fumigating season is a practical impossibility.

The first season the improred srstem of fumigation was adopted schedule No. 1 was used almost unirersally. As this schedule gires dosages considerably in excess of those formerly used, fumigators in general became somewhat uneasy about using it, with the result that during the season of 1909 a three-fourths schedule. rather than full schedule No. 1. was used br the majority of outfits. Although the results with the three-fourths schedule have been very good, this schedule is far less satisfactory than the full schedule No. 1.

The writer adrises the use of full schedule No. 1 (see fig. 9, p. 34) for the purple scale. The results with this dosage are so superior, as shown by experience, that most orchards are rendered so clean that thereafter they do not require fumigation oftener than once in two rears. It is more economical to use schedule No. 1 and escape treatment alternate rears even if a little fruit is pitted in the operation than to use a smaller dosage and be obliged to treat an orchard erery rear. It is seldom, howerer, that any marked degree of pitting takes place with -chedule No. 1, if proper care is exercised during the operation. 
LENGTH OF EXPOSURE.

Experiments against the purple scale showed that in using a 2-ounce dosage rate eradication occurred on the leaves and branches with a 30-minutes exposure, whereas with a one-hour exposure it was possible to accomplish the same results by using a $1 \frac{1}{2}$-ounce dosage rate. This demonstrates that decidedly better results can be secured by leaving the tents on the trees one hour than is possible with 30 minutes of gassing. With the present character of tents in use practically all gas has escaped on most nights by the end of an hour. This furnishes sufficient evidence that a longer exposure would be unnecessary. However, experiments have been carried on in which exposures of greater duration than one hour were made, but no better killing resulted. From all the experimental evidence at hand, an exposure of one hour is advised for the purple scale. This length of time readily enables an outfit to go through the complete operation of preparing the chemicals and dosing the trees, with a few minutes to spare for rest.

ERADICATION.

Experiments during the earlier part of the investigation showed that the purple scale could be eradicated from the leaves and branches of trees by using a dosage equivalent to a $1 \frac{1}{2}$-dosage schedule. During the first part of September, 1908, an isolated orange orchard containing: about 1 acre of trees from 10 to 18 feet tall and severely infested with the purple scale was fumigated, using a $1 \frac{1}{2}$-dosage schedule (dosage schedule No. 1 increased one-half). No old scaly fruit was left on the trees. The results were as follows: An inspection of this orchard during the latter part of the autumn failed to reveal any live insects. The crop of fruit on the trees was entirely free of scale for the first time in the memory of the owner. Many examinations have been made since, yet without the finding of a single live insect.

This experiment has shown that eradication of the purple scale on trees free of infested fruit is possible with a $1 \frac{1}{2}$-dosage schedule, if the work be carefully done. In small isolated orchards it might be practicable at certain times to use this dosage. For general work the employment of this eradication dosage is not advised. The writer's experience has assured him that careful work under the most favorable conditions would largely avoid pitting of fruit even with this high dosage. But, as a matter of fact, the work in the field is not always carefully done, nor are the most favorable conditions always taken advantage of. Experience has shown that the pitting of fruit with regular schedule No. 1 sometimes causes a slight dissatisfaction among growers. If the injury from schedule No. 1 sometimes produces dissatisfaction, it is very evident that the greater risk with a larger dosage is too great to justify its general adoption.

$67330^{\circ}-$ Bull. $90-12-5$ 
Other conditions exist which take part in prohibiting this greater dosage. If this dosage were used in general orchard work, it is doubtful if eradication would occur in all cases. Tents not properly. pulled down on all sides of the tree, a hole in the tent, mistake in measuring the trees or in reading the dosage from the schedule, erroneous measuring of chemicals, boiling over of a generator, overturning of a generator, and numerous other considerations which will sometimes escape eren the most careful manipulator, make the difference between eradication and noneradication more variable in practice than in theory. If the fumigator is inclined to be a little careless, some of the above errors will frequently creep in.

Moreover, unless compelled to do so the orchardists in any one locality would not all use this dosage, while possibly some would not fumigate at all. To go to the extra expense required in an eradication dosage and then be subject to reinfestation from one's neighbors presents no special attractiveness to the grower. Supposing that the growers in any one locality were willing to use an eradication dosage, the present number of fumigation outfits is inadequate to meet this requirement within the limited time necessary in order to prevent reinfestation. These practical considerations demonstrate that the eradication of the purple scale from any large district is impracticable at the present time.

DIFFICULTY OF DESTROYING THE SCALE ON THE FRUIT.

There is one more important point which must be considered in connection with fumigation for the purple scale. In experiments to which attention has been called it has been shown that destruction of scale is much more difficult on the fruit than on the leaves and branches. Careful investigation of this point for about two years has also shown that the susceptibility of the scale on some fruit is much greater than on others. Hence, no exact standard of destruction for the scale on fruit is possible. When scales become matured and deposit eggs the dosage required for eradication is rery much greater on the fruit than on the leares and branches. It may require a one-fourth to one-half or in some cases an even greater increase. A dosage sufficient for eradication of the scale on the fruit is impractical for the very same reasons that make eradication on the leaves and branches commercially impractical. A grower possessing a few trees on which he intends to eradicate the scale at one fumigation should remove all infested fruit before the operation and then use a $1 \frac{1}{2}$ schedule. It is advisable to remove the old scaly fruit in any fumigation. At picking, fruit badly infested with scale is usually left on the tree, and frequently from one to a half dozen or more old, scaleinfested oranges per tree remain throughout an orchard. Even after a good fumigation one of these old fruits might carry more healthy 
purple-scale eggs than all the rest of the tree, and on the hatching of these eggs the insects will spread to other parts of the tree. The danger from old scaly fruit is evident, and all such should be removed from the trees before fumigating an orchard.

There are times in which a scale-infested orchard to be treated contains some scale on the green fruit. During the autumn season when fumigation is most practiced the purple scale is largely in its earlier stages of development, in which it may be destroyed by the employment of schedule No. 1. The immature fruit which is scale infested can be left on the tree. It is the old scaly fruit which requires removal at the time of fumigation.

TWO SUCCESSIVE TREATMENTS.

A few growers whose groves are severely infested with the purple scale will desire to have the scale eradicated if possible, even though the initial expense is considerably above the cost of a regular treatment, yet they do not care to assume the risk of having any fruit on the trees injured. In such cases some authorities advise two successive treatments during the early autumn and about five or six weeks apart. The dosages used should be sufficient to destroy the mature insects. The first treatment would destroy all the insects, leaving only eggs on the trees. The time elapsing between this and the second treatment should be just long enough to allow all the eggs to hatch. About five weeks is supposed to be sufficient unless the weather be exceptionally cool. Careful inspection will settle this point. If the first treatment has been thorough and there are no eggs present at the second, eradication should result. A three-fourths schedule should be used in each treatment. The first fumigation should be in the autumn, not later than the first part of October. Double fumigation is seldom resorted to, as its economy in the long run is somewhat questionable.

THE RED SCALE.

The red scale is generally held as the most difficult of all citrus scales to destroy. Extensive experiments during this investigation, carried out in many sections of southern California, have proved it to be one of the easiest to destroy. It is, however, the most difficult insect to keep out of an orchard when once it has become established in a community, and this may be the basis for the opinion as to its greater resistant power to hydrocyanic-acid gas. By reason of its great prolificness, its infestation of some weeds common about citrus orchards as well as many trees and shrubs which are sometimes planted on driveways or about the buildings on the premises, and the ease with which it spreads, this insect frequently will quickly reinfest an orchard which has been treated. Live insects left on a few trees in an orchard quickly multiply and infest the others. The author has eradicated 
the red scale in orchards and yet these have become reinfested within a year. In one orchard the reinfestation was traced to some fig trees on one side which had not been fumigated; in another, the scale spread from a neighboring orchard across the way; while in a third, the scale came from nightshade (Solanum sp.) which had not been destroyed. The insect is distributed by the wind, by birds, and especially by clinging to the bodies of the hordes of insects which frequent citrus trees and carry them to other trees. Foremost among these insects are the ladybirds (Coccinellidæ), of which there are numerous species as well as vast quantities of individuals. Before fumigating for the red scale care should be taken that host weeds along irrigation flumes, ditches, and fences are. destroyed so far as possible and all neighboring trees subject to its attacks cleaned up.

Dosage.-The first orchard treated for the red scale (December, 1907) was a severely infested one of between 2 and 3 acres of trees in an unhealthy condition, and was located at Sierra Madre. The height of the trees was about 10 to 14 feet. The 1-1-3 formula was used. Exposure lasted one hour. Dosages of from one-half to 3 ounces per 100 cubic feet were used. Eradication took place with all strengths.

In September, 1908, about 1 acre of trees about 10 feet tall, located at Whittier, was treated with dosages of from of 1 to $1 \frac{1}{2}$ ounces per 100 cubic feet. Exposure lasted one hour. Eradication resulted.

During April, 1909, 4 to 5 acres of unhealthy orange and lemon trees at Villa Park, Orange County, were fumigated with dosages of from one-half to $1 \frac{1}{2}$ of schedule No. 1. The exposures lasted 45 minutes, 1 hour, and $1 \frac{1}{2}$ hours. Complete eradication occurred.

An acre of entirely healthy orange trees severely infested with the red scale-fruit as well as leaves and branches-was treated during September, 1909. The results of this experiment showed that a one-half schedule usually would destroy the scale on the leaves and branches, but that it required a three-fourths schedule to accomplish this on the fruit. As satisfactory work was done with an exposure of 45 minutes as with 1 hour.

The examination of much work carried on by practical outfits using both a three-fourths schedule and a No. 1 schedule has demonstrated that eradication would result when careful work was done.

Results from these extensive observations show that the red scale is more easily destroyed on unhealthy than on healthy trees, and that it is slightly more difficult to destroy on the fruit than on the leaves and branches. The dosage used must be based on a strength sufficient to destroy the scale on all parts of all trees; thus it is apparent that a three-fourths schedule is the most economical for the red scale. In all fumigation work against this insect it is advised that a three-fourths schedule (three-fourths of schedule No. 1) (see fig. 11) be used. An exposure of 45 minutes is sufficient. 
THE BLACK SCALE.

To specify a certain dosage for use at all times against the black scale is impractical. The reason is that this insect is more difficult to destroy in some stages of its development than in others. While young and in a soft condition it can be destroyed by a light dosage. As the insect approaches maturity its body becomes leathery and tough, which renders it difficult to destroy. The eggs require even a heavier dosage. The great variation in development among the black scale results that at most times of the year trees will contain insects in all stages of development, from those recently hatched to

\begin{tabular}{|c|c|c|c|c|c|c|c|c|c|c|c|c|c|c|c|c|c|c|c|c|c|c|c|c|c|c|c|c|c|}
\hline & & & & & & & & & & 157 & $A N$ & $C E$ & $A$ & POC & $U N$ & 10 , & 11 & $N F$ & $F E E$ & $E T$. & & & & & & & & & \\
\hline & & 16 & 18 & 20 & 22 & 24 & 26 & 28 & 30 & 32 & 34 & 36 & 38 & 40 & 42 & 44 & 46 & 48 & 50 & 52 & 54 & 56 & 58 & 60 & 626 & 64 & 66 & 68 & \\
\hline 10 & & 2 & 2 & 2 & 2 & 2 & & & & & & & & & & & & & & & & & & & & & & & 10 \\
\hline 12 & & 2 & 2 & 3 & 3 & 3 & 3 & & & & & & & & & & & & & & & & & & & & & & 12 \\
\hline 14 & & 3 & 3 & 3 & 3 & 3 & 3 & 4 & 4 & 4 & 4 & 4 & 5 & & & & & & & & & & & & & & & & 14 \\
\hline 16 & & 3 & 3 & 3 & 3 & 4 & 4 & 4 & 4 & 4 & 5 & 5 & 5 & 5 & 5 & & & & & & & & & & & & & & 16 \\
\hline 18 & & 3 & 3 & 3 & 4 & 4 & 4 & 5 & 5 & 5 & 5 & 5 & 5 & 5 & 6 & & & & & & & & & & & & & & 18 \\
\hline & & & & 20 & 22 & 24 & 26 & 28 & 30 & 32 & 34 & 36 & 38 & 40 & 42 & 44 & 46 & 48 & 50 & 52 & 54 & 56 & 58 & 60 & 626 & 646 & 66 & 68 & \\
\hline 20 & & & & 3 & 4 & 4 & 5 & 5 & 5 & 5 & 5 & 5 & 6 & 6 & 6 & 7 & 7 & 8 & 8 & & & & & & & & & & 20 \\
\hline 22 & & & & & & 5 & 5 & 5 & 5 & 5 & 5 & $\sigma$ & 6 & 7 & 7 & 8 & 8 & 8 & $\theta$ & & & & & & & & & & 22 \\
\hline 24 & & & & & & & 5 & 5 & 5 & 6 & 6 & 6 & 7 & 8 & 8 & 8 & 8 & 9 & 9 & & & & & & & & & & 24 \\
\hline 26 & & $=$ & & & & & & 5 & 6 & 6 & 7 & 7 & 8 & 8 & 8 & 8 & 9 & 10 & 10 & 10 & 11 & 11 & 11 & & & & & & 26 \\
\hline 28 & & & & & & & & & 6 & 7 & 8 & 8 & 8 & 8 & 9 & 9 & 10 & II & 11 & 11 & /1 & 12 & \begin{tabular}{|l|}
12 \\
\end{tabular} & & & & & & 28 \\
\hline & & & & & & & & & 30 & 32 & 34 & 36 & 38 & 40 & 42 & 44 & 46 & 48 & 50 & 52 & 54 & 56 & 58 & 60 & 626 & 64 & 66 & 68 & \\
\hline 30 & & & & & & & & & 7 & 8 & 8 & 8 & 9 & 9 & 10 & 10 & II & 11 & 11 & 11 & 12 & 13 & 14 & 14 & 14 & 15 & 16 & 16 & 30 \\
\hline 32 & & & & & & & & & & & & 9 & 10 & 10 & 11 & II & 12 & 12 & 12 & 13 & 13 & 14 & 14 & 14 & 15 & 16 & 16 & 17 & 32 \\
\hline 034 & & & & & & & & & & & & & 10 & II & 11 & 12 & 13 & 13 & 14 & 14 & 14 & 14 & 15 & \begin{tabular}{|l|l}
16 \\
\end{tabular} & 161 & 17 & 17 & 17 & 34 \\
\hline 36 & 6 & & & & & & & & & & & & 11 & 11 & 12 & 13 & 13 & 14 & 14 & 15 & 15 & 16 & 17 & 17 & 17 & 17 & 18 & 19 & 36 \\
\hline 438 & 8 & & & & & & & & & & & & & \begin{tabular}{|l|}
12 \\
\end{tabular} & 12 & 13 & \begin{tabular}{|l|l|}
14 \\
\end{tabular} & 14 & 15 & 16 & 16 & 17 & 17 & 17 & 18 & 18 & 19 & 20 & 38 \\
\hline$<$ & & & & & & & & & & & & & & 40 & 42 & 44 & 46 & 48 & 50 & 52 & 54 & 56 & 58 & 60 & 626 & 64 & 66 & 68 & \\
\hline 40 & & & & & & & & & & & & & & 12 & 13 & 14 & 14 & 15 & 15 & 16 & 17 & 17 & \begin{tabular}{|l|}
18 \\
\end{tabular} & \begin{tabular}{|l|}
18 \\
\end{tabular} & 19 & 20 & 20 & 20 & 40 \\
\hline 541 & & & & & & & & & & & & & & & 14 & \begin{tabular}{|l|}
14 \\
\end{tabular} & 15 & 15 & 16 & 17 & \begin{tabular}{|l|}
17 \\
\end{tabular} & 18 & 18 & \begin{tabular}{|l|}
19 \\
\end{tabular} & 202 & 20 & 20 & 21 & 41 \\
\hline 042 & & & & & & & & & & & & & & & & 15 & 15 & 16 & 17 & 17. & 18 & 19 & 19 & 20 & 202 & 20 & 21 & 21 & 42 \\
\hline 43 & & & & & & & & & & & & & & & & & \begin{tabular}{|l|l|}
16 \\
\end{tabular} & 17 & 17 & 17 & 19 & 19 & 20 & 20 & 202 & 20 & 21 & \begin{tabular}{|l|}
222 \\
\end{tabular} & 43 \\
\hline 44 & & & & & & & & & & & & & & & & & & & \begin{tabular}{|l|l}
17 \\
\end{tabular} & 17 & 19 & 20 & 20 & 20 & 202 & 21 & 22 & 22 & 44 \\
\hline & & & & & & & & & & & & & & & & & & & 50 & 52 & 54 & 56 & \begin{tabular}{|l|}
58 \\
\end{tabular} & 60 & \begin{tabular}{l|l|l}
62 & 6 \\
\end{tabular} & 64 & 66 & 68 & \\
\hline 45 & & & & & & & & & & & & & & & & & & & \begin{tabular}{|l|}
17 \\
\end{tabular} & 19 & 20 & 20 & 20 & $\begin{array}{ll}20 & 1 \\
\end{array}$ & \begin{tabular}{|l|l|}
21 & 2 \\
\end{tabular} & 22 & 23 & 23 & 45 \\
\hline 46 & & & & & & & & & & & & & & & & & & & \begin{tabular}{|l|l}
18 & \\
\end{tabular} & 20 & 20 & 20 & 20 & \begin{tabular}{|l|}
21 \\
\end{tabular} & 222 & 22 & 23 & \begin{tabular}{|l|l}
23 \\
\end{tabular} & 46 \\
\hline 47 & & & & & & & & & & & & & & & & & & & \begin{tabular}{|l|}
18 \\
\end{tabular} & 20 & 20 & 20 & 21 & \begin{tabular}{|l|}
22 \\
\end{tabular} & 222 & 23 & 232 & \begin{tabular}{|l|l}
24 \\
\end{tabular} & 47 \\
\hline 48 & & & & & & & & & & & & & & & & & & & \begin{tabular}{|l|}
19 \\
\end{tabular} & 20 & 20 & 21 & 22 & 22 & 232 & 23 & 242 & 24 & 48 \\
\hline 49 & 19 & & & & & & & & & & & & & & & & & & 19 & 20 & 21 & 21 & 22 & \begin{tabular}{|l|l|}
23 \\
\end{tabular} & \begin{tabular}{|l|}
232 \\
\end{tabular} & 23 & 242 & 25 & 49 \\
\hline
\end{tabular}

FIG. 11.-Dosage schedule No. $\frac{3}{4}$, for potassium cyanid. (Original.)

tough or even leathery ones. In such cases a dosage sufficient to destroy the more resistant individuals is necessary.

Experiments during this investigation, as well as observation of the work of practical outfits, has demonstrated that in the younger and tenderer stages this insect can be destroyed by one-half of schedule No. 1. Very few of those in the later stages of development are affected by such a dosage. A three-fourths schedule not only destroyed those in the earlier stages of development, but also those of a leathery nature and many that are tough and full grown, as evidenced by their size, together with the absence of the characteristic letter " $H$ " on the upper side. A considerable percentage of eggs is also destroyed at this strength. A full schedule No. 1 dosage 
will destroy all insects except a few of the toughest of the matured scales. It will also destroy a large percentage of the eggs.

In fumigating for the black scale the treatment should be applied at the time when the insects are largely or all, if possible, in the early stages of development. Close watch of the condition of the scale in his orchard will enable the grower to determine the proper time. There is a general breeding period during late summer or early autumn when this condition usually exists. Wait until the eggs of the old brood have all hatched, even if by this time some of the earliest issuing insects are becoming leathery. This is the time at which fumigation is advised and a three-fourths schedule (see fig. 11, p. 59) should be used.

If it be desirable to fumigate at a time when the insects are in all stages, including the mature and tough individuals as well as those of the younger generations, a full schedule No. 1 (see fig. 9, p. 34) should be used.

It would be difficult to advise a dosage sufficient to destroy the eggs, because of the wide variability in the action of such a dosage. The writer has seen the eggs of some species of scale insects destroyed by employing schedule No. 1, whereas in other instances the eggs have been unaffected even where a very much heavier dosage was used. This is partly attributable to the closer attachment to the host plant of the different individual scales and partly to a small parasitic insect (Scutellista cyanea Motsch.) which attacks the eggs of the black scale very freely. The larvæ of this parasite cements the edges of the scale to the host plant, making it more difficult for the gas to penetrate to the eggs under such scales than under those not parasitized. The exposure should last one hour.

\section{THE YELLOW SCALE.}

The yellow scale is comparable in almost all respects with the red scale except that it is much less destructive. The region in and about Redlands, San Bernardino County, is the principal section in southern California in which special effort for the control of this insect alone is required.

During September, 1909, 2 to 3 acres of orange trees at Redlands infested with the yellow scale were treated with dosage rates of from one-half to $1 \frac{1}{2}$ of schedule No. 1. The insects were destroyed on all trees except those on which a one-half schedule was used. A very few survived on these. No difference in effect was apparent between an exposure of 45 minutes and one of an hour.

A three-fourths schedule (see fig. 11, p. 59) is recommended for the yellow scale. The section in which the yellow scale is most serious is about Redlands, where a great acreage is on terraced land. In such fumigation it is believed that a full schedule No. 1 should be 
used, to make sufficient allowance for the irregularity in the surface of the ground, which renders the possibility of leakage from underneath greater than in regular orchard work.

\section{DOSAGES IN GENERAL FUMIGATION.}

If the treatment is for any one of the insects mentioned previously, the dosage recommended for that particular insect should be used. Frequently, however, two, or even three, different species may be found in the same grove. In such cases use that dosage which is heavy enough to destroy the most resistant one. For instance, if the purple and red scales, or the purple and black scales, occur in the same orchard use dosage schedule No. 1 for an exposure of one hour. If the red and black scales, or the yellow and black scales, occur simultaneously, use a three-fourths schedule for one hour, unless the black scale is in an advanced or matured stage, in which case a full No. 1 schedule is required.

\section{TIME OF THE YEAR FOR FUMIGATION.}

Although fumigation is carried on in California at all times of the year, there are certain periods in which the operations are more general. There are two main factors to be taken into consideration in fumigating, i. e., the species of scale insect and the condition of the tree. As to the latter, it may be said that at certain periods of the year the fruit is in such a tender condition that it can not withstand a heavy dosage without injury. This period is while the fruit is of small size, usually from April until about August. The bulk of fumigation in California at the present time is carried on between the latter part of August and December. Probably the principal reason for treating during this period is that the black scale is usually at that time most successfully reached. Although the life history of the black scale has never been thoroughly worked out for the region in which these investigations were made, it is generally understood that the majority of the insects of the largest and most regular brood are hatched and in their least resistant stage during the months of September and October. In some favorable seasons the eggs are almost all hatched in August.

The black scale occurs in practically every citrus-growing locality in southern California, while the purple, red, and yellow scales are more localized. Where any of these other species occur in orchards infested with the black scale it is a common practice to fumigate during the regular black-scale period, using the dosage necessary to destroy the most resistant species. The majority of these scale insects can thus be caught at one time. When fumigating for the purple scale alone, operations can be commenced as early in the season as the trees are in a condition to withstand the heavy dosage 
required without injury to the fruit, although probably it would be preferable to fumigate a little later in the fall. The purple scale can be found in the egg stage throughout the year. There is, however, a period in the fall during which the smallest proportion of eggs is to be found. With dosages lower than that of eradication the best results can be accomplished at this time, which usually is somewhere about October. The red and yellow scales are born alive and can be successfully destroyed throughout the year.

In fumigating for any of the scale insects there is one point worthy of consideration. Aside from trying to save the tree from destruction or from having its vitality impaired by the attack of scale pests, the orchardist fumigates principally in order to have his fruit come into the packing house as clean as possible. It would be well, therefore, to fumigate as nearly as possible at the time which would insure him the cleanest fruit. Although lemons are gathered throughout the entire year, the bulk of the orange crop is taken during the first six months. Thus fumigation during the fall and early winter would be sure to place the cleanest fruit in the packing house. If carried on in the late spring or early summer, such insects as remain undestroyed would have the opportunity to breed throughout a period of several months and infest much fruit.

The small size of the fruit and to some extent the heat renders fumigation generally unsafe before the month of August. From this time up to December the weather is usually quite dry and not especially cold. December is usually the month during which cold, rainy, and generally unsettled weather may be expected to commence and to continue with more or less irregularity into the following March. Serious injury to the trees may result unless the greatest care is exercised in treating during these winter months. At this period most fruit is almost fully grown, which adds a great weight to the tree. Covering heavily laden trees with fumigation tents not only tears off and scars a considerable amount of fruit, but also breaks off heary branches. The writer does not believe it advisable to treat trees in such condition.

The labor question, at all times a perplexing one in fumigation operations, is especially serious where the work is carried on in the winter. The frequent delays, possibly for sereral days at a time, necessitated by the rainy and damp weather render it difficult to secure good and careful men who will remain continuously with the outfits. As they are paid only for actual work performed, operators earn little more than their living expenses during the irregular hours when work is possible in the winter season.

After viewing all sides of the question, it is advised that the preferable months for general fumigation are from August to December. The treatment can, however, be carried on with both safety and 
efficiency between December and April, provided the work be performed by careful men who observe the various factors affecting these two considerations. These factors are given at various places throughout this bulletin.

\section{FUMIGATION FOR THE MEALY BUG.}

Considerable excitement has been aroused in some parts of southern California during the last year or so over a so-called threatened invasion of the citrus mealy bug (Pseudococcus citri Risso). This insect has been known in this region for at least 15 years. Its greatest injury has been done in the vicinity of National City, San Diego County; along the Sierra Madre foothills, near Monrovia, Los Angeles County; and very recently at Santa Paula, Ventura County. There have also been sporadic occurrences in many other sections. This sporadic activity has been of a somewhat puzzling nature. A tree severely infested with the mealy bug one day might be found to be practically free of this insect a month later, though no artificial measures of control had been applied. The mealy bug might reappear on this same tree the following year, or even sooner. The writer is inclined to attribute this disappearance largely to the activity of parasitic and predaceous insect enemies. The general appearance of the remains of the mealy bug, as well as the rearing of several beneficial insects therefrom, including two or three species of Hymenoptera, a brown lacewing (Hemerobius sp.), and a syrphus fly, lead the writer to this conclusion. Several species of Coccinellidæ also have been found present in severe infestations of this insect. Undoubtedly climatic conditions as well as fungous and bacterial diseases produce some effect.

The recent prominence of this insect in the immediate vicinity of Santa Paula, Ventura County, is well worthy of mention. Its infestation here has been so severe that the proportion of fruit in some orchards ruined by this insect during 1909 was very great. The large amount of damage caused there, together with the difficulties experienced in destroying the mealy bug, has led to agitation for its control in several other localities.

At various times during this investigation a few trees infested with mealy bugs have been treated. The usual dosage has been $1 \frac{1}{2}$ to 2 times schedule No. 1. The results have been variable. Some trees would appear to be entirely freed, while on others many live insects would remain.

During the autumn of 1909 a prominent orchardist of Santa Paula carried on some very extensive fumigation work against this insect, partly according to the writer's directions. Some trees were treated with $2,2 \frac{1}{2}$, and 3 times schedule No. 1 for from one to one and onehalf hours without eradicating the scale in any case. The results 
with these different dosages were about the same. The very roung insects were destroyed, but a large proportion of the matured ones and eggs escaped. A few trees were then corered with double tents (two tents, one over the other) in order to render them tighter and twice schedule No. 1 was used. An examination of these results a few dars after treatment showed eradication on some trees, while others contained a small percentage of live adult insects. A 10-acre block of trees was then fumigated with double tents (two tents, one over the other) and twice schedule No. 1. An examination of this work showed a considerable percentage of lire matured insects and eggs.

From the results of the aforementioned fumigation against the mealy bug it is seen that the early stages of this insect are destroyed br the use of twice dosage schedule No. 1. If a study of the life history should reveal that at some certain time they may all be found in this early stage of development fumigation might then prove of some arail. The failure, howerer, to secure eradication of the mealy-bug in its more mature stages, eren where dosages as high as three times schedule No. 1 were used, indicates that general commercial fumigation for the mealy bug is impractical. ${ }^{1}$

\section{FUMIGATION DURING THE BIOSSOMING PERIOD.}

The statements by experts on fumigation as to the amount of injury resulting from work while the trees are in blossom are rery conflicting. Some fumigators hold that a verr light dosage will destroy tender blossoms, while others believe that the blossoms will stand a heary dosage. In order to decide this point, much experimentation has been carried on and many observations made throughout this investigation. To attempt to relate the details of the scores of experiments and observations made along this line in all parts of southern California would require too much space, so mention will be made here only of general results. Fumigation observations by the writer have corered the entire period from the time the blossoms first appear until the petals drop. In not a single instance during this period has ant serious injury resulted eren though dosages as high as $1 \frac{1}{2}$ and 2 times schedule No. 1 hare sometimes been used.

Occasionally some blossoms were affected, and dropped off soon after the treatment, ret these blossoms were normally weak and would have fallen without fumigation. The fumigation merely hastened their shedding. Even if a heary shedding took place (which never happens), there would be no cause for alarm, as the setting of only a small percentage of the blossoms on a citrus tree is necessary to produce a full crop of fruit.

1 This same conclusion has heen reached by Mr. E. O. Essig, horticultural commissioner of Ventura County. (See Pomona College, Journal of Entomology, December, 1909.) 
The blossoms appear to be much more resistant to the gas than the young leaves or leaf shoots. Trees in which there are blossom shoots and tender leaf shoots side by side will have the leaf shoots burned back, while the blossoms remain unaffected. This shows that the blossoms wil! stand a much heavier dosage than the tender leaves and leaf shoots.

The young leaf shoots grow so rapidly in certain varieties of trees, or even in the same variety of tree in different localities, that during the latter part of the blossoming period they almost obliterate the blossoms. Although fumigation of these trees will not injure the blossoms it will frequently burn back these leaf branches very severely. In such cases the grower should not become alarmed by the burning, as his trees and future crop of fruit are in no way endangered. Renewed growth will soon take place, while the crop of fruit will be exactly as large as if the trees were untreated.

In conclusion, it might be said that experience in this investigation has shown that fumigation can be safely conducted during the blossoming period with the dosages at present generally employed by fumigators, namely, schedule No. 1.

\section{FUMIGATION WHILE THE FRUIT IS OF SMALL SIZE.}

The records of several experiments during 1908 in fumigating while the fruit was of small size are given in Bulletin 79 of this bureau. The results of these experiments demonstrated that heavy dosages can not be used while the fruit is small without more or less injury. Additional evidence has been secured during the latter part of this investigation which has entirely corroborated the earlier experiments. Thus it may be stated that the most critical period for conducting fumigation is between the time the fruit sets and the time it attains a diameter of about an inch. This period occurs during the late spring and summer. It is advised not to fumigate during this period, which is usually from April to August. Although in some cases an orchard may be treated during this period with a light dosage without injury, yet the risk is too great to justify such action. It is better to wait until the regular season immediately following the month of July.

\section{FUMIGATING LEMONS.}

Throughout this bulletin the recommendations are always for citrus trees, which include the orange, the grapefruit (pomelo), and the lemon. The acreage of grapefruit is very small. Oranges and lemons occur more or less promiscuously throughout the same districts where lemons are grown, while frequently an orchard will consist partly of each. The orange and grapefruit are about equally susceptible to injury from fumigation, while the lemon is much more 
resistant. As all three kinds of citrus are fumigated at the same time, regardless of kind, it is necessary to base advice on the one most susceptible to injury. If the tenderest kinds escape injury the more resistant very naturally will do so. Hence, in reality the recommendations in this bulletin are based on the orange, partly because of its greater acreage but mainly because any recommendations made for it will apply equally to the grapefruit or lemon.

The lemon blossoms throughout the year in California, so that different sized fruit may be found at all times. This is very different from the orange, which has one regular crop. Lemons usually will escape pitting or burning under conditions which might seriously injure oranges. This allows a wider range of activity in fumigating lemon trees. The work can be continued somewhat later in the spring and commence earlier in the summer than with the orange. In fumigating a section containing lemon and orange trees it is good policy, where convenient, to commence on the lemons, leaving the oranges until a later period.

\section{EFFECTS OF FUMIGATION ON UNHEALTHY TREES.}

Unhealthy citrus trees are found universally. Occasionally a part or whole of an orchard is composed of trees weakened by lack of such essential treatment as proper cultivation, fertilization, or irrigation. Many orchards contain trees weakened from attacks of a gum disease, of "gophers" (ground squirrels), scale insect pests, and numerous other causes which check their normal development. These unhealthy trees are less resistant to injury from fumigation than perfectly healthy ones. In examining results in an orchard recently fumigated the writer has noticed frequently that the fruit on a few trees that had been weakened by disease was severely pitted or burned, while that on all healthy trees was uninjured. $\mathrm{A}$ heavy dropping of fruit might have taken place in the unhealthy trees, while the others were unaffected in any way. A most striking example of severe injury to unhealthy trees was seen in an orchard fumigated with double tents (one tent over the other) using a dosage twice schedule No. 1. Healthy trees in some cases were severely burned back at the top for about a foot, accompanied by the dropping of some leaves, while the trees weakened by gum disease usually would be burned back from 2 to 3 feet and drop practically ali their leaves. Severe injury to unhealthy trees has been seen even where the three-fourths schedule was used.

Practical fumigators have always been aware of the susceptibility of weakened trees to injury and have decreased their dosage greatly in treating such trees. The grower should not complain if the fruit and leaves on their unhealthy trees are slightly injured. Such fruit is normally of the inferior grades, while the damage caused by the 
shedding of leaves is more apparent than real. These weakened leaves normally would not be held on the trees much longer. The fumigation merely hastens their removal and is usually followed by a fresh invigorated growth superior in all respects to the old.

\section{GREATER SUSCEPTIBILITY TO INJURY OF SOME VARIETIES THAN OTHERS.}

The lemon tree is much more resistant to injury from fumigation than the orange and seldom suffers any appreciable damage when treated under normal conditions. Some varieties of oranges are more easily injured than others. Of the varieties of commercial importance in California the Navel and Valencia are the least susceptible to injury from the gas treatment. The seedling is almost equally hardy. Next comes the Mediterranean Sweet while the Homosassa and St. Michael can seldom be treated with schedule No. 1 without some injury resulting. Fortunately the Navel and Valencia comprise the bulk of the oranges grown in this State.

\section{THE DISTRIBUTION OF GAS WITHIN A TENT.}

Hydrôcyanic-acid gas, being lighter than air, has a tendency to rise toward the top of the tent. The column of gas rises straight up from the generating vessel until broken up by coming in contact with the leaves and branches of the tree. The greater density of gas toward the top of a tent is indicated by the greater amount of injured fruit there than elsewhere. Only infrequently is fruit at the bottom of the tree pitted. Dr. Morrill has given records of the difference in destruction to the citrus white fly at different heights in a tree. ${ }^{1}$ Similar results have been observed against the scale insects in California. The insects at the top of a tree may all be destroyed while some on branches close to the ground will escape. Hence, in the case of the purple scale, when the infestation is generally toward the bottom of the tree the necessity of a strong gas is evident.

\section{FUMIGATION FOR PHYSIOLOGICAL EFFECTS.}

There are people in California who believe that citrus trees should be treated with hydrocyanic-acid gas whether they are infested with scale or not; that the treatment invigorates the tree, producing a heavier crop and superior fruit than would otherwise result.

A tree infested with scale, on being relieved of its burden responds to the treatment. This response is not due to the physiological action of the gas on the tree itself but rather to the destruction of the large number of insects which have been constantly sapping the plant juices. The removal of this heavy drain allows the tree to resume its normal activity, which it does by first producing invigorated growth. 
During this investigation many acres of perfectly healthy trees free of insect pests have been treated throughout the period of sereral months preceding blossoming up until the blossoms fall. No effect producing an increase or perfection of the coming crop of fruit has ever resulted from these efforts. Although the acreage treated has not been sufficiently great to justify the absolute statement that fumigation, in itself, never produces a greater crop of fruit, nevertheless the negative results in all the orchards treated certainly prove that if an increased crop erer results it is of infrequent occurrence and under peculiar conditions.

\section{EFFECTS OF METEOROLOGICAL ELEMENTS ON FUMIGATION.}

\section{MOISTURE.}

The great affinity of water for hydrocyanic-acid gas is well known. Writers on greenhouse fumigation contend that the plants should be dry when treated, else injury might result. It has been the universal opinion among California fumigators that if the fumigation treatment was carried on while the trees were wet injury might follow. Gossard, ${ }^{1}$ and more recently Morrill, ${ }^{2}$ assert that moisture does not produce injury to the fruit and that the destruction of insects is as great under wet as under dry conditions. Quaintance ${ }^{3}$ has corroborated these results of Gossard and Morrill where the work is done on moist fruit (apples) in cold storage.

The fumigation work which has been performed by the Government outfit during this investigation has been carried on in all sections of southern California, at all times of the year, and under all conditions of weather-when the trees were entirely dry, when the trees were wet, so wet that the moisture was falling off in drops, and when it was raining. Mr. G. R. Pilate, a temporary assistant, was stationed with a practical outfit during October, November, and December, 1909, at Rivera and Downey, than which the writer believes there is no generally damper citrus section in California. Careful records were kept of all the climatic elements which might affect fumigation. These records show that almost every night the trees became thoroughly moistened before the work was discontinued. In addition to this, the results of the treatment of hundreds of acres by other practical outfits have been followed during the writer's residence in southern California.

From all this experience not a single authentic instance has been seen in which burning was directly attributable to absorption of gas by the moisture on the fruit or leares. Thus the writer has felt justified in concluding that the presence of moisture on trees can be ignored

\footnotetext{
1 Bul. 67, Fla. Agr. Exp. Sta., pp. 647-64S, 1903.

2 Bul. 76, Bur. Ent., U. S. Dept. Agr., pp. 12-14, 1908.

s Bul. 84, Bur. Ent., U. S. Dept. Agr., pp. 24, 31, 1909.
} 
in so far as the effect of its direct action on the hydrocyanic-acid gas treatment is concerned.

There are other reasons of indirect and largely mechanical nature on account of which it is necessary to consider the presence of moisture, for ignorance of these will frequently result in much burned fruit. (1) When tents become moist they become heavier. This renders them more difficult to handle. Much fruit is torn off, while branches and limbs are frequently broken. (2) The damp tents collect much dirt and as they are pulled over the trees they sometimes scrape the fruit with which they come in contact. Such abrased fruit is frequently burned by the action of the gas. (3) As the trees become damp from the dew or fog, whichever it may be, so also do the tents get damp. The moisture affects the fiber of the cloth so that it hecomes tighter and retains the gas better than when dry. Any person of any considerable experience in fumigation knows that more gas is left under the tents when they are pulled off on a damp night than on a dry one; therefore, the gas remaining in the tops of tall peaked trees is much more concentrated than is normally the case. This intense strength of gas sometimes causes pitting, especially in the case of some varieties least resistant to hydrocyanic-acid gas. Hence, considering the disadvantages resulting from wet tents, it is evident that fumigation should not be carried on at such a time. Fumigation should be stopped after the leaves and tents become thoroughly damp.

The author's experience has been that the presence of moisture on trees does not reduce the efficacy of hydrocyanic-acid gas against. scale insects. Results have been exactly as good when the trees were wet as when dry, and observation of the work accomplished by commercial outfits has corroborated it.

Experiments by Penny ${ }^{1}$ on plants in a closed box showed that moisture on the leaves absorbed the gas. This would make it appear that moisture on the foliage of orange trees absorbs some gas, and undoubtedly such is the case. Remembering that on dry nights all the gas within tents of the character ordinarily used has escaped within an hour's exposure but on damp nights frequently much gas remains when the tents are removed, it is at once apparent that the retardation of gas by the damp cloth easily offsets any absorption which may have taken place.

TEMPERATURE.

Heat.-Heat probably is the factor which is responsible for more injury to fruit than any other cause. Throughout the experience of commercial fumigation instances of very severe injury have occurred almost every year in some one of the different citrus fruit producing 
regions. The cause of this injury has for the most part been an enigma, but it has been known to occur during that character of weather locally spoken of as "electric" or "Santa Ana," which is in reality a dry condition of the atmosphere caused by the hot dry winds of the desert sweeping through passes in the mountains onto the lower lands adjacent to the ocean. The nights in southern Califormia are usually cool, but during these disiurbances from the desert they frequently become very warm.

Records of fumigation when the temperature was about $65^{\circ} \mathrm{F}$. were secured during the autumn of 1909. A part of an orange orchard was treated on three consecutive nights during the so-called "electric" weather, when temperature ranged from $66^{\circ} \mathrm{F}$. to $77^{\circ} \mathrm{F}$. Considerable burning resulted. Work was then stopped for a week until the nights became cooler. when the rest of the orchard was treated. No burning at all occurred. The injury to the fruit during the hot nights consisted of real burns covering much of the fruit-not small pits which are the usual indications of fumigation injury. This burning was exactly of the same character as was produced in a large orchard at Redlands fumigated during the late summer of 1908 on similar warm nights. Records have been secured of burning in other orchards treated under similar weather conditions.

From the data at hand it appears that injury from fumigation will take place at high temperatures. Based on the author's experiments, it is advised that fumigation be stopped at a temperature above $65^{\circ} \mathrm{F}$. Although in some instances work may be carried on at a slightly higher temperature with impunity, the risk of injury appears to be too great.

Cold.-During December, 1908, a part of an orange grove at Rivera was fumigated by a private outfit which kept temperature records during its work. At the time the work commenced the temperature was above $40^{\circ} \mathrm{F}$. No injury was done until the fourth or fifth set, when the temperature had fallen to $37^{\circ} \mathrm{F}$. This set was slightly burned. The next set was badly burned, much fruit dropping. Unfortunately, the temperature for this set was not taken. The following set, which was the last, was made while the temperature was at $32^{\circ} \mathrm{F}$. The tops of many of these trees were severely burned back, while all the fruit on some of them dropped.

On December 3, 1909, exact records of burning from fumigation were obtained. Three sets were made on this particular night-the first while the temperature reached about $36^{\circ} \mathrm{F}$. to $37^{\circ} \mathrm{F}$; d during the second it dropped from $36^{\circ} \mathrm{F}$. to $32^{\circ} \mathrm{F}$; while during the third set the temperature reached $31^{\circ} \mathrm{F}$. The first set was slightly injured; the second was severely burned and much fruit dropped; while practically all fruit on the third set dropped, and some trees were so severely burned as to lose most of their leares. 
With these records as a basis, the writer advises that fumigation be stopped at $38^{\circ} \mathrm{F}$. or below. It is known that there are instances in which fumigation can be carried on with impunity at a temperature lower than $38^{\circ} \mathrm{F}$; in fact, there are records of fumigation carried on as low as $33^{\circ} \mathrm{F}$. without any considerable injury. The fact remains, however, that there are authentic cases of severe injury at temperatures below $38^{\circ}$, and any person carrying on work at these lower temperatures runs the risk of inflicting injury; and with products of the commercial value of citrus fruits one can not well afford to assume such risks.

\section{LIGHT.}

Coquillett, in the course of his early investigations in the use of hydrocyanic-acid gas, determined that daylight fumigation was more injurious than fumigation at night. This he attributed principally to the fact that the actinic rays of light decomposed the gas into other gases of a more injurious nature. Commercial fumigation work since then has been carried on exclusively at night. Occasionally a person of questioning mind has attempted some experiments hoping to dispet the old idea of daylight injury, but current information has it that these attempts have never been successful.

Some records of daylight work have been taken during this investigation. In one instance about 50 large orange and lemon trees were treated, partly while cloudy and partly in the sunshine. These trees had the whole upper half burned back-branches as well as leaves and fruit. It was the severest injury to citrus trees the writer has ever seen.

One very cloudy afternoon about 25 trees (orange and lemon) were fumigated for red scale with a three-fourths schedule. The temperature ranged between $70^{\circ} \mathrm{F}$. and $80^{\circ} \mathrm{F}$. The lemon trees were only slightly affected, but the orange trees were very severely damaged, a large part of their tops being burned back.

The first row of trees fumigated at night and the last in the morning are frequently more or less injured. The cause of this injury in the former case is that the work is sometimes commenced before the sun has set and while it is still warm. In the latter case the sun has come up before the tents were removed from the last row of trees. The injury under such conditions is most apparent from fumigation carried on in the late summer and early autumn when the weather is warm. On the cool days late in autumn the treatment can be and is carried on with impunity at a degree of light at which injury would result on the warm days earlier in the season. Judging from the experiments and many observations which the author has made respecting the effect of fumigation during the daytime, the contention that daylight work is generally unsafe is entirely correct. Although $67330^{\circ}-$ Bull. $90-12-6$ 
the rays of light appear to have a direct effect in producing injury, these investigations hare shown that this injury is intensified by the presence of heat, and the writer contends that burning during the daytime is directly attributable to heat as well as to the light itself.

Fumigation should never be attempted in the daytime, eren on cloudy days. Carry on the work at night and do not commence the operations until the sun has disappeared and the shades of darkness are approaching. Remore the last row of tents in the morning before the sun rises.

WINDS.

Fumigation should never be attempted during a heary wind, for two reasons: First, the gas escapes out of the tent so that poor work results; second, injury to the trees might result. Dr. Morrill has called attention ${ }^{1}$ to the variability of results on trees fumigated during a stiff breeze, stating that on different parts of the same tree he found the killing to vary from 30 to 100 per cent. ${ }^{1}$ Observations made during this inrestigation corer instances in which the gas was driven from tents by winds in a very few minutes. The trees, of course, required a second treatment. The burning of trees fumigated during winds has frequently been observed. In light winds the injury appears to be more prevalent on that side of the tree from which the wind comes. Heary winds appear to produce the burning fully as much on the opposite side, or may affect the entire tree. A sudden change in temperature accompanying a wind appears to be especially serere in its results. Undoubtedly some of the cases of severe burning during "electric" weather are due partly to the wind as well as to the heat.

The author's experience has led to the conclusion that fumigation should nerer be carried on during a windstorm. As soon as a breeze arises sufficiently strong to "flap" the tents, it is well to discontinue work until calmer weather.

\section{INJURY TO SPRAYED TREES.}

Distillate oils are still used by a few orchardists in combating scale pests. As these men become discouraged with the oil treatment they adopt fumigation. In this connection it appears desirable to state a recent experience in the fumigation of trees previously sprayed with an oil combination spray.

$A$ lemon orchard of 40 acres was sprayed early in the autumn with a combination of Bordeaux mixture and distillate oil. Two months later about 25 acres of this orchard were fumigated partly with a No. 1 and partly with a three-fourths schedule. This fumigation con-

${ }^{1}$ Bul. 76, Bur. Ent., U. S. Dept. Agr., p. 12, 190 S. 
tinued over a period of fully two weeks, much of which was ideal fumigation weather. The resultant injury was very severe, being marked chiefly by a dropping of leaves. In many trees the leaves and fruit were also burned. The old leaves on the tree at the time of spraying especially were affected, the number of these shed being sometimes so great as to form a thick, blanket underneath the tree, entirely covering the ground. In these very same trees the young tender growth at the top of the tree, which had appeared since the spraying and which normally is the first to be injured by the gas treatment, escaped uninjured.

The trees were healthy and well cared for, which, coupled with the fact that only the sprayed portion of the trees was affected and not the younger and tenderer growth, proves that the cause of the injury was the spraying. It is well known that distillate oil weakens a tree, and possibly the unnatural addition of Bordeaux mixture makes this weakening even more severe. As further proof of this situation, trees in a neighboring orchard similarly sprayed at about the same time were fumigated. Injury resulted. Unsprayed trees under the same conditions and treated with the same dosages at the same time were uninjured.

These results show that it is unsafe to fumigate trees which have been recently treated with a Bordeaux-distillate emulsion. Although it does not also prove that trees recently sprayed with distillate alone would be injured, it would seem good policy not to attempt such fumigation until proof of its harmlessness has been secured.

\section{THE APPEARANCE OF FUMIGATED TREES.}

Orange trees containing young growth usually will have the tender tips of this growth burned back with the ordinary fumigation dosage. The wilting of this affected portion is visible the following day, especially if sunshiny. During cloudy weather the effects are not marked until fully a day afterwards. The tender growth in lemons is burned back even more severely than in the orange. Where the new growth in the tops of the tree is very long it may be affected for 6 inches or even a foot.

Some weakened old leaves might be shed a few days following the treatment. Healthy leaves are seldom shed and seldom burn, unless some abnormal condition is present. Even in such conditions it is the fruit that is first injured.

The burning back of the tender growth does not injure the tree in any way. With such vigorous plants as citrus trees all indications of injury have disappeared within a few weeks following the treatment. Fumigators and many growers look upon the burning of young growth as an indication that the proper dosage has been given the tree for good results. Of course such assumptions are correct only in part. 


\section{THE PRESENCE OF OLD SCALES ON FUMIGATED TREES.}

Scales do not fall from the different parts of a tree as soon as destroyed. On young and growing fruit they are easily shed, but they may cling to the old fruit, leaves, and branches of trees until removed by mechanical means. Dead purple scales probably cling to the different parts of a tree much more generally than any of the other common citrus pests. Leaves, branches, or old fruit sererely infested will normally remain so as long as they continue to be a part of the tree. This condition leads many growers to condemn a treatment as unsuccessful because on examining a tree long after the operation scales are found present. The mere presence of scales may incorrectly indicate to them that they have not been destroyed.

The prevalence with which successive generations of scale insects exist simultaneously on citrus trees renders it impracticable and really impossible to draw conclusions in exact percentages as to net results of experimental work whenever the results fall short of eradication. At the time of the treatment the scale on some leares might all be alive, while on other leaves the majority may be dead, and with all gradation between to be found elsewhere.

\section{A DEVICE FOR COVERING FUMIGATION GENERATORS.}

During the course of this investigation much attention has been giren to perfecting a device for attachment to the top of the commonly used open-style fumigation generator that will serve to interrupt the direct rise of the hydrocyanic-acid gas. The result of these efforts, in which the writer was greatly aided by Mr. Frederick Maskew, is shown in figure 12. The device itself consists of a copper cover of such size as to make it available for use with any of the regular-pattern generators now employed by the fumigators of southern California. It is stamped in a concave form from a sheet of copper, with corrugations to permit the escape of gas. The shape is such as to conform to the size of the opening of generators of different capacities and also to direct the course of the escaping gas downward and distribute it uniformly through the lower part of the tent. It is attached to the generator by hinges of stout copper wire secured by a key bolt passing through the handle. The corer is raised by a slight pressure of the thumb on a projecting piece which is curred in such a manner that the cover will remain in an upright position when so required. When the generator is emptied of its contents, the corer swings clear by its own weight. A glance at the illustration will satisfy the practical fumigator that it is adapted to all the requirements of rapid work in the dark, while its use has demonstrated that it is simple, strong, and durable. It is very possible that if the copper cover were lined with a thin covering of lead its durability would be increased. A common 
result of the use of heavy dosages of fine fragments of cyanid is the burning and ultimate dropping of many of the leaves directly above the generator in the pathway of the rapidly rising gas. This result is usually spoken of as the "chimney" effect. The generator cover eliminates this "chimney" burning.

A second and highly important point is the effect of open generators on the tent. The outer part, or skirt, as it is sometimes called, of fumigating tents is constantly being perforated with small holes, even when used by the most careful of workers. This effect has been noticed to some extent in the outfit of this investigation, which is believed to have been as carefully handled as any fumigation outfit could be. These holes are known to be acid burns. A few simple tests have demonstrated conclusively that many of these acid holes are due to acid carried along with the escaping gas and reaching that part of the tent nearest the generator. By placing large pieces of canvas in the path of gas escaping from open generators in which dosages similar to those often used in field work are employed it was found that drops of acid reached the canvas as high as 5 feet from theground. The writer has frequently seen generating vessels placed not more than 2 feet inside the tent. At such a distance one can

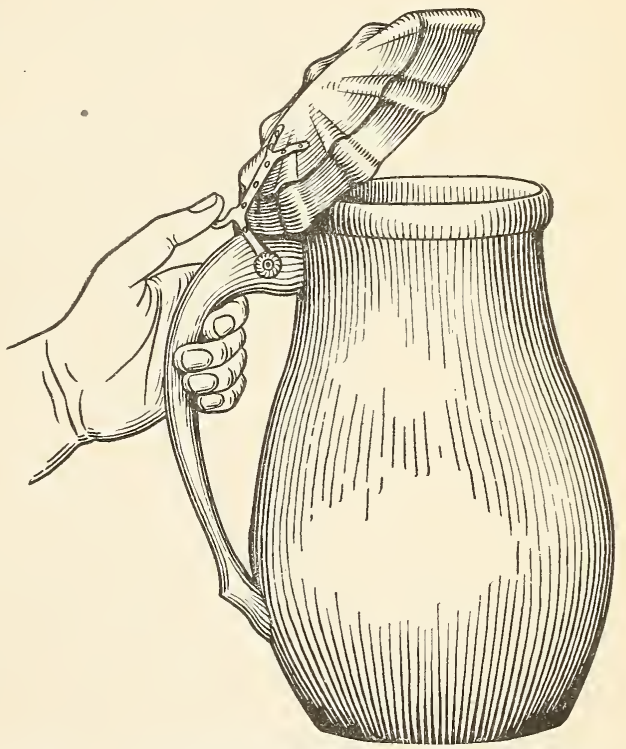

Fig. 12.-A co ver device attached to a fumigation generator. Corrugations in cover allow gas to escape. (Author's illustration.) readily see that drops of acid might reach the tent. The cover described above so deflects the gas, and incidentally such acid as is carried with it, that the drops are thrown to the ground, thus saving the tents. The decreased cost in mending of tents will doubtless pay for the cost of such a cover device several times over in a season of fumigation.

A third advantage, which has not as yet been demonstrated, but which there is reason to believe will develop, is a better distribution of gas through the tent. Heretofore the most difficult part of the tree in which to destroy insects has been the lower part. This is also the part of the tree in which the purple scale is largely to be found. With the open generator the gas rises straight up in a narrow column for several feet, being broken up and distributed through the top of the tree first. As the gas is lighter than air, it is not to be expected 
that it will quickly become uniformly distributed throughout the bottom of the tent even if at any time it becomes as concentrated here as at the top. The greater burning effect and better killing effect in the top of the tree would tend to substantiate this assumption. Field obserrations in fumigating large trees show that the gas is of no great strength at the lower part of the tent for several minutes after the charge is set off. With this new corer the gas is broken up and distributed through the bottom of the tent first. By the time it reaches the top it is pretty generally distributed throughout the tent. As the bottom of the tree is among the first to receive the full benefit of the gas, a more complete killing of scale at the bottom of the tent may be expected than with an open generator.

\section{THE EFFECT OF CLIMATIC CONDITIONS ON SCALE INSECTS.}

Climatic conditions exercise a marked effect on the different insects affecting citrus trees. The purple scale and black scale thrive best in the more moist country adjacent to the ocean. The red scale thrires well in the drier interior regions of southern California as well as near the coast, while the yellow scale is more of a heat-withstanding form than any of the others. This is demonstrated by its preralence in citrus trees in the hot interior valleys of northern California where the purple scale and to a large extent the black scale appear unable to survive.

The direct effect of heat on scale insects may be eridenced by data on the black scale collected during the summer of 1907. Commencing at Pasadena, which is at the opening or gateway of the San Gabriel Talley, the writer proceeded to Duarte, Pomona. Ontario, Rirerside, Orange, and Santa Ana, Cal., respectirely. The San Gabriel is one of the interior valless and Pasadena is situated near that end which opens toward the ocean. As one approaches Riverside from Pasadena the climate becomes generally hotter. Orange and Santa Ana are nearer the ocean and much cooler than any of the other places examined.

It might be mentioned that about a month previous to this special investigation there had been a very hot spell of a few days' duration. At Pasadena examination showed that about one-fourth of the eggs under the old scales were dried up and brown, this condition showing the effects of heat. At Duarte the destruction was somewhat greater. At Pomona and Ontario, which were much hotter eren than the two preceding places, more than three-fourths of the eggs and young insects were dead. At Riverside, where the heat was most intense, a very small percentage of healthy eggs or live insects was found. In the cooler sections of Orange and Santa Ana rery much less than a fourth of the eggs and young were destroyed, while insects in all stages of derelopment were in evidence. 
The orchards in Riverside and San Bernardino Counties are seldom as severely infested as elsewhere. These observations explain why scale-insects are less destructive in these two counties than in regions nearer the coast. The hot weather appears to be almost as efficient as some insecticide treatments.

\section{THE EFFECT OF FUMIGATION ON LADYBIRDS (COCCINELLIDE) AND SCUTELIISTA CYANEA MOTSCH.}

Several writers on fumigation have mentioned that ladybirds are less easily killed by hydrocyanic-acid gas than the scale-insects of the citrus. In order to prove this contention, specimens of the two common ladybirds (Coccinella californica Mann. and Hippodamia convergens Guér.) were suspended under a fumigation tent in an open cage 6 to 7 feet above the ground, while others were placed right on the ground. Schedule No. 1 was used. The tent was left on the tree one hour. The temperature was $60^{\circ} \mathrm{F}$. The insects were examined about ten minutes after the tents had been removed, but exhibited no signs of life whatever; all appeared to be dead. The following morning a second examination showed that many had revived from their previous stupefied condition. A count made of those suspended from 6 to 7 feet above the ground showed that out of a total of 64,32 , or just 50 per cent, were killed. Of 85 on the ground 33, or about 39 per cent, were destroyed. Both species appeared equally resistant to the gas.

It thus appears that the insects on the ground survive a gas treatment somewhat more readily than those toward the top of a tree. When it is considered that the strength of gas was as great as is ever used in commercial work against the common scale insects of citrus trees, in fact somewhat stronger than is used by most fumigators, and also that in regular operations many of the ladybirds after becoming stupefied fall off onto the ground, where they are less affected by the gas, it would seem safe to presume that the larger number of these insects on a tree at the time of fumigation will survive the treatment.

Scutellista cyanea Motsch. is a small hymenopterous parasite of the black scale which was introduced into California from South Africa several years ago. The larvæ feed on the eggs of the black scale, usually one in each scale, although there may be 2,3 , or even 4 present. Frequently as high as from 50 to 75 per cent, or even more, of the black scale on a tree have been seen attacked by this parasite. The work of this insect is remarkably good, yet not sufficiently perfect to allow the fruit to come into the packing house in a clean condition. 'This necessitates fumigation as though the parasites were not present.

This is not meant to depreciate the usefulness of this parasite, even though it fails to keep citrus trees entirely free of the black scale. By destroying, as it does, a large percentage of eggs it confers a 
decided benefit. The prevalence of the black scale on many other hosts offers a wide range of activity for the parasite, and it is on these noncitrus plants that our little friend does some of its very best work. If it did nothing else, its work against the black scale on the pepper tree (Schinus molle) makes it especially worthy of praise, and the question has frequently come up whether or not fumigation destroys the Scutellista. Numerous observations and experiments respecting this point have been made during this investigation indicating that fumigation destroys many of the Scutellista in its adult and pupal stages. The majority of the parasites, however, are unaffected, even when schedule No. 1 is used. Parasitized scales have been removed the day following such treatment and placed in vials, with the result that some adults would immediately issue and others continue to issue for many days afterwards. The adults of Scutellista in the open are destroyed by a weak dosage. The reason they escape beneath the scales is that such parasitized scales are tightly sealed to the leaf or branch, apparently by some secretion produced by the larvæ. and the gas does not penetrate such scales as easily as it does those nonparasitized.

One of the greatest benefits of the Scutellista is its work in trees which have been fumigated. The eggs of the black scale to a large extent survive the gas treatment. This leaves abundant opportunity for a future infestation on trees treated when eggs are present. If Scutellista occurs in the orchard, these undestroyed eggs are devoured, thus completing a treatment for which fumigation itself is only partially successful.

\section{THE COST OF FUMIGATION.}

The cost of fumigating an orchard depends principally on the size of the trees and the dosage-rate used. The arerage California citrus orchard requires an average expenditure of from $\$ 25$ to $\$ 40$ per acre for one fumigation treatment. Large seedling trees are much more expensive, while young trees cost considerably less.

The directors of fumigating outfits base their estimates on two distinct considerations: The chemicals and covering the trees. Contract fumigators usually furnish the cyanid at 30 cents per pound, which also includes the sulphuric acid necessary for generation of the gas. The price of covering trees varies with their size, number, location, topography of land, etc. The fumigator will charge more per tree where the orchard consists of a half acre than if it has 50 acres. Trees that require a 45 -foot tent usually will cost more to cover than those requiring a 36 -foot tent. The average price of covering in commercial work where nothing larger than 45 -foot tents is used is from 10 to 12 cents per tree. Large seedling trees whose covering requires derricks may cost from 40 to 50 cents, or eren more, 
per tree. After completing the treatment of an orchard, knowledge of the number of trees covered and the amount of cyanid used furnishes immediate means of calculating the cost.

The estimates of association, county, and private work will vary somewhat from the above figures, for in these cases the work is supposed to be performed at actual cost. The following figures enter here and are the average of field conditions. Cyanid is purchased at practically 25 cents per pound in large quantities (tons) and $25 \frac{1}{2}$ cents in smaller lots. Sulphuric acid costs about $1 \frac{1}{2}$ cents per pound. Five men are required to run an outfit. The foreman receives about 50 cents per hour, while the other 4 men receive about 35 cents each per hour. This makes a total cost of about $\$ 1.90$ per hour for labor. By adding to the cost of labor the cost of cyanid and acid, as well as allowing a certain amount for transporting the chemicals to the field, and including the cost of, as well as wear and tear on the tents and other equipment necessary in fumigation work, we have a basis for estimating the real cost of the operation.

Most trees fumigated require between 5 and 18 ounces of cyanid. An average dosage would be about 10 ounces. A supply cart (pp. $22-23$ ) can be equipped complete for about $\$ 35$.

Generating pots cost as follows: One and one-half gallon, 35 cents; 2-gallon, 45 cents; 3-gallon, 65 cents.

Below are given the prices of different sized octagonal sheet tents ready for use, as furnished by one of the largest dealers in fumigating tents in southern California. These prices are based on the assumption that an entire outfit of 30 tents is to be purchased. If only a single tent is purchased, the cost will be slightly greater than these figures. Fluctuations in the cotton market will cause a variation in the price of tents.

\begin{tabular}{|c|c|c|c|}
\hline Size. & $\begin{array}{l}230(7- \\
\text { ounce) } \\
\text { special } \\
\text { drill. }{ }^{1}\end{array}$ & $\begin{array}{l}200(8- \\
\text { ounce) } \\
\text { special } \\
\text { drill. }{ }^{1}\end{array}$ & $\begin{array}{l}\text { 8-ounce } \\
\text { special } \\
\text { Army } \\
\text { duck. }\end{array}$ \\
\hline 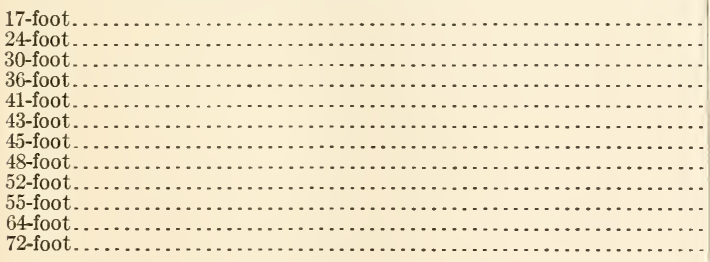 & $\begin{array}{r}\$ 6.46 \\
12.92 \\
19.95 \\
28.50 \\
36.10 \\
43.70 \\
45.60 \\
50.35 \\
62.70 \\
69.35 \\
91.20 \\
114.76\end{array}$ & $\begin{array}{r}\$ 6.97 \\
13.94 \\
21.53 \\
30.75 \\
38.75 \\
47.15 \\
49.20 \\
54.32 \\
67.65 \\
74.82 \\
98.40 \\
123.82\end{array}$ & $\begin{array}{r}\$ 6.12 \\
12.24 \\
18.90 \\
27.00 \\
34.20 \\
41.40 \\
43.20 \\
47.70 \\
59.40 \\
65.70 \\
86.40 \\
108.72\end{array}$ \\
\hline
\end{tabular}

1 The 7 and 8 ounce special drills are those recommended by this investigation (p. 12): The inferior grades of drill ordinarily employed are about 20 per cent cheaper than the 7 -ounce special.

The cost of thirty 45-foot tents of special 7-ounce drill together with the other equipment necessary to complete the outfit will approximate $\$ 1,400$. 


\section{GENERAL CAUTIONS.}

Hydrocyanic-acid gas is one of the most deadly of gases, so that considerable care is necessary in its use. Such exaggerated cautions have been written, in view of its poisonous properties, that the public at large have come to believe that a single whiff of this gas will produce the immediate death of an individual. This erroneous idea should be corrected. A whiff of the gas will not cause immediate death; neither will two or three whiffs. If subjected to a strong gas for a minute or two, undoubtedly a person would be overcome. The writer has never yet had a record of a person killed by hydrocyanicacid gas while fumigating. In California, men work around tents every night for weeks at a time without any ill effects. During these operations they are breathing the gas in a diluted form much of the time. Repeatedly field men are seen sitting, either to rest or eat their lunch, on the edge of a tent covering a tree which had been dosed a few minutes previously. The writer has personally stood within a foot of a generator for an hour at a time, taking temperatures of the escaping gas as different dosages were tried out, some of which would be in excess of a pound. Frequently the wind would waft the fumes into his face. Outside of an occasional dizziness and headache, no serious results were experienced. Scores of similar cases could be cited.

These experiences have been mentioned, not with the idea of tempting people to be careless in the use of this gas, but merely to correct the erroneous conception that a whiff of the gas will cause instant death. This gas is most dangerous, and the writer has seen men who were subjected to a great strength of it for several minutes at a time overcome by its effects, although they revived later. If the proper precautions are taken the careful operator will run no risk whatever. Place the charge in the generating vessel with extended arm so that the head of the operator is away from the escaping gas. Being lighter than air, the gas rises straight up in a narrow column until several feet above the ground. As soon as the dosage has been set off, quickly leave the tent or room, whichever it may be. If this procedure is followed there is no danger of ill effects to the operator. 


\section{LIST OF THE WRITER'S PUBLISHED ARTICLES AND ADDRESSES ON THE FUIMIGATION INVESTIGATION IN CALIFORNIA.}

The following list includes the addresses and reports made, and the papers issued by the writer during this investigation:

1908. Investigations of the use of hydrocyanic-acid gas in fumigating citrus trees. Lecture delivered at the Thirty-fourth Convention of the California State Fruit Growers, Riverside, Cal., April 30, 1908. < Printed in the proceedings of this convention, pp. 103-111.

Fumigation investigations. Talk given before meeting of the Whittier Farmers' Club, Whittier, Cal., August 12, 1908.

Fumigation investigations in California. Lecture delivered before the Horticultural Commission of Los Angeles County, fruit growers, and fumigators, courthouse, Los Angeles, Cal., August 15, 1908. <California Cultivator, August 20, 1908.

Device for covering fumigation generators. In cooperation with Frederick Maskew. <California Cultivator, October 1, 1908.

An improved system of fumigation. Talk given at the annual picnic of the Pomona Farmers' Club, Pomona, Cal., October 5, 1908.

Fumigation. Talk given at Farmers' Institute, Ontario, Cal., October 28, 1908.

The use of water in fumigation. < Los Angeles Times Sunday Magazine, -p. 602, November 8, 1908.

The latest in fumigation. Paper presented at the Thirty-fifth Convention of the California State Fruit Growers, Sacramento, Cal., December 2, 1908. $<$ Printed in Third Biennial Report of the Commissioner of Horticulture of the State of California for 1907-8, pp. 99-112.

1909. Fumigation invertigations in California. <Bul. 79, Bur. Ent., U. S. Dept. Agr.

Marking of tents for practical fumigation. <California Cultivator, August 12, 1909.

Fumigation dosage for the pests of citrus trees. <California Cultivator, September 16, 1909.

1910. Fumigation in California. Lecture delivered before horticultural officers, fruit growers, and fumigators, courthouse, Los Angeles, Cal., February 12, 1910. <California Cultivator, February 24 and March 3. Also issued in pamphlet form by the San Antonio Fruit Exchange, Pomona, Cal.

Value of sodium cyanide for fumigation purposes. <Journ. Econ. Ent., vol. 3 , no. 1 , pp. $85-88$.

Morrill system-a reply. <California Cultivator, April 7, 1910. 



\title{
HYDROCYANIC-ACID GAS FUVIGATION IN CALIFORNIA.
}

\section{THE VALUE OF SODIUM CYANID FOR FUMIGATION PURPOSES.}

\author{
By R. S. Woglum, M. S. A., \\ Special Field Agent, Bureau of Entomology.
}

INTRODUCTION.

The present treatise comprises the results secured with sodium cyanid during the investigation of the use of hydrocyanic-acid gas for the fumigation of citrus trees in California and is supplementary to the extended report on the use of potassium cyanid. The results with the sodium salt are issued as a separate part of the report in order to avoid confusion between its use and that of the universally used potassium cyanid.

Numerous cyanids which will furnish hydrocyanic-acid gas are known to chemists, but only two, those of potassium and sodium, possess all the requirements essential for commercial work. Potassium cyanid was the chemical first used in California in the generation of hydrocyanic-acid gas, and has continued to be employed for this purpose until to-day it is popularly considered, both in this country and abroad, as the only source from which gas can be economically made. The grade of potassium cyanid furnished during recent years for citrus fumigation in southern California has generally been of such a high degree of purity that no special effort has ever been made to find a substitute.

With the exception of fumigation, sodium cyanid is used more extensively for general commercial purposes than potassium cyanid. C. P. Lounsbury, government entomologist of Cape Colony, was the first to call particular attention in literature to sodium cyanid for fumigation when, in 1905, he wrote:

It is possible that within a few years cyanid of soda will be used, instead of cyanid of potash, as the source of the gas. The soda compound gives off more gas from a given weight and costs no more; hence by its use some saving may be made in both original cost and transportation charges. But the reaction with acid appears to be more violent than with potash salt, which is a disadvantage owing to a greater risk of the covers getting burnt, and its adoption would necessitate an entire revision of our fumigation 
tables. The quantities of acid and water for a tree of any given size would remain the same, but the weight of cyanid for use with any given measure of acid would have to be reduced one-fourth. ${ }^{1}$

This last statement of Prof. Lounsbury assumes that the reaction would require the same proportion of chemicals as with potassium cyanid, an assumption which the earlier chemical work of this investigation shows to be without any foundation.

The potassium cyanid used in California for fumigation is manufactured in Germany, and is popularly styled "German" cyanid. This is in distinction to a grade of cyanid made in this country, termed "American" cyanid, which has had an occasional and limited usage in California for a number of years. This so-called "American" cyanid has been popularly beliered to be the very same kind as the imported potassium cyanid. Such a conception has been misleading, for chemical analyses have shown it to be not potassium cyanid but a cyanid of sodium equivalent to a potassium cyanid of 98 to 100 per cent purity.

This 98 to 100 per cent sodium cyanid was found by fumigators to be inferior to the regular potassium salt ordinarily employed. It was of very hard composition and generated so slowly that large proportions of acid were commonly used in an attempt to hasten the reaction. Some fumigators used large quantities of water, believing this was necessary in order to secure the best results. Tests performed by the writer showed that frequently it would require 10 to 15 minutes before all the available gas was expelled from a generation of this cyanid. Furthermore, the writer was informed by the president of a firm which supplies most of the cyanid used in California, that extensive chemical experiments carried on in its laboratory indicated that this sodium cyanid produced a less satisfactory generation than did potassium cyanid, and from these considerations he believed its use would never be economical. The work of the firm also indicated that large proportions of water were necessary for a satisfactory and rapid reaction.

Under the belief that sodium cyanid had not received sufficiently exhaustive tests, the writer ignored all local unfarorable eridence, and, in December, 1908, outlined in detail a broad series of chemical experiments to secure reliable data, with reference to this salt, on the various factors which might enter into hydrocyanic-acid generation. This outline was submitted to the Bureau of Chemistry of this department for execution. Mr. C. C. McDonnell, under the direction of Dr. J. K. Haywood, Chief of the Miscellaneous Division, made a very careful and elaborate series of determinations, and in August, 1909, the results of these tests were submitted to the writer in a carefully prepared manuscript, which forms Part III of this bulletin. These results are used in part in the preparation of the present paper.

1 Office of Gorernment, Entomologist, Department of Agriculture, Cape of Good Hope. "Cyanid Gas Remedy for scale Insects." July, 1905. 


\section{STRENGTH OF SODIUM CYANID EXPRESSED IN TERMS OF POTASSIUM CYANID.}

The strength of sodium cyanid is commonly reckoned in terms of potassium cyanid. Chemically pure potassium cyanid is 100 per cent pure, while chemically pure sodium cyanid is commonly spoken of as 133 per cent pure. The explanation for this is that pure sodium cyanid contains, for the same weight, practically one-third more cyanogen (available hydrocyanic-acid gas) than potassium cyanid and this greater strength is expressed in terms of the potassium salt for convenience sake. Thus we have 133 per cent sodium cyanid, meaning that, when absolutely pure, it contains 33 per cent more cyanogen (available hydrocyanic-acid gas) than a pure potassium cyanid. It is evident, therefore, that if 1 pound of pure sodium cyanid can be purchased as cheaply as 1 pound of pure potassium cyanid, there will result a great economy by the use of the former provided the generation of the gas be equally perfect for each. The price is, however, usually based on the percentage of cyanogen present and the saving in cost may be thus offset to a large extent.

\section{PROPORTION OF CHEMICALS.}

A large number of experiments was carried on with a high-grade sodium cyanid, with the idea of determining the best proportion of chemicals for use. As a result of these tests Mr. McDonnell recommended a 3-4-6 formula: 3 ounces (avoirdupois) of cyanid, 4 fluid ounces of sulphuric acid, and 6 ounces of water. Reduced to its lowest units for rapid work in the field, the writer has used $1 \frac{1}{2}$ fluid ounces of acid and 2 ounces of water to each ounce (avoirdupois) of cyanid of sodium. This $1-1 \frac{1}{2}-2$ formula is recommended.

The 1-1 $\frac{1}{2}-2$ formula with a high-grade sodium cyanid produces exactly as satisfactory a generation in the laboratory as can be obtained from a high-grade potassium cyanid, using the proportion of chemicals adapted for the best generation of gas with the latter. This is exhibited by a comparison of the generation from two highgrade commercial products, as shown in the following table:

\begin{tabular}{|c|c|c|c|c|c|}
\hline \multirow{2}{*}{ Kind of cyanid. } & \multicolumn{3}{|c|}{ Proportion of - } & \multirow{2}{*}{$\begin{array}{l}\text { Purity of } \\
\text { cyanid. }\end{array}$} & \multirow{2}{*}{$\begin{array}{l}\text { Per cent } \\
\text { of total } \\
\text { gas } \\
\text { evolved. }\end{array}$} \\
\hline & Cyanid. & Acid. & Water. & & \\
\hline 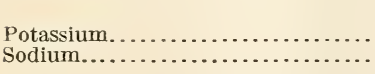 & $\begin{array}{l}1 \\
1\end{array}$ & $\begin{array}{l}1 \\
1 \frac{1}{2}\end{array}$ & $\begin{array}{l}2 \\
2\end{array}$ & $\begin{array}{r}\text { Per cent. } \\
98 \\
124\end{array}$ & $\begin{array}{l}93.88 \\
94.32\end{array}$ \\
\hline
\end{tabular}

Although these laboratory determinations exhibited that the yield of gas, or reaction, with a high-grade sodium cyanid is as satisfactory as with a potassium cyanid, the writer did not feel justified in recommending its use until these results could be confirmed by actual field experience. 


\section{FIELD TESTS.}

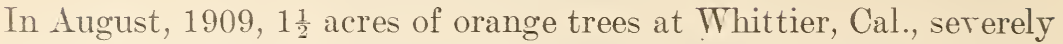
infested with the purple scale (Lepidosaphes beckii Newm.), which was largely in the ego stage-the most difficult one in which to destroy it-were fumigated with a 124 per cent sodium cyanid, using the 1-1 $\frac{1}{2}-2$ formula. The length of exposure was one hour. Three strengths of gas were used, calculated from the cyanogen present in the cyanid as equiralent to $1,1 \frac{1}{1}$, and $1 \frac{1}{2}$, of the strength of regular schedule No. 1 of potassium cyanid, as giren in this Bulletin. The writer says strengths equiralent to these different schedules of potassium, because it is known from prerious discussion that an ounce of high-grade sodium cyanid will produce considerably more gas than an ounce of high-grade potassium cyanid owing to its higher cyanogen content. In the $12 t$ per cent sodium cyanid the advantage in faror of that product is practically one-fourth. It follows that if a highgrade sodium cyanid is used with dosages of the same size as threefourths of schedule No. 1 of potassium cyanid practically the same strength of gas will be given off as with potassium cyanid at the dosages of full schedule No. 1 of potassium cyanid.

In examining the results where the equiralent of schedule No. 1 of potassium cyanid was used, only 4 live insects, 2 with healthy eggs, were found, these being distributed between 3 different trees. No live insects or eggs were found on the trees treated with dosages equivalent to $1 \frac{1}{1}$ and $1 \frac{1}{2}$ of schedule No. 1 of potassium cyanid.

Experiments against the purple scale where potassium cyanid was used have shown that it required a $1 \frac{1}{4}$ schedule of that chemical to produce practically the same results as have been secured in this experiment with sodium cyanid at a strength equivalent to No. 1 schedule of the potassium cyanid. With this high-grade sodium compound the equiralent of a $1 \frac{1}{4}$ schedule of potassium cyanid eradicates the purple scale, whereas with potassium a $1 \frac{1}{2}$ schedule has been required to accomplish this result. Hence this field experiment would indicate that under the crude conditions of orchard work sodium cyanid produces not only as good a generation as the potassium but a decidedly superior one.

In a second experiment an acre of orange trees rery sererely infested with purple scale was fumigated, partly with a high-grade sodium cyanid and partly with the regular potassium cyanid. The tents used were of a new character of material of very tight texture. The sodium cyanid produced exactly as satisfactory results in this experiment as the potassium cyanid.

During Norember, 1909, a t-acre block of orange and lemon trees severely infested with the purple scale was fumigated with sodium cyanid by an outfit of the Whittier Citrus Association, using the 
1-1 $\frac{1}{2}-2$ formula. The dosage strength was equivalent to that of schedule No: 1 of potassium cyanid. The operation was carried out under the guidance of the foreman of the crew exactly as work is done by any commercial outfit. Several months later an examination was made of a large number of trees located promiscuously throughout the orchard. Live purple scales were seen on only one of the trees examined, and on this much of the fruit was infested at the time of fumigation. This is the most successful work the writer has ever seen done by a practical outfit with gas of a strength equivalent to schedule No. 1 of potassium cyanid.

Several hundred pounds of this high-grade sodium cyanid were used by another practical outfit in fumigating orange and lemon trees. These fumigators were as satisfied with this cyanid as with the regular potassium cyanid.

From the results of field work in this investigation it has been found that the use of a high-grade, or almost chemically pure, sodium cyanid produced exactly as perfect a generation of gas in all cases as the use of a similar grade of potassium cyanid; in the majority of cases where used the generation was apparently superior to that from a potassium cyanid. -

\section{ACTION OF SODIUM CHLORID.}

The above recommendations are for a high-grade sodium cyanidone almost 133 per cent pure. Experience in California with a 98 to 100 per cent sodium cyanid has proved unsatisfactory. The reason is given herewith. Chemical analyses have shown that practically all commercial potassium and sodium cyanids contain more or less common salt, which is technically spoken of as sodium chlorid.

Newell, ${ }^{1}$ in 1905, pointed out that sodium chlorid, when present in the reaction producing hydrocyanic-acid gas, causes a secondary reaction which liberates an acid called hydrochloric acid, and that this liberated hydrochloric acid immediately attacks the hydrocyanicacid gas, decomposing it to a great extent. In order to ascertain more thoroughly the status of this salt Mr. McDonnell carried on a large amount of experimental work. These results not only showed conclusively that the presence of sodium chlorid results in a decomposition of the hydrocyanic-acid gas, but also that if a sufficiently large percentage of sodium chlorid is present the decomposition will be so great as to result in little if any hydrocyanic-acid gas. The conclusion to be drawn from these experiments is that the cyanids suitable for fumigation work should be practically free of sodium chlorid.

The serial numbers $6523-6529$ in the table on page 92 , Part III of this bulletin, are samples of cyanids which have been used to some 
extent in fumigation work in California. An examination of the data in this table shows that only Nos. 6523, 6525, 6527, and 6528 are suitable for use in fumigation. Each of these is a high-grade article and each contains less than 1 per cent of sodium chlorid. The other three samples contain greatly in excess of 1 per cent. It should be noticed that these last three samples were sold as 98 to 100 per cent sodium cyanids.

Whenever sodium cyanids have been used in the past, the same dosages have been scheduled as for the regular potassium cyanid. Inasmuch as decomposition was then unknown, and no allowance was made for it, the strength of gas given off was much less than was believed to be the case. The result has been poor work. This explains the past unsatisfactory work with the "American," or 98 to 100 per cent, sodium cyanid.

\section{THE KIND OF CYANID TO PURCHASE.}

The results of these experiments direct attention to a second consideration in the purchasing of a cyanid. That a cyanid be of a certain grade of purity is no longer the only consideration. It is of equal importance that it be practically free of sodium chlorid. The writer would condemn as unfit for use in fumigation any cyanid containing in excess of 1 per cent of sodium chlorid.

Returning to a high-grade sodium cyanid, it has been found on analysis of several samples that these contain only a fraction of 1 per cent of sodium chlorid. It generally can be held as a safe consideration that a cyanid approaching chemical purity will contain not more than a trace of sodium chlorid, and that such a cyanid can be safely used, even though the degree of cyanid purity is alone known. The writer would consider as generally satisfactory for fumigation work a sodium cyanid 124 per cent pure or above. A chemical of lower purity should never be used. Preferably the grade demanded should be a little higher than that given, or 126 to 130 per cent pure. Absolute chemical purity in a commercial cyanid can not be expected, but cyanids of the degree of purity recommended herein not only are within reasonable limits of expectation but should be demanded. When chemicals of this degree of purity are used, analysis for sodium chlorid is unnecessary. It is the lower grade of sodium cyanid-the grade " 100 per cent pure" or less, which contains the large amounts of sodium chlorid.

\section{DOSAGES WITH SODIUM CYANID. ${ }^{1}$}

All recent dosage recommendations in fumigation have been based on a high-grade potassium cyanid. Such a situation renders it necessary to revise our present schedules should we desire to use sodium

1 Whenever sodium cyanid is mentioned in this bulletin, a high-grade article, one 124 to 130 per cent pure, is meant unless otherwise specified. 
Bul. 90, Part 11, Bureau of Er

Plate IX.

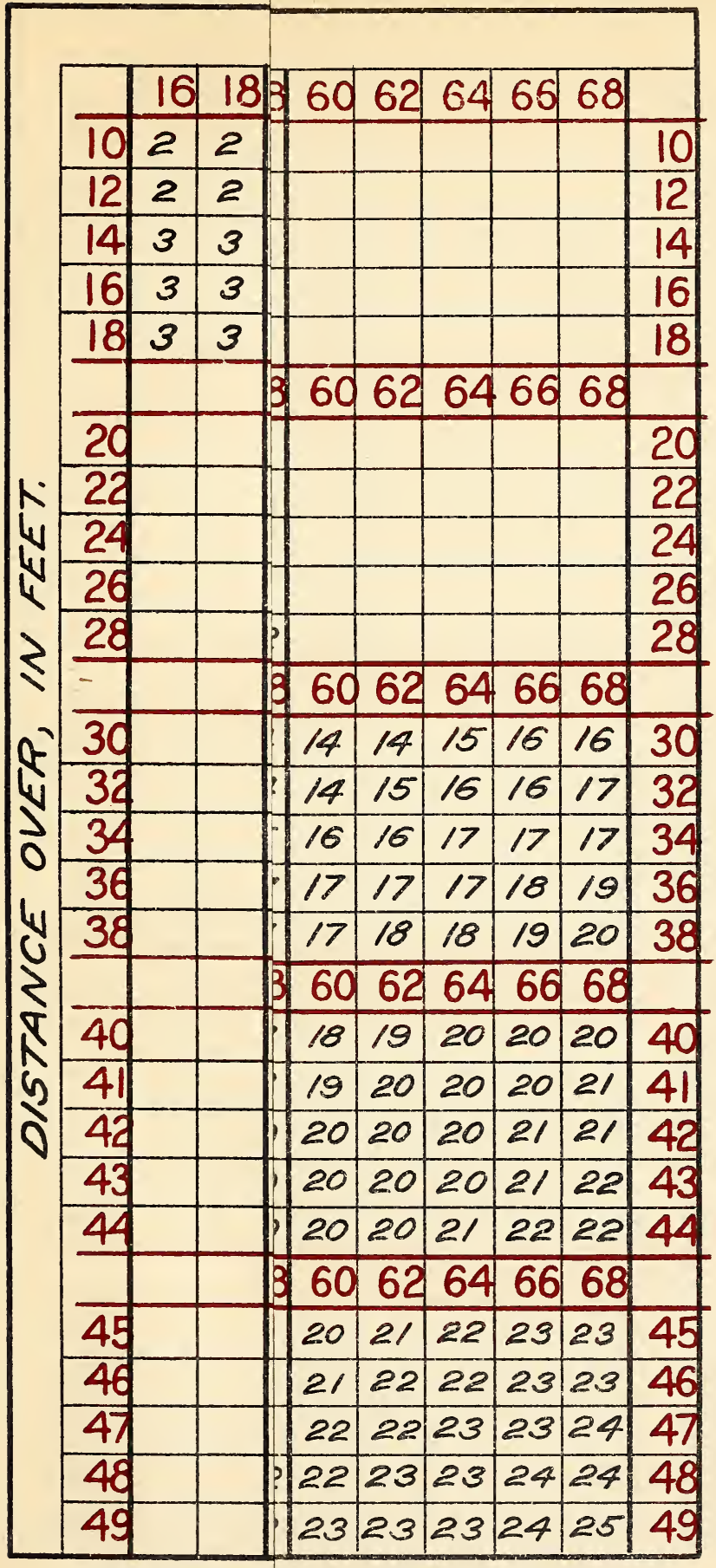

DOSAGE. SS). (ORIGINAL). 

\begin{tabular}{|l|l|l|llllllllll|llllllll|l|l|l|l|l|l|l|}
\hline 16 & 18 & 20 & 22 & 24 & 26 & 28 & 30 & 32 & 34 & 36 & 38 & 40 & 42 & 44 & 46 & 48 & 50 & 52 & 54 & 56 & 58 & 60 & 62 & 64 & 65 & 68
\end{tabular}

\begin{tabular}{l|l|l|l|l|l}
\hline 10 & 2 & 2 & 2 & 2 & 2
\end{tabular}

\begin{tabular}{l|l|l|l|l|l|l|}
12 & 2 & 2 & 3 & 3 & 3 & 3 \\
\hline
\end{tabular}

\begin{tabular}{l|l|l|l|l|l|l|l|l|l|l|l|l|}
14 & 3 & 3 & 3 & 3 & 3 & 3 & 4 & 4 & 4 & 4 & 4 & 5 \\
\hline
\end{tabular}

\begin{tabular}{ll|l|l|l|l|l|l|l|l|l|l|l|l|l|}
16 & 3 & 3 & 3 & 3 & 4 & 4 & 4 & 4 & 4 & 5 & 5 & 5 & 5 & 5 \\
\hline
\end{tabular}

\begin{tabular}{l|l|l|l|l|l|l|l|l|l|l|l|l|l|l|}
18 & 3 & 3 & 3 & 4 & 4 & 4 & 5 & 5 & 5 & 5 & 5 & 5 & 5 & 6 \\
\hline
\end{tabular}

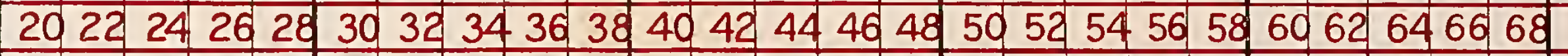

20

ㅅ. 22

\begin{tabular}{l|l|l|l|l|l|l|l|l|l|l|l|l|l|l|l|}
3 & 4 & 4 & 5 & 5 & 5 & 5 & 5 & 5 & 6 & 6 & 6 & 7 & 7 & 8 & 8
\end{tabular}

24

\begin{tabular}{l|l|l|l|l|l|l|l|l|l|l|l|l|l}
5 & 5 & 5 & 5 & 5 & 5 & 6 & 6 & 7 & 7 & 8 & 8 & 8 & 8
\end{tabular}

426

\begin{tabular}{l|l|l|l|l|l|l|l|l|l|l|l|l|}
5 & 5 & 5 & 6 & 6 & 6 & 7 & 8 & 8 & 8 & 8 & 9 & 9
\end{tabular}

\begin{tabular}{|c|c|c|c|c|c|c|c|c|c|c|c|c|c|c|c|}
5 & 6 & 6 & 7 & 7 & 8 & 8 & 8 & 8 & 9 & 10 & 10 & 10 & 11 & 11 & 11 \\
& 6 & 7 & 8 & 8 & 8 & 8 & 9 & 9 & 10 & 11 & 11 & 11 & 11 & 12 & 12 \\
\hline
\end{tabular}

2

28

$\begin{array}{lllllllllllllllllllllllllll}30 & 32 & 34 & 36 & 36 & 40 & 42 & 44 & 46 & 48 & 50 & 52 & 54 & 56 & 58 & 60 & 62 & 64 & 66 & 68\end{array}$

Q 30

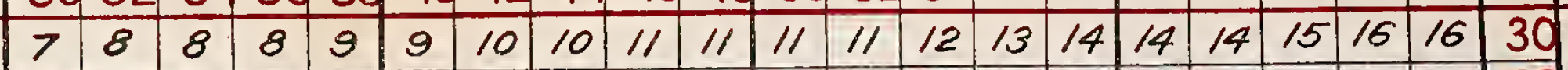

(v) 32

34

36

38

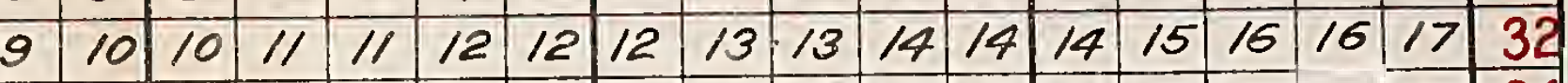
\begin{tabular}{l|l|l|l|l|l|l|l|l|l|l|l|l|l|l|l|l|l|}
10 & 11 & 11 & 13 & 13 & 14 & 14 & 14 & 17 & 15 & 16 & 16 & 17 & 17 & 17 & 34 \\
\hline
\end{tabular}

0

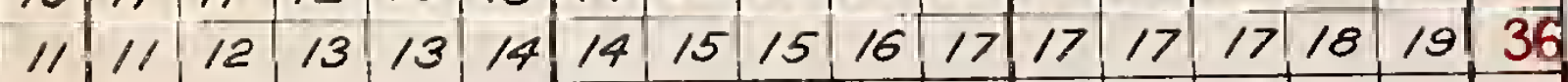

$\sum^{2}$

$\pi 40$

至

0

4

43

45

46

47

49

\begin{tabular}{l|l|l|l|l|l|l|l|l|l|l|l|l|l|l|l|}
12 & 12 & 13 & 14 & 14 & 15 & 16 & 16 & 17 & 17 & 17 & 18 & 18 & 19 & 20 & 38 \\
\hline
\end{tabular}

$40 \quad 42 \quad 4446 \quad 48 \quad 5052 \quad 54 \quad 5658 \quad 60626466 \quad 68$

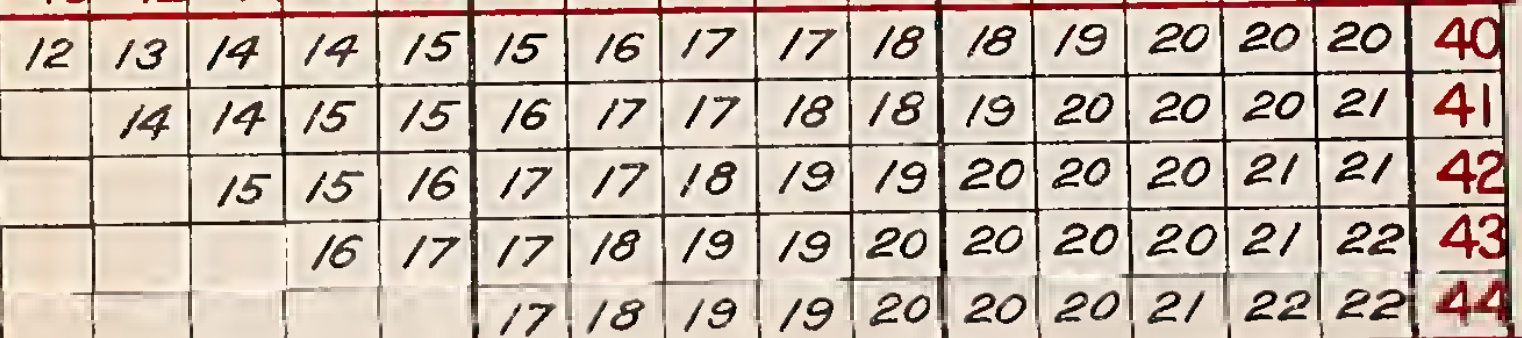

\begin{tabular}{|l|l|l|l|l|l|l|l|l|l|l|}
17 & 18 & 19 & 19 & 20 & 20 & 20 & 21 & 22 & 22 & 44 \\
\hline 50 & 52 & 54 & 56 & 58 & 60 & 62 & 64 & 66 & 68
\end{tabular}

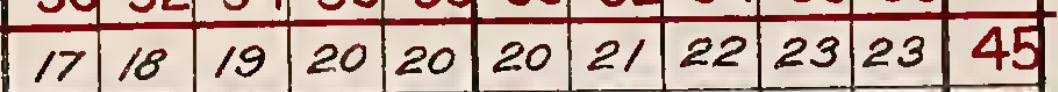
\begin{tabular}{l|l|l|l|lllllll}
18 & 19 & 20 & 20 & 20 & 21 & 22 & 22 & 23 & 23 & 46 \\
\hline
\end{tabular}

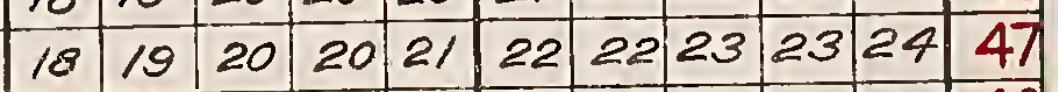
\begin{tabular}{lllllllllll|l}
19 & 20 & 20 & 21 & 22 & 22 & 23 & 23 & 24 & 24 & 48
\end{tabular}

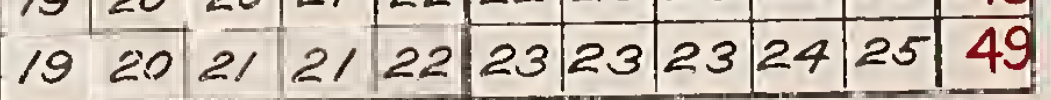

DOSAGE. SCHEDULE A, FOR HIGH GRADE SODIUM CVANID. (IN OUNCES). (ORIGINAL). 

\begin{tabular}{|l|l|l|l|l|l|l|l|l|l|l|l|l|l|l|l|l|l|l|l|l|l|l|l|l|l|l|}
16 & 18 & 20 & 22 & 24 & 26 & 28 & 30 & 32 & 34 & 36 & 38 & 40 & 42 & 44 & 46 & 48 & 50 & 52 & 54 & 56 & 58 & 60 & 62 & 64 & 66 & 68 \\
\hline
\end{tabular}

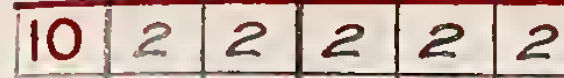

\begin{tabular}{llllllll}
12 & 2 & 2 & 3 & 3 & 3 & 3 \\
\hline & 14 & 3 & 3 & 3 & 3 & 3 & 3
\end{tabular}

$\begin{array}{lllllllllllllllll}14 & 3 & 3 & 3 & 3 & 3 & 3 & 3 & 3 & 3 & 3 & 3 & 4\end{array}$

\begin{tabular}{llllllllll|l|l|l|l|l|l}
16 & 3 & 3 & 3 & 3 & 3 & 3 & 3 & 3 & 3 & 4 & 4 & 4 & 4 & 4
\end{tabular}

\begin{tabular}{l|l|l|l|l|l|l|l|l|l|l|l|l|l|l|}
18 & 3 & 3 & 3 & 3 & 3 & 3 & 4 & 4 & 4 & 4 & 4 & 4 & 4 & 5 \\
\hline
\end{tabular}

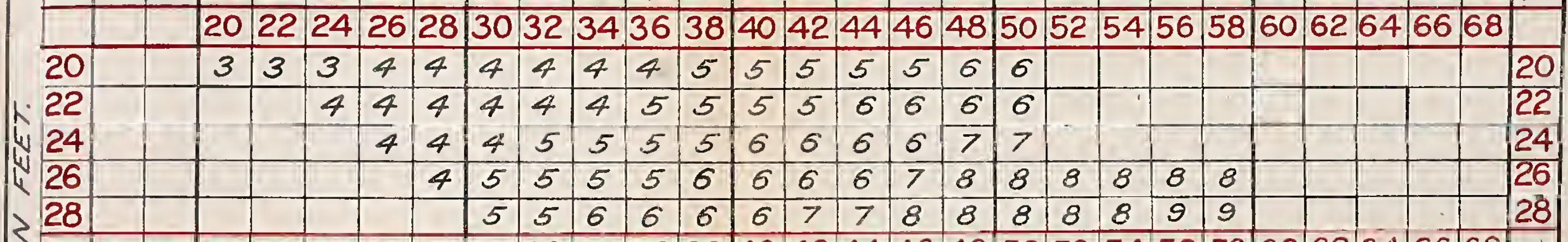
$\leqslant$

$30 \quad 32,34 \quad 36 \quad 3840 \quad 4244 \quad 46 \quad 48 \quad 50525456 \quad 5860626466 \quad 68$

(6) 30

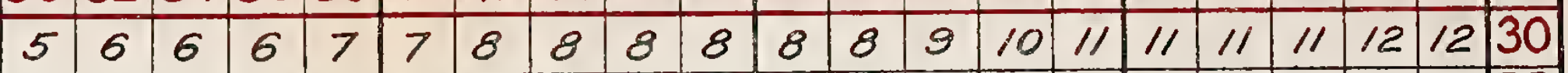

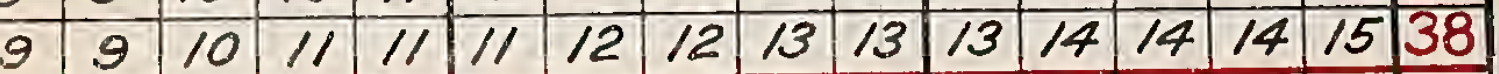

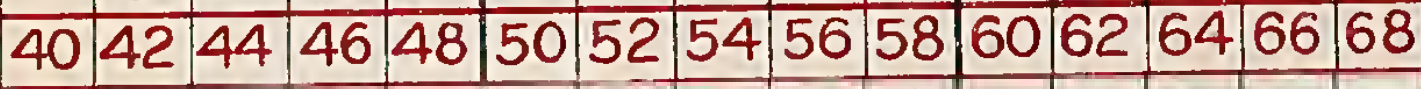

\section{4}

\section{5}

46

47

48

49

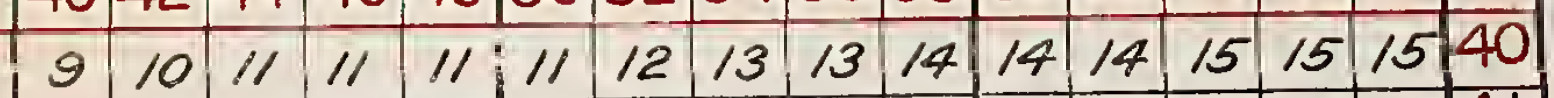

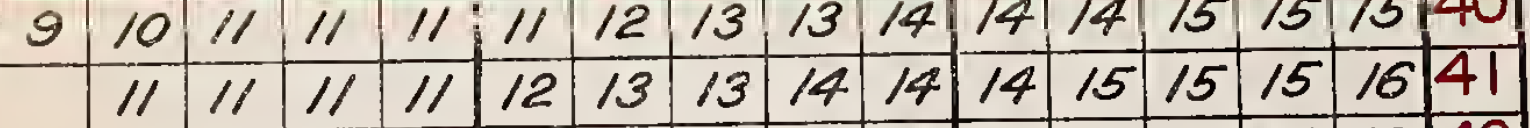

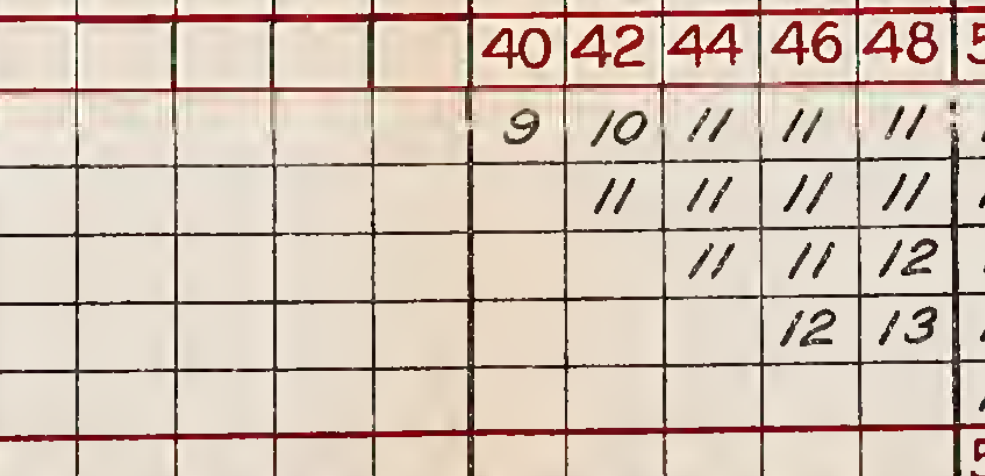
\begin{tabular}{llllllllllllll}
14 & 14 & 19 & 15 & 15 & 15 & 16 & 17 & 17 & 44 \\
\hline
\end{tabular} \begin{tabular}{llllllllllll|l|l|}
50 & 52 & 54 & 56 & 58 & 60 & 62 & 64 & 66 & 68 \\
\hline
\end{tabular} \begin{tabular}{l|l|l|l|l|l|l|l|l|l|l|}
13 & 14 & 14 & 15 & 15 & 15 & 16 & 17 & 17 & 17 & 45 \\
\hline
\end{tabular} \begin{tabular}{l|l|l|l|l|l|l|l|l|l|l|}
14 & 14 & 15 & 15 & 15 & 16 & 17 & 17 & 17 & 17 & 46 \\
\hline
\end{tabular} \begin{tabular}{l|lll|l|l|l|l|l|l|l|l|}
14 & 14 & 15 & 15 & 16 & 17 & 17 & 17 & 17 & 18 & 47 \\
\hline
\end{tabular} \begin{tabular}{|l|l|l|l|l|l|l|l|l|l|l|}
\hline 14 & 15 & 15 & 16 & 17 & 17 & 17 & 17 & 18 & 18 & 48 \\
\hline 14 & 15 & 16 & 16 & 17 & 17 & 17 & 17 & 18 & 19 & 49 \\
\hline
\end{tabular} DOSAGE SCHEDULE. $\frac{3}{4}-A$ 

cyanid. This revision is accomplished by using a high-grade sodium cyanid with dosages one-fourth less than the amounts scheduled for the potassium salt. Thus if a dosage recommended should read that it requires 12 ounces of potassium cyanid to secure certain results against a particular insect the same results could be accomplished with 9 ounces of a high-grade sodium product. In general fumigation against the purple scale (Lepidosaphes beckii Newm.). the writer has recommended a full schedule No. 1 of potassium cyanid. ${ }^{1}$ Should one desire to produce the same results against this insect with sodium cyanid, he would use a schedule one-fourth less, or dosage equal to three-fourths of the dosage amounts given in schedule No. 1 of potassium. Such a three-fourths schedule with high-grade sodium cyanid will produce practically the same amount of gas as the full schedule No. 1 of potassium.

Plate IX gives such a schedule, which is called schedule A for sodium cyanid. ${ }^{1}$ By using this schedule with a 124 to 130 per cent cyanid of sodium practically the same results will be secured as with full schedule No. 1, as given in Part I of this bulletin, with potassium cyanid.

These dosages are in ounces and are based on a knowledge of two measurements of the tree-the distance around the bottom and the longest distance over the top. Having secured these two distances for any tree, the dosage for that tree may be found in that part of the table where the lines for these measurements intersect.

\section{DOSAGES RECOMMENDED FOR SCALE PESTS.}

Purple scale.-In general fumigation for the purple scale (Lepidosaphes beckii Newm.) use full schedule A of sodium cyanid (Plate IX). With its use all insects and more than 99 per cent of the eggs are destroyed on the leaves and branches. Exposure should last 1 hour.

Red scale.-For the red scale (Chrysomphalus aurantii Mask.). use a three-fourths schedule (three-fourths of schedule A of sodium cyanid [Plate $\mathrm{X}]$ ). An exposure of 45 minutes is sufficient.

Yellow scale.-For general work against the yellow scale (Chrysomphatus citrinus Coq.) three-fourths of schedule A of sodium cyanid (Plate X) will prove satisfactory. The section in which the yellow scale is most serious is about Redlands, San Bernardino County, where a great acreage is planted on terraced land. Owing to the irregular topography of terraced orchards the tents seldom lie as closely to the ground as on level land, and as a consequence thise usually is a greater amount of leakage. For terrace fumigation full schedule A (Plate IX) should be used. Exposure should be 45 minutes.

\footnotetext{
1 For detailed use of such schedule, as well as methods of measuring trees, see pp. 34-37, Part I, of this Bulletin.
} 
Black scale.-When the black scale (Saissetia olex Bern.) is partly grown, or before the insects become tough and leathery, three-fourths of schedule A (Plate $\mathrm{X}$ ) will be most economical for use. However, when many of the insects are full grown or nearly so, full schedule A (Plate IX) is recommended. The proper time to fumigate for the black scale is while the insects are in the earlier stages of development, i. e., before they become tough and leathery. Exposure should be 1 hour if any eggs are present. Where only young scales are present, 45 minutes is sufficient.

\section{COMPARISON OF SODIUM CYANID AND POTASSIUM CYANID FOR GENERAL FUMIGATION.}

A perusal of the discussion thus far ventured in this bulletin has shown that the results with the use of a high-grade sodium cyanid were equally as satisfactory as with a high-grade potassium cyanid. A pound of the sodium cyanid contains at least one-fourth more available gas than a pound of the potassium cyanid. Hence if we pay one-fourth more per pound for the high-grade sodium cyanid than for the high-grade potassium cyanid, the ultimate cost of fumigating an orchard will be practically the same in either case; or the cost of potassium cyanid at 24 cents per pound is equivalent to sodium cyanid at 30 cents. If sodium cyanid (124 to 130 per cent) does not cost one-fourth more per pound than potassium cyanid (9s to 99 per cent), there is an economy in the use of the former. At the present prices in California potassium cyanid costs 25 to $25 \frac{1}{2}$ cents per pound, whereas the sodium cyanid costs practically 28 cents per pound. This means an economy of 2 to 3 cents per pound in faror of the sodium cyanid.

The writer recommends a 124 to 130 per cent sodium cyanid as strongly as a 98 to 99 per cent potassium cyanid for fumigation purposes. The sole question to decide between the use of these two cyanids in any particular case is the cost. When it is considered that the present manufacture of sodium cyanid is more universal and greatly in excess of the potassium cyanid; that the sodium compounds required in the manufacture of sodium cyanid are widely distributed through the world, while commercial deposits of the potassium compounds required in the manufacture of potassium cyanid are largely confined to the German Empire; and that the present unit price of sodium cyanid averages slightly less than that of the other, it may be reasonably expected that at no very distant time the sodium cyanid may be found supplanting the potassium cyanid for fumigating purposes. 


\title{
HYDROCYANIC-ACID GAS FUMIGATION IN CALIFORNIA.
}

\section{CHEMISTRY OF FUMIGATION WITH HYDROCYANIC-ACID GAS. ${ }^{1}$}

\author{
By C. C. McDonnelL,
}

Chief, Insecticide and Fungicide Laboratory, Miscellaneous Division, Bureau of Chemistry.

\section{INTRODUCTION.}

The Miscellaneous Division of the Bureau of Chemistry was requested by Mr. C. L. Marlatt, Assistant Chief of the Bureau of Entomology, to analyze certain chemicals which were being uscrl by Mr. R. S. Woglum, in charge of the field work with hydrocyanicacid gas in southern California, and at the same time to investigate certain chemical problems in connection with this work which $\mathrm{Mr}$. Woglum had outlined.

In view of the great importance of the subject from an economic standpoint and the small amount of work that has been done in the study of the chemical problems involved, the question has been thoroughly investigated. The action of mineral acids on cyanids and hydrocyanic acid has been quite thoroughly studied by a number of chemists, but the important bearing of this point on the question of fumigation has not been brought to the attention of those engaged in this work with the force which it demands.

\section{ANALYSES OF CHEMICALS USED FOR THE PRODUCTION OF HYDROCYANIC-ACID GAS.}

SULPHURIC ACID.

Ordinary commercial sulphuric acid is usually sold of the strength known as $66^{\circ}$ Baumé, which corresponds to a pure product containing 96 per cent of sulphuric acid $\left(\mathrm{H}_{2} \mathrm{SO}_{4}\right)$. The specific gravity of commercial acid, owing to the presence of impurities, is always higher than that of the pure acid, and commercial acid of this grade will not average over 93 or 94 per cent of sulphuric acid. A sample

1 A detailed outline of experiments covering certain problems in the chemistry of hydrocyanic-acid gass fumigation was submitted by the writer to the Bureau of Chemistry for execution. This work was carried out under the direction of Dr. J. K. Haywood, Chief of the Miscellaneous Division, by Mr. C. C. McDonnell, Chief of the Insecticide and Fungicide Laboratory. A report by Mr. McDonnell covering the results of this chemical investigation was sent to the Bureau of Entomology, August, 1909, and is here given. Certain important considerations included in this report have already been made public.- R. S. WoGLUM. 
of commercial acid forwarded by Mr. Woglum had the following composition :

No. 6530: Specific gravity, 1.827 (65.4
\[ \mathrm{H}_{2} \mathrm{SO}_{4} \text {. } \]

It contained merely a trace of ferrous sulphate, and no chlorids or nitrates were present. This is a fairly representative sample of commercial acid. A trace of nitric acid is sometimes present in commercial sulphuric, but the amount would probably never be large enough to be of any consequence when used for fumigation purposes.

CYANID SAMPLES.

Certain cyanid samples received from Mr. Woglum have been analyzed for cyanogen and chlorin. Practically all commercial cyanids contain small amounts of cyanates, carbonates, and traces of other compounds, but none of them has been determined quantitatively in these samples, as their presence in small amounts does not interfere with the use of these substances for fumigation.

Table of analyses.

\begin{tabular}{|c|c|c|c|c|c|}
\hline $\begin{array}{l}\text { Serial } \\
\text { No. }\end{array}$ & Material. & $\begin{array}{l}\text { Total } \\
\text { HCN. }\end{array}$ & $\begin{array}{l}\text { Calculated } \\
\text { to NaCN. }\end{array}$ & $\begin{array}{l}\text { Calculated } \\
\text { to KCN. }\end{array}$ & $\begin{array}{l}\text { Chlorin, } \\
\text { calculated } \\
\text { to NaCl. }\end{array}$ \\
\hline $\begin{array}{l}6523 \\
6524 \\
6525 \\
6526 \\
6527 \\
6528 \\
6529\end{array}$ & 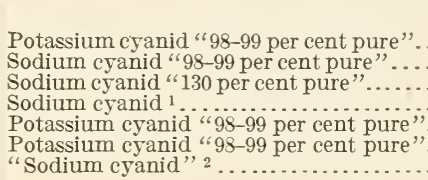 & $\begin{array}{r}\text { Per cent. } \\
40.42 \\
41.78 \\
51.22 \\
41.45 \\
39.96 \\
39.28 \\
41.02\end{array}$ & $\begin{array}{r}\text { Per cent. } \\
75.78 \\
92.92 \\
75.18 \\
\cdots \ldots .\end{array}$ & $\begin{array}{r}\text { Per cent. } \\
97.41 \\
100.68 \\
123.44 \\
99.88 \\
96.30 \\
94.67 \\
98.85\end{array}$ & $\begin{array}{r}\text { Per cent. } \\
0.40 \\
14.20 \\
.57 \\
5.82 \\
.60 \\
.77 \\
6.15\end{array}$ \\
\hline
\end{tabular}

1 A mixture of potassium and sodium cyanids (potassium equivalent to 21.03 per cent KCN).

$2 \mathrm{~A}$ mixture of potassium and sodium cyanids (potassium equivalent to 57.92 per cent $\mathrm{KCN}$ ).

The purity of sodium cyanid is frequently stated in terms of potassium cyanid, 100 parts of sodium cyanid being equivalent to 132.85 parts of potassium cyanid; that is, 100 parts of sodium cyanid will yield, theoretically, as much hydrocyanic-acid gas as 132.85 parts of potassium cyanirl.

All of these results are calculated to the potassium cyanid equiralent for comparison. Samples Nos. 6527 and 6528 had been exposed to the air for three months or longer before they were received and were undergoing slow decomposition, as shown by the odor of ammonia which they possessed. Decomposition would have been much more rapid than here shown if the samples had been exposed to moist air. Cyanids should always be kept dry and out of contact with the sir to prevent their decomposition. From the table of analyses it will be seen that samples Nos. 6524, 6526, and 6529 contain con- 
siderable amounts of sodium chlorid. While the amount of cyanid present is equivalent to that found in a high-grade potassium cyanid, owing to the presence of this chlorid they will vield considerably less gas, as subsequently shown in this paper, and are therefore not as valuable for fumigating purposes.

\section{PROPORTION OF CYANID, SUIPHURIC ACID, AND WATER FOR BEST YIELD OF GAS.}

\section{POTASSIUM CYANID.}

When dilute sulphuric acid acts on potassium cyanid, resulting in complete decomposition, the theoretical reaction is as follows:

$$
2 \mathrm{KCN}+\mathrm{H}_{2} \mathrm{SO}_{4}=\mathrm{K}_{2} \mathrm{SO}_{4}+2 \mathrm{HCN} .
$$

According to this reaction 1 ounce (avoirdupois) of potassium cyanid (KCN 100 per cent) would require 0.75 ounce (avoirdupois) of sulphuric acid, $\mathrm{H}_{2} \mathrm{SO}_{4}$, or 0.81 ounce (avoirdupois) of commercial sulphuric acid containing 93 per cent sulphuric acid, which would be equal to 0.42 fluid ounce.

The above reaction can not be obtained under the conditions existing in fumigation work, and to get the best yield of gas it is necessary to have a considerable excess of sulphuric acid. Under such conditions it would be the acid potassium sulphate that would be formed and the reaction would proceed thus:

$$
\mathrm{KCN}+\mathrm{H}_{2} \mathrm{SO}_{4}=\mathrm{KHSO}_{4}+\mathrm{HCN},
$$

or for each ounce (avoirdupois) of potassium cyanid there would be required 0.84 fluid ounce of 93 per cent sulphuric acid. This amount has been found in practice to give the best results, or, in round numbers, for convenience in practical field work, 1 part cyanid to 1 part acid. According to laboratory work the proportion of water that should be used with these amounts of cyanid and acid in order to obtain the best yield of gas was 2 parts. ${ }^{1}$ In field practice, however, Mr. Woglum has pointed out ${ }^{2}$ that it is not always practicable to use this amount on account of the fact that the residue sometimes solidifies in the generating jar, and he has therefore adopted and recommends 3 parts of water, or a $1-1-3$ formula.

\section{SODIUM CYANID.}

The action of sulphuric acid on sodium cyanid is identical with its action on the potassium salt, and is as follows:

$$
2 \mathrm{NaCN}+\mathrm{H}_{2} \mathrm{SO}_{4}=\mathrm{Na}_{2} \mathrm{SO}_{4}+2 \mathrm{HCN} \text {. }
$$


As sodium has a lower atomic weight than potassium, a greater yield of gas is obtained from the same weight of the cyanid of the former and a larger amount of sulphuric acid is required for its decomposition. According to this reaction, 1 ounce (avoirdupois) of sodium cyanid requires 1 ounce (avoirdupois) of sulphuric acid, $\mathrm{H}_{2} \mathrm{~S}_{2} \mathrm{O}_{4}$, or 1.07 ounces of commercial sulphuric acid containing 93 per cent of sulphuric acid, which is equivalent to 0.56 fluid ounce. As before noted, to get the best yield of gas the sulphuric acid must be in considerable excess, when the reaction would be:

$$
\mathrm{NaCN}+\mathrm{H}_{2} \mathrm{SO}_{4}=\mathrm{NaHSO}_{4}+\mathrm{HCN} \text {, }
$$

or for each ounce of sodium cyanid there would be required 2.14 ounces (avoirdupois) of 93 per cent sulphuric acid, equivalent to 1.12 fluid ounces. To determine the best proportions of sodium cyanid, sulphuric acid, and water to use in actual practice in order to obtain the largest yield of gas, the following experiments were carried out, using pure sodium cyanid containing 94 per cent actual sodium cyanid, the remainder being mainly moisture, and commercial sulphuric acid " $66^{\circ}$ Baumé," which on analysis showed 93.52 per cent sulphuric acid. Three-ounce (aroirdupois) portions of the sodium cyanid were employed in each experiment and varying amounts of sulphuric acid and water were taken. The decomposition was carried out in tall beakers of 4-liter capacity in order to prevent any possibility of loss from spattering. The water was first measured into the beaker, then the acid added, and the weighed package of cyanid was immediately dropped in. After standing 40 minutes the residue was washed out of the beaker into a graduated flask, cooled, made up to mark, thoroughly mixed, and aliquots taken for the determination of the amount of hydrocyanic acid remaining in solution. As has been shown by experiments herein reported, the difference between the total amount of cyanid in the quantity of material taken and that remaining in the residue does not represent correctly the amount of gas given off and available for fumigating purposes, but when operating on a pure cyanid, the less hydrocyanic acid remaining in the solution the greater will be the yield, and for measuring the relative efficiency of the different mixtures of acid and water it is only necessary to determine the amount of hydrocyanic acid in the residue.

In all determinations of cyanid Liebig's ${ }^{1}$ method has been used. In every case where ammonia was present in the solution, due to previous decomposition of the cyanid (in which case the end reaction would not appear as soon as it should, due to the solvent action of ammonia on the silver cyanid), a few drops of a dilute solution of potassium iodid were added in order to overcome this source of error, silver iodid being insoluble in dilute ammonia. 
Experiments to determine the best proportion of chemicals to be used.

\begin{tabular}{|c|c|c|c|c|c|}
\hline Experiment No. & $\begin{array}{c}\text { Sodium } \\
\text { cyanid } \\
(\mathrm{NaCN}) .\end{array}$ & $\begin{array}{c}\text { Sulphuric } \\
\text { acid } \\
\left(\mathrm{H}_{2} \mathrm{SO}_{4}\right) .\end{array}$ & $\begin{array}{l}\text { Water } \\
\left(\mathrm{H}_{2} \mathrm{O}\right) \text {. }\end{array}$ & $\begin{array}{l}\text { HCN re- } \\
\text { maining in } \\
\text { residue } \\
\text { (per cent } \\
\text { of total). }\end{array}$ & $\begin{array}{l}\text { HCN ex- } \\
\text { pelled (by } \\
\text { difference). }\end{array}$ \\
\hline
\end{tabular}

The following experiments were then made on samples of sodium cyanid of varying composition: No. 6524 contained 75.78 per cent of sodium cyanid and 14.20 per cent of sodium chlorid; No. 6525 contained 92.92 of sodium cyanid; and No. 6526 contained 75.18 per cent calculated as sodium cyanid and 5.82 per cent of sodium chlorid.

Experiments with different samples of sodium cyanid.

\begin{tabular}{|c|c|c|c|c|c|c|}
\hline \multirow{2}{*}{ Experiment No. } & \multicolumn{3}{|c|}{ Amount of chemicals used. } & \multicolumn{3}{|c|}{$\begin{array}{l}\mathrm{HCN} \text { remaining in residue } \\
\text { (per cent of total). }\end{array}$} \\
\hline & $\begin{array}{l}\text { Sodium } \\
\text { cyanid. }\end{array}$ & $\begin{array}{c}\text { Sulphuric } \\
\text { acid. }\end{array}$ & Water. & No. 6524 . & No. 6525 . & No. $6526 .^{1}$ \\
\hline $\begin{array}{l}19 \ldots \ldots \\
20 \ldots \ldots \\
21 \ldots \ldots \\
22 \ldots \ldots \\
23 \ldots \ldots \\
24 \ldots \ldots \\
25 \ldots \ldots\end{array}$ & $\begin{array}{r}\text { Oz., avoir. } \\
3 \\
3 \\
3 \\
3 \\
3 \\
3 \\
3\end{array}$ & $\begin{array}{r}\text { Fluid oz. } \\
3 \\
3 \\
3 \\
4 \\
4 \\
4 \\
5 \\
6\end{array}$ & $\begin{array}{r}\text { Fluid oz. } \\
3 \\
6 \\
9 \\
4 \\
6 \\
5 \\
6\end{array}$ & $\begin{array}{r}10.74 \\
7.68 \\
7.27 \\
.62 \\
1.65 \\
.39 \\
.24\end{array}$ & $\begin{array}{r}12.22 \\
8.16 \\
9.32 \\
3.16 \\
\ldots . . \\
1.73 \\
2.28\end{array}$ & $\begin{array}{r}8.53 \\
7.22 \\
\cdots . .2 \\
.80 \\
3.21 \\
.53 \\
.58\end{array}$ \\
\hline
\end{tabular}

1 A mixture of sodium cyanid, potassium cyanid, and sodium chlorid.

The acid acts very energetically on the sodium cyanid, and by comparing the results with those obtained in previous work with potassium cyanid it is shown that less hydrocyanic acid remains in the residue when using sodium cyanid. It may be stated here that the very low results obtained with the impure cyanids Nos. 6524 and 6526 are due to the decomposing action of hydrochloric acid, liberated from the sodium chlorid, on the hydrocyanic acid. When equal quantities of cyanid, acid, and water were used, there was not enough acid present to cause complete decomposition of the cyanid-decomposed lumps of which always remained in the residue-nor was 
there sufficient water to readily dissolve the sodium sulphate formed, as a result of which the residue in the beaker became semisolid. With the proportions $3-4-4,3-5-5$, and 3-6-6, less than 2 per cent of the total amount of hydrocyanic acid yielded by the cyanid remained in the residue when operating on a pure salt. There is little difference in the results from the three proportions, and 4 fluid ounces of acid to 3 ounces (avoirdupois) of cyanid appear to be sufficient. It is not necessary to have as much water present to keep the residue in the jar from "freezing" as when potassium cyanid is used, because the sodium sulphate formed is more soluble than potassium sulphate. There was no trouble from this cause in the use of the 3-4-4 formula. These experiments were carried out on a warm day, and the vessels were placed on a tin roof. If they were placed on the ground uncier a tent, the tendency would be to cool more rapidly, and under such conditions it may be found necessary in order to prevent "freezing" to increase the proportion of water, though it is desirable to keep this as low as possible, as an excess of water lowers the temperature of the acid and also holds in solution more of the hydrocyanic-acid gas.

Using the 3-4-6 formula, which contains sufficient acid to decompose all of the cyanid and also enough water to readily dissolve all of the sodium sulphate formed and prevent "freezing," only about $2 \frac{1}{2}$ per cent of the theoretical yield of the hydrocyanic acid remained in the residue. The following formula, therefore, is recommended as a good one for practical fumigation work in the field: 3 parts sodium cyanid, 4 parts acid, and 6 parts water-the sodium cyanid being expressed in ounces avoirdupois and the acid and water in fluid ounces.

\section{ACTION OF MINERAL ACIDS ON CYANIDS AND HYDROCYANIC ACID.}

The reactions which take place when sulphuric acid acts on potassium and sodium cyanids have been given and the amounts of hydrocyanic acid remaining in the residue after mixing these substances under certain conditions determined, it being assumed that the remainder was given off and available for fumigation purposes. This assumption, however, is not entirely correct, as all mineral acids cause more or less decomposition of hydrocyanic acid. With sulphuric acid this action, under the conditions in which fumigations are conducted, amounts to very little; in fact, it is scarcely worth considering, but in the case of an impure cyanid containing sodium chlorid (a frequent impurity), which on addition to sulphuric acid liberates hydrochloric acid, this decomposing action becomes a very importaht consideration and no doubt accounts for numerous reported instances of failure in fumigation work. It is possible to conceive of 
conditions under which all of the hydrocyanic acid may be decomposed by the hydrochloric acid and none whatever expelled into the medium which it is desired to fill with the gas.

This action of acids on hydrocyanic acid has been known to chemists for years, but the first work the writer has seen in which its bearing upon the subject of fumigation had been brought to the attention of the public was by Newell, ${ }^{1}$ in which he shows the decomposing action of hydrochloric and nitric acids on hydrocyanic acid and points out the necessity of using pure cyanids for fumigation work.

\section{ACTION OF SULPHURIC ACID ON HYDROCYANIC ACID.}

When potassium cyanid or sodium cyanid is treated with sulphuric acid, the first action which takes place is the liberation of hydrocyanicacid gas, as shown by previous equations. This is then acted upon to a greater or less extent, depending upon the conditions, and a portion of it decomposed: The principal products of decomposition are ammonia and formic acid, according to the following reaction:

$$
\mathrm{HCN}+2 \mathrm{H}_{2} \mathrm{O}=\mathrm{HCOOH}+\mathrm{NH}_{3} .
$$

The ammonia formed combines with the excess of sulphuric acid present and forms ammonium sulphate. If the sulphuric acid is concentrated, it attacks the formic acid, extracting water therefrom and liberating carbon monoxid, $\mathrm{CO}$, thus:

$$
[\mathrm{H}[\mathrm{CO}] \mathrm{OH}]=\mathrm{H}_{2} \mathrm{O}+\mathrm{CO} \text {. }
$$

Wade and Panting ${ }^{2}$ have shown that, on treating potassium cyanid with sulphuric acid, by suitably varying the concentration of the acid a practically quantitative yield of either hydrocyanic acid or carbon monoxid can be obtained. With dilute sulphuric acid and up to a strength of 1 part acid to 1 part water, which is as strong as it is ever used in fumigation work, nearly pure hydrocyanic acid is formed. With a stronger acid, however, "a certain amount of carbon monoxid is formed, and as the concentration of the acid is increased the volume of gas increases, while the amount of hydrogen cyanid diminishes; and finally, when ordinary concentrated sulphuric acid is allowed to act on the cyanid, nearly pure carbon monoxid is evolved in almost theoretical quantity." Concentrated sulphuric acid at a high temperature is reduced by hydrocyanic acid, sulphur dioxid, carbon dioxid, and ammonia being formed.

$$
\mathrm{HCN}+\mathrm{H}_{2} \mathrm{SO}_{4}=\mathrm{NH}_{3}+\mathrm{CO}_{2}+\mathrm{SO}_{2} \text {. }
$$

As sulphuric acid stronger than 1 part acid to 1 part water is never used in fumigation work, we need not concern ourselves with the 
effects produced by an acid of greater strength than this. With a more dilute acid than 1 to 1 the decomposing action on hydrocyanic acid amounts to very little, as shown by experiments which are reported herein.

\section{ACTION OF HYDROCHLORIC ACID ON HYDROCYANIC ACID.}

According to the researches of Gautier ${ }^{1}$ hydrocranic acid combines directly and sometimes violently with hydrochloric acid, resulting in bodies comparable with the ammonium salts or the amids. Gautier found that on passing dry hydrochloric-acid gas into dry hydrocyanic-acid gas, then heating to from $30^{\circ}$ to $40^{\circ}$, sealed in glass vessels, and allowing to cool, a colorless crystalline substance separated. From the results of the analysis of this compound he concluded that the formula must be HCN,HCl. He found that this body was extremely hygroscopic and underwent partial dissociation, but decomposed mainly into ammonium chlorid and formic acid in the following manner:

\section{$\mathrm{HCN}, \mathrm{HCl}+2 \mathrm{H}_{2} \mathrm{O}=\mathrm{NH}_{3} \mathrm{Cl}+\mathrm{HCOOH}$}

Several years later Claisen and Matthews ${ }^{2}$ made a study of the action of hydrochloric acid on hydrocyanic acid, and by employing a different method also obtained a white crystalline compound, which conducted itself similarly to the compound obtained by Gautier, but on analysis the results did not agree with the formula $\mathrm{HCN}, \mathrm{HCl}$ as found by him.

Claisen and Matthews, from their analytical results, ascribed to the compound the formula $2 \mathrm{HCN}, 3 \mathrm{HCl}$, and the following properties: "A colorless crystalline mass, inodorous in dry, and fuming strongly in moist, air. It appears to be only slightly poisonous and on solution in water shows only traces of hydrocyanic acid, probably present as an impurity in the original compound. It is insoluble in ethylic, formic, or acetic ethers; soluble, but with decomposition, in water and alcohol. On exposure to air it is rapidly converted into ammonium chlorid and formic acid." In fact, it resembled physically and gave exactly the same reactions as the compound obtained by Gautier.

More recently $\mathrm{Nef}^{3}$ has made an exhaustive study of the cyanogen compounds, including the action of hydrochloric acid on hydrocyanic acid. He arrived at the conclusion that these addition products are derivatives of imidoformyleyanid,

Comptes rendus, vol. 65 , p. 410,1867 .

1 Annalen der Chemie und Pharmacie, vol. 145, p. 11s, 1568.

Annales de chimie et de physique, ser. 4, vol. 17, p. 128, 1869.

- Jour. Chem. Soc. vol. 41, p. 264, 1882.

Berichte der deutschen chemischen Gesellschaft, vol. 16, p. 30s, $18 \$ 3$.

3 Liebig's Annalen der Chemie und Pharmacie, vol. 287, pp. 265-359, 1895. 


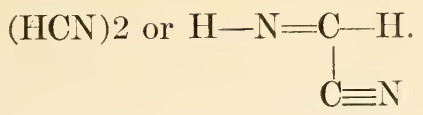

The first product formed being imidoformylchlorid<smiles>[N]=CCl</smiles>

which compound immediately combines with a second molecule of HCN thus

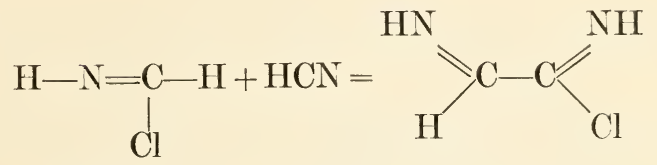

forming an imid-chlorid. This in turn takes up one or two molecular proportions of $\mathrm{HCl}$ with the formation of compounds of the following constitution:<smiles>N=C(Cl)C(Cl)(Cl)Cl</smiles>

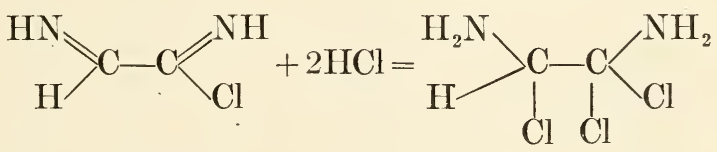

These compounds decompose in the presence of moisture, as before described, mainly into formic acid and ammonium chlorid.

\section{EFFECT OF THE PRESENCE OF SODIUM CHLORID IN CYANIDS ON THE YIELD OF HYDROCYANIC-ACID GAS IN FUMIGATIONS. ${ }^{1}$}

In order to determine the actual effect of different proportions of sodium chlorid (which on being treated with strong sulphuric acid liberates hydrochloric acid) in cyanids, when used for fumigation work, on the amount of hydrocyanic-acid gas liberated, the following experiments were conducted. Samples were prepared from pure sodium cyanid and sodium chlorid containing various proportions of sodium chlorid from 9 to 66.66 per cent.

Several experiments were also conducted, using pure sodium cyanid, containing 94 per cent of actual sodium cyanid (the remainder mainly moisture), for the purpose of determining the loss when using pure chemicals. These experiments were carried out as nearly as possible under the conditions actually obtaining in practical fumigation work, 
except, of course, on a small scale, and provision was made for the collection of the liberated hydrocyanic acid that it might be quantitatively determined. Figure 13 shows a cut of the apparatus employed for this purpose. On account of the inability to control the large volume of gas which is so rapidly generated when the solid cranid is all added to the acid at one time (as is done in actual practice) it was necessary to add it slowly, and in order to do this the charge was dissolved in water.

\section{DESCRIPTION OF APPARATUS.}

"A" is a flask of about 100 ce capacity into which the chemicals are placed for the generation of the hydrocyanic-acid gas; "B,"

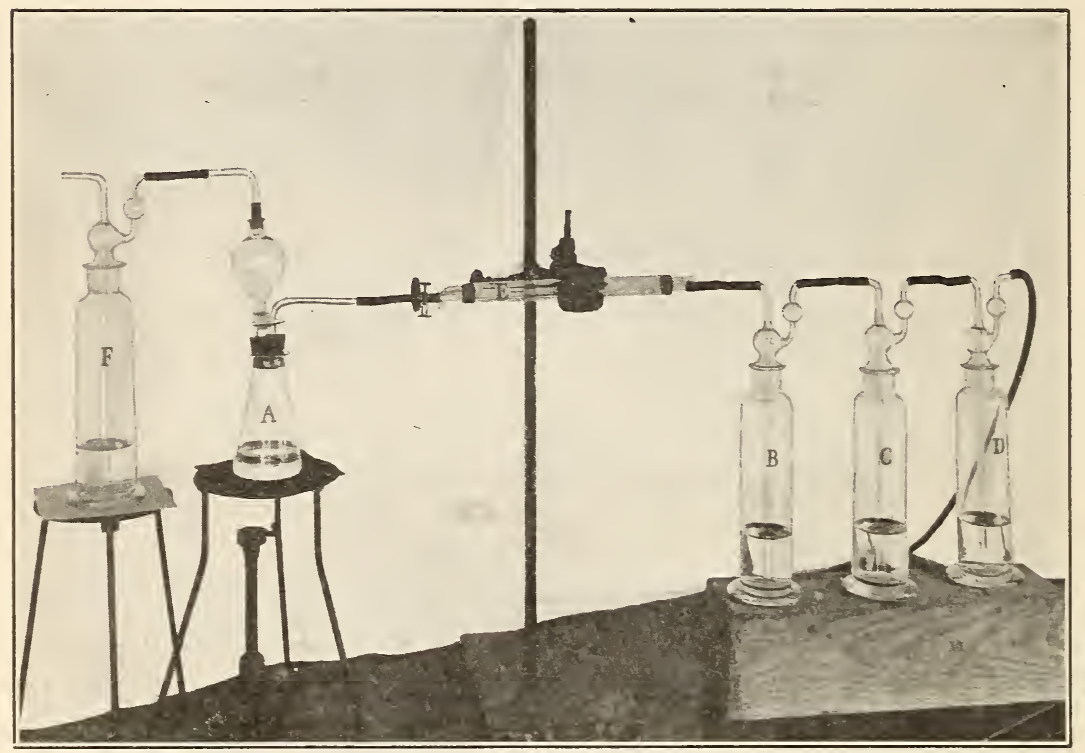

FIG. 13.-A pparatus used in the decomposition of cyanids and collection of the liberated hydrocyanicacid gas. (Original.)

"C," and "D" are Drechsel's gas wash bottles, and into each is put about 100 ce of a dilute solution of potassium hrdrate to absorb the gas. Bottle "F" contains a potassium hydrate solution to free the air that is drawn through from carbon dioxid, which decomposes cyanids in solution when passed through them. " $\mathrm{E}$ " is a condenser containing cold water to cool the gases before reaching " $\mathrm{B}$ " and thus prevent heating the solution in "B," which would cause decomposition of the potassium cyanid formed.

\section{DETAILS OF MANIPLLATION.}

To " add 10 ce of water, then 10 ce of concentrated sulphuric acid, after which add immediately to the separatory funnel 5 grams 
of the cyanid, previously dissolved in $10 \mathrm{cc}$ of water, and partially open the stopcock, allowing the solution of the cyanid to flow slowly into the acid. As soon as the stream of hydrocyanic-acid gas reaches "B," containing the potassium hydrate, it is absorbed very readily; in fact, so readily that unless the flow is quite rapid the potassiumhydrate solution rises in the tube and in several instances was drawn back into flask "A." In order to prevent this it is necessary to watch the apparatus constantly and not permit the flow of gas to subside; or, if this is impossible, to close the pincheock on the tube connecting the two flasks for an instant and apply suction. As soon as the solution of the cyanid has all been added the separatory funnel is washed. down with 1 ec of water, heat is applier to flask " $A$," and the temperature of the acid brought to $110^{\circ} \mathrm{C}$., which is about the average temperature obtained by adding 1 part acid to 2 parts water. 'The heat is then removed, flask " $\mathrm{F}$ " attached, suction applied, and air drawn through the apparatus for about 40 minutes. According to the authorities, air alone drawn through a solution of a cyanid causes it to decompose, but this action is very slow and for this work can be neglected. The residue in " $\Lambda$ " is washed out into a beaker, cooled, made alkaline with potassium hydrate, and the amount of cyanid present determined by titration with tenth-normal silver nitrate. The solution in " $\mathrm{B}$ " is washed out into"a $500 \mathrm{cc}$ flask, made to the mark, and aliquot portions used for the determination of the cyanid present. Solutions in "C" and "D" were also tested for cyanid, but in only two or three instances was any present, as in most cases it had all been absorbed in "B."

\section{RESULTS OF EXPERIMENTS.}

The results of the experiments conducted as outlined, when employing pure chemicals, are given in the following table:

Results of experimental work.

\begin{tabular}{|c|c|c|c|c|}
\hline Experiment No.- & $\begin{array}{c}\text { Equivalent } \\
\text { of HCN in } \\
\text { the sam- } \\
\text { ple. }\end{array}$ & $\begin{array}{l}\text { Per cent of } \\
\text { total HCN } \\
\text { evolved. }\end{array}$ & $\begin{array}{l}\text { Per cent of } \\
\text { total HCN } \\
\text { remaining } \\
\text { in "A.", }\end{array}$ & $\begin{array}{l}\text { Per cent of } \\
\text { total HCN } \\
\text { decom- } \\
\text { posed (by } \\
\text { ditference). }\end{array}$ \\
\hline $\begin{array}{l}1 . \ldots \ldots \\
2 \ldots \ldots \\
3 \ldots \ldots \\
4 \ldots \ldots \\
5 \ldots \ldots \ldots\end{array}$ & $\begin{array}{c}\text { Per cent. } \\
51.82 \\
51.82 \\
51.82 \\
51.82 \\
51.82\end{array}$ & $\begin{array}{l}94.81 \\
94.40 \\
93.77 \\
96.90 \\
96.28\end{array}$ & $\begin{array}{l}3.59 \\
3.29 \\
3.84 \\
2.20 \\
1.40\end{array}$ & $\begin{array}{r}1.60 \\
2.31 \\
2.39 \\
.90 \\
2.32\end{array}$ \\
\hline Average. . & 51.82 & 95.23 & 2.86 & 1.91 \\
\hline
\end{tabular}

These results indicate that there is some variation in the amount of hydrocyanic acid decomposed, but this would be expected from the fact that the experiments are subject to slight variations in the 
manipulation. The average amount decomposed is less than 2 per cent and the average remaining in the residue is practically 3 per cent, which shows that when operating with pure sodium cyanid and sulphuric acid we may expect to obtain close to 95 per cent of the theoretical yield of hydrocyanic-acid gas expelled and available for fumigation purposes. Sodium cyanids were then prepared containing varying quantities of sodium chlorid and the determinations made in) the same way. The results are tabulated as follows:

\begin{tabular}{|c|c|c|c|c|c|c|c|c|}
\hline \multirow{2}{*}{ Experiment No.- } & \multirow{2}{*}{$\begin{array}{l}\text { Equiva- } \\
\text { lent of } \\
\text { HCN in } \\
\text { sample. }\end{array}$} & \multirow{2}{*}{$\begin{array}{l}\text { Sodium } \\
\text { chlorid } \\
\text { in sam- } \\
\text { ple. }\end{array}$} & \multirow{2}{*}{$\begin{array}{c}\text { HCN } \\
\text { evolved. }\end{array}$} & \multirow{2}{*}{$\begin{array}{l}\text { HCN re- } \\
\text { maining } \\
\text { in resi- } \\
\text { due. }\end{array}$} & \multirow{2}{*}{$\begin{array}{l}\text { HCN de- } \\
\text { com- } \\
\text { posed } \\
\text { (by differ- } \\
\text { ence.) }\end{array}$} & \multicolumn{3}{|c|}{ Per cent of total HCN. } \\
\hline & & & & & & Evolved. & $\begin{array}{l}\text { In res- } \\
\text { idue. }\end{array}$ & $\begin{array}{l}\text { Decom- } \\
\text { posed. }\end{array}$ \\
\hline 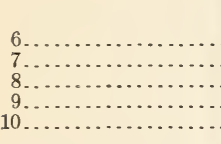 & $\begin{array}{r}\text { Per cent. } \\
47.16 \\
43.18 \\
34.55 \\
25.91 \\
17.27\end{array}$ & $\begin{array}{c}\text { Per cent. } \\
9 \\
16_{3}^{2} \\
33^{\frac{1}{3}} \\
50^{2} \\
66_{3}^{2}\end{array}$ & $\begin{array}{r}\text { Per cent. } \\
41.96 \\
27.42 \\
10.57 \\
5.85 \\
1.27\end{array}$ & $\begin{array}{r}\text { Per cent. } \\
0.66 \\
1.71 \\
.37 \\
.05 \\
.10\end{array}$ & $\begin{array}{r}\text { Per cent. } \\
4.54 \\
14.05 \\
23.61 \\
25.91 \\
15.90\end{array}$ & $\begin{array}{r}83.98 \\
63.49 \\
30.61 \\
22.58 \\
7.35\end{array}$ & $\begin{array}{r}1.40 \\
3.97 \\
1.06 \\
.21 \\
.63\end{array}$ & $\begin{array}{r}9.62 \\
32.54 \\
68.33 \\
77.21 \\
92.09\end{array}$ \\
\hline
\end{tabular}

\section{AMMONIA FORMED FROM THE DECOMPOSITION OF THE CYANID.}

The amount of ammonia, existing as ammonium sulphate, in the residue in flask " $\mathrm{A}$ " and that passed over into " $\mathrm{B}$ " was determined in several cases and the nitrogen calculated therefrom. These amounts added to the calculated amount of nitrogen in the hydrocyanic acid recovered in "A" and "B" correspond almost exactly with the theoretical amount of nitrogen in the quantity of cyanid employed. The distribution of nitrogen was as follows:

Distribution of nitrogen in the residue.

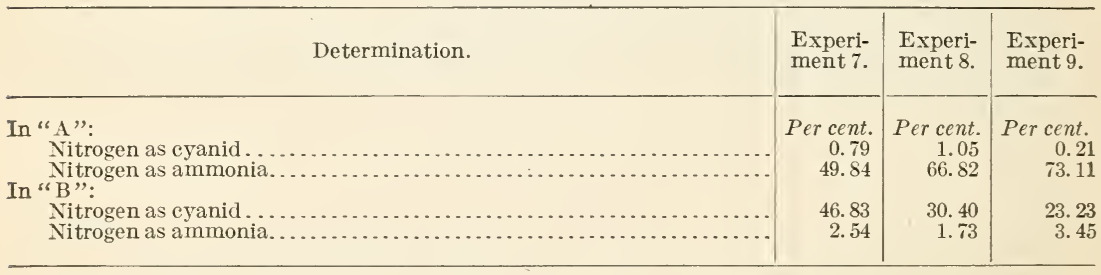

This shows that one of the principal decomposition products is ammonia, the greater part of which is held in solution in the generating flask by the excess of sulphuric acid as ammonium sulphate.

Experiments carried out on the samples of commercial cyanids, the analyses of which are given on page 92 , gave the following results: 
Experiments on commercial cyanids.

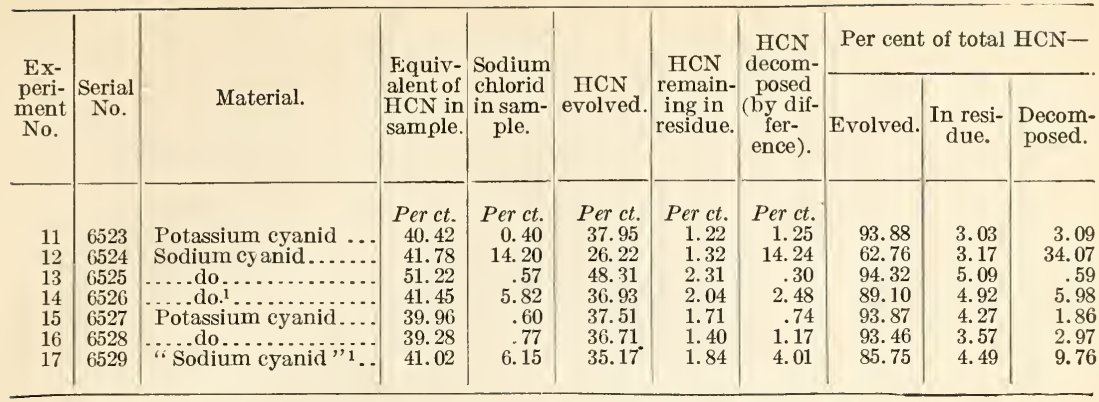

1 A mixture of potassium and sodium cyanids and sodium chlorid.

This work shows the great variation in the yield of hydrocyanic acid obtained when using samples as they appear upon the market, nearly twice as much being obtained from sample No. 6525 as from No. 6524. In view of such varying results as these it is not surprising that fumigation has so often proved a failure.

\section{EFFECT OF THE PRESENCE OF SODIUM NITRATE IN CYANIDS ON THE YIELD OF HYDROCYANIC-ACID GAS.}

Experiments carried out in the same way, using the same pure sodium cyanid, to which varying proportions of sodium nitrate had been added, gave results similar to those in which sodium chlorid was present. This fact is of no practical utility in so far as fumigation work is concerned, as cyanids do not contain nitrates as an impurity. Commercial sulphuric acid may contain traces of nitric acid, but the amount is so minute that it would have no appreciable effect on the results. Aside from this, the action of such an energetic oxidizing agent as nitric acid, in the presence of strong sulphuric acid, upon cyanids would be attended with some danger. The results of these experiments are given in the following table:

Effect of nitrates on the yield of hydrocyanic-acid gas.

\begin{tabular}{|c|c|c|c|c|c|c|c|c|}
\hline \multirow{2}{*}{ Experiment No. } & \multirow{2}{*}{$\begin{array}{l}\text { Equiva- } \\
\text { lent of } \\
\text { HCN in } \\
\text { sample. }\end{array}$} & \multirow{2}{*}{$\begin{array}{c}\text { Sodium } \\
\text { nitrate } \\
\text { in sam- } \\
\text { ple. }\end{array}$} & \multirow{2}{*}{$\begin{array}{c}\text { HCN } \\
\text { evolved. }\end{array}$} & \multirow{2}{*}{$\begin{array}{c}\text { HCN re- } \\
\text { maining } \\
\text { in resi- } \\
\text { due. }\end{array}$} & \multirow{2}{*}{$\begin{array}{l}\text { HCN de- } \\
\text { com- } \\
\text { posed (by } \\
\text { differ- } \\
\text { ence). }\end{array}$} & \multicolumn{3}{|c|}{ Per cent of total HCN- } \\
\hline & & & & & & Evolved. & $\begin{array}{l}\text { In resi- } \\
\text { due. }\end{array}$ & $\begin{array}{l}\text { Decom- } \\
\text { posed. }\end{array}$ \\
\hline $\begin{array}{l}18 \ldots \\
19 \ldots \\
20 \ldots \\
21 \ldots\end{array}$ & $\begin{array}{r}\text { Per cent. } \\
47.16 \\
43.18 \\
25.91 \\
17.27\end{array}$ & $\begin{array}{r}\text { Per cent. } \\
9 \\
16_{3}^{2} \\
50^{2} \\
66_{3}^{2}\end{array}$ & $\begin{array}{r}\text { Per cent. } \\
39.92 \\
37.73 \\
21.22 \\
13.12\end{array}$ & $\begin{array}{r}\text { Per cent. } \\
1.26 \\
1.32 \\
1.14 \\
.79\end{array}$ & $\begin{array}{r}\text { Per cent. } \\
5.98 \\
4.13 \\
3.65 \\
3.36\end{array}$ & $\begin{array}{l}84.66 \\
87.39 \\
81.51 \\
75.95\end{array}$ & $\begin{array}{l}2.67 \\
3.05 \\
4.40 \\
4.56\end{array}$ & $\begin{array}{r}12.67 \\
9.56 \\
14.09 \\
19.49\end{array}$ \\
\hline
\end{tabular}

The presence of nitrates exerts a very decided decomposing action on the hydrocyanic acid, but this action is much less than that produced by chlorids. The nitrogen in the decomposed cyanid is in this case also converted into ammonia.

$67330^{\circ}-$ Bull. $90-12-8$ 


\section{SUMMARY.}

In order that the results may be more readily compared they are all presented in one table, as follows:

Comparison of results obtained on evolution of hydrocyanic-acid gas under different conditions.

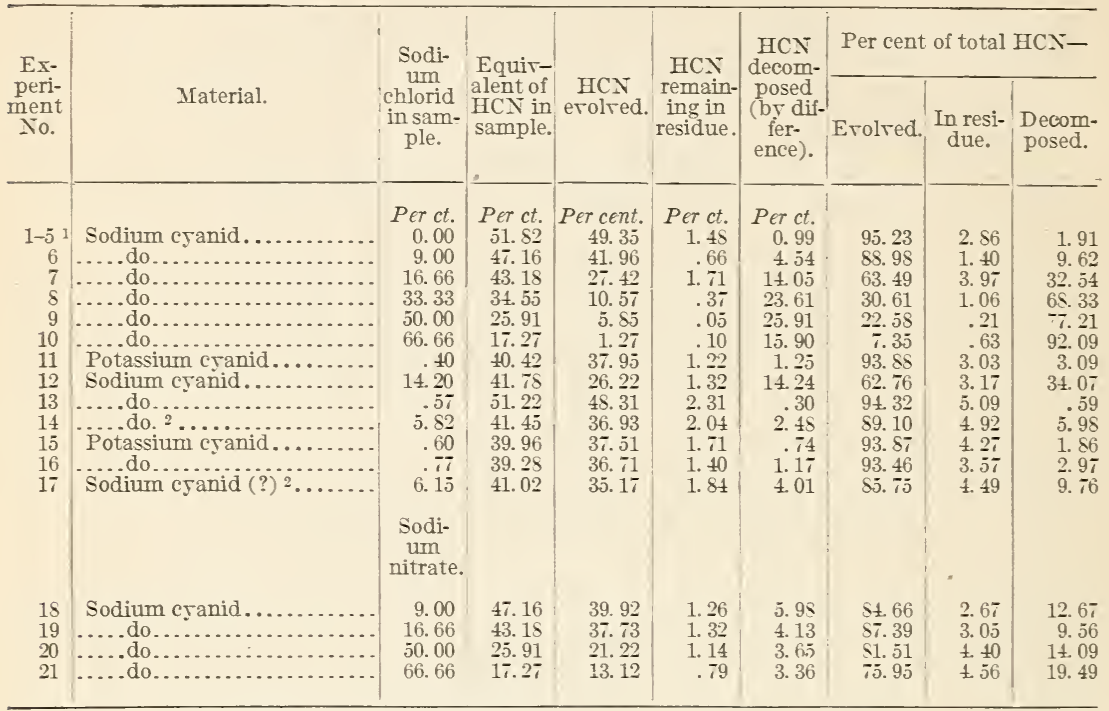

1 Arerage of five determinations.

2 A mixture of potassium and sodium cranid and sodium chlorid.

These experiments show conclusirely that the presence of chlorids and nitrates in cranids which liberate hydrochloric and nitric acid respectively, together with hydrocranic acid, on treatment with sulphuric acid cause rery marked decomposition of the hydrocranic acid. The effect produced by hydrochloric acid is much more marked than that produced by nitric acid. In one case (experiment 10) orer 92 per cent of the hydrocyanic acid was decomposed and only a little orer 7 per cent erolred. This is a larger amount of sodium chlorid than would erer be found in a commercial sample, but it shows the important bearing this impurity has upon the results. Practically all commercial potassium and sodium cyanids contain sodium chlorid in greater or less amount. Potassium cranid is frequently sold as "9S-99 per cent pure," which in reality is a mixture of potassium cyanid, sodium cranid, and sodium chlorid and on analysis may show eren 100 per cent expressed as potassium cyanid yet there may be sereral per cent of sodium chlorid present. For fumigation work an analysis of a cranid is of little value unless the chlorin content is also determined. In order that satisfactory results may bo obtained in the fumigation of trees for the control of insects 
the amount of hydrocyanic-acid gas that can be used falls within narrow limits. If the application is too strong serious injury will result to the trees, while on the other hand if too weak many of the insects will escape the poisonous action of the gas, thus necessitating a second fumigation or giving inefficient results. It is therefore necessary that the strength and quality of the reagents used be known and that the conditions under which the work is done be uniform. When these points are fully realized by entomologists and orchardists there is no doubt that better and more satisfactory results will be obtained. 



\section{N D X.}

Acids, minerol, action on cyanids and hydrocyanic acid .................. Page.

Ammonia formed by decomposition of cyanid...................... 102-103

Ammonium sulphate, residue from decomposition of cyanid............. 102-103

Bordeaux-distillate emulsion, injury through fumigation to trees sprayed there-

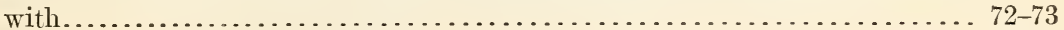

Cactus. (See Opuntia engelmanni.)

Carboy with handles to facilitate pouring acid in fumigation $\ldots \ldots \ldots \ldots \ldots \ldots 25,26$

Cart. (See Supply cart.)

Chart for dosage (see also Dosage schedule).

how to use it..................................... 34

Chemicals in fumigation................................. 40-51

amount in very small dosages................. 48

mixing................................. $48-49$

most economical proportion................ $47-48$

proportion when sodium cyanid is used........... 85

Chemistry of fumigation with hydrocyanic-acid gas................. 91-105

summary.............. 104-105

Chrysomphalus aurantii. (See Scale, red.)

citrinus. (See Scale, yellow.)

Citrus fruits, insect enemies in California ....................... $7-10$

orchards in California, extent and character................ 6-7

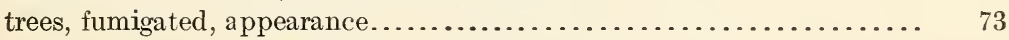

presence of old scales thereon.................. 74

fumigation. (See Fumigation of citrus trees.)

greater susceptibility of some varieties than others to injury from

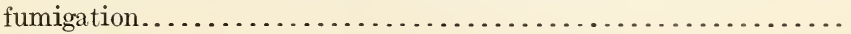

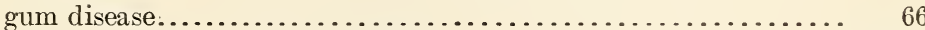

sprayed, injury to those fumigated .................... $72-73$

unhealthy, effects of fumigation thereon............... 66-67

Climatic conditions (see also Meteorological elements).

effect on scale insects of citrus................. $76-77$

Coccinella californica, effect of fumigation thereon................... 77

Coccinellidæ. (See Ladybirds.)

Cold, effects in fumigation of citrus trees........................ $70=71$

Cyanid, "American," not potassium cyanid but sodium cyanid............. 84

ammonia formed by its decomposition.................. 102-103

"German"............................................. 84

of potassium, analyses of samples used for production of hydrocyanica cid gas................................ 92-93

comparison with sodium cyanid for general fumigation.. $\quad 90$

cost.................................... 79

dosages of sodium cyanid in comparison with dosages of former.

in fumigation......................... $40-41$

proportion for best yield of hydrocyanic-acid gas....... 93

strength of sodium cyanid expressed in terms thereof.. $\quad 85$ 
Cyanid of sodium, analyses of samples used for production of hydrocyanic-acid gas.................................. 92-93

comparison with potassium cyanid for general fumigation.. dosages in fumigation compared with dosages of potassium cyanid.

first published suggestion as to use in fumigation.......... 83-84

inauguration of experiments by Bureau of Entomology and

Bureau of Chemistry......................... 84

in fumigation of citrus trees, field tests............. 86-87

kind to purchase for fumigation.................. 88

proportion for best yield of hydrocyanic-acid gas........ 93-96

of chemicals when used for fumigation......... 85

used in fumigation................... 85

strength expressed in terms of potassium cyanid....... 85

value for fumigation purposes..................... 83-90

Cyanids, action of mineral acids thereon........................ 96-99

effect of presence of sodium chlorid on yield of hydrocyanic-acid gas

in fumigation................... 99-102

nitrate on yield of hydrocyanic-acid gas.. 103

Derricks for fumigating tents................................... 20-21

Distillate emulsion and Bordeaux mixture, injury through fumigation to trees

sprayed therewith ................................ $72-73$

spray against citrus scales, efficiency as compared with fumigation.... 2

Dosage calculation in fumigation of citrus trees..................... 27-28

factors affecting it in fumigation....................... 52-53

formula for measuring fumigating tents...................... 28

schedule $A$, for high grade sodium cyanid.................. 88

No. 1, for potassium cyanid ........................ 34

$\frac{3}{4}$, for potassium cyanid........................ 59

$\frac{3}{4}-\mathrm{A}$, for high grade sodium cyanid................ 88

under improved system (with potassium cyanid).......... 34-37

Dosages for scale pests in general (with potassium cyanid) ............. 61

"Firing" effect produced in orchards by purple scale.................. 8

Fumigation against black scale............................. $59-60$

mealy-bug.................................. $63-64$

purple scale.............................. . 53-57

difficulty of destroying scale on fruit........ 56-57

dosage for eradication (with potassium cyanid). 55-56

length of exposure..................... 55

two successive treatments.............. $\quad 57$

red scale................................ 57-58

dosage with potassium cyanid.............. 58

yellow scale............................. 60 . 61

chemistry thereof............................... 91-105

summary ........................... 104-105

generators, device for covering them................. . $74-76$

of citrus trees..................................... 1-81

apparatus........................... 10-24

appearance of fumigated trees................ 73

by associations........................... 5

contract......................... $4-5$

counties............................. 5

private individuals................... $5-6$ 
chart for dosage (see also Fumigation of citrus trees, dosage schedule).

how to use it................ 34-37

chemicals.

amount in very small dosages. . . . . . . . . .

mixing

proportions, most economical......... . 47-48

proportion when sodium cyanid is used.. $\quad 85$

comparison of sodium cyanid and potassium cyanid

for general fumigation...................... 90

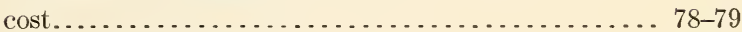

cover for generators. . . . . . . . . . . . . . . . . . . . 74-76

cyanid of potassium.................... . . 40-41

sodium, kind to purchase............. $\quad 88$

proportion used............. 85

derricks and poles..................... 20-21

distribution of gas within a tent............. 67

dosage calculation. . . . . . . . . . . . . . . . 27-28

factors affecting it................... 52-53

schedule A, for high grade sodium cyanid... 88

No. 1, for potassium cyanid...... 34

$\frac{3}{4}$, for potassium cyanid ....... 59

$\frac{3}{4}-\mathrm{A}$, for high grade sodium cyanid...................

under improved system (with potassium cyanid $) . \ldots \ldots \ldots \ldots \ldots . . . .34-37$

dosages for scale pests in general (with potassium

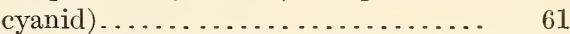
various scale pests, with potassium cyanid 51-61 sodium cyanid.. 88-90 during blossoming period................... 64-65 effect of presence of sodium chlorid on amount of gas given off ...................... 49-50

on ladybirds (Coccinellidæ) and Scutellista cyanea........................... . 77-78

effects of cold ............................ . $70-71$

heat....................... $69-70$

light.......................... $71-72$

meteorological elements. . . . . . . . . . . . 68-72

moisture ....................... . 68-69

temperature ...................... 69-71

winds.............................. 72

on different varieties.................. 67

unhealthy trees..................66-67

extent to which it is now practiced in California... 3-4 factors which affect dosage ................. $52-53$

field tests with sodium cyanid.............. 86-87

for physiological effects.................. . 67-68

fumigating lemons.................... 65-66

generating vessels........................... 24

cover device................ . 74-76

historical.......................... 1-2

improved system.................... 32-40 
Page.

Fumigation of citrus trees, improved system, advantages............. $37-38$

experience with it............. $38-40$

injury to sprayed trees................. $72-73$

leakage of gas, allowance therefor under improved

system............................ 33-34

McFadden machine for hoisting tents over trees... 21-22

suppiy magon.................. 23-24

nature of residue resulting from generation of gas. . 50-51

poles and derricks.................... 20-21

presence of old scales on fumigated trees........ 74

procedure. general....................... 24-31

improved system................ 37

old method .................... 30-31

published articles and addresses by R. S. Woglum.. $\quad 81$

renewal of interest in California............. 2-3

securing measurements around and over tents...... 28-30

securing measurements around and over tents, Mor-

rill method ........................... 29-30

sulphuric acid....................... 41-43

amount necessary . . . . . . . . . . . 42-43

proportion used with sodium cranid.. 85

supply cart and supply wagon. . . . . . . . . . . . 22-24

systems employed in California............. . 4-6

tents...................................

bell......................... 16

gas-proofing.......................... 16-18

marking.......................... 19-20

mildew-proofing..................... 1s-19

sheet............................. 10-16

amount of cloth required for different-

sized tents.................. 14-15

construction..................... 13-14

experiments with new tent material.... 12

material used.................... 11

new tenting material.............. 11-12

ring attachments and reenforcements... $1 \tilde{j}-16$

sizes........................... 11

size to purchase................... 15

what cloth to use.................. 12-13

time of year........................... 61-63

water as a factor....................... . 44-47

correct proportion with potassium cyanid.... 47

sodium cyanid....... \$5

effect of different proportions on amount of

available gas.................... $45-47$

effect of different proportions on temperature

of gas............................. 45

while fruit is small ........................ 65

Fungus, black, following infestation of citrus fruits by mealy-bug......... 10

sooty-mold, following infestation of oranges by black scale........ 3,9

Gas. (See Hydrocyanic-acid gas.)

Generating vessels, for fumigation............................... 24

cost............................ 79

cover derice...................... $74-76$ 
"Gophers," injury to citrus trees .............................. 66

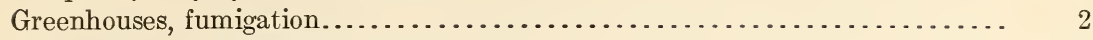

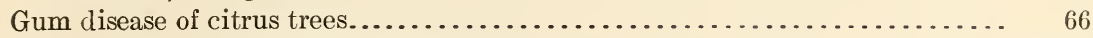

Heat, effects in fumigation of citrus trees........................... . $69-70$

Hemerobius sp., enemy of mealy-bug (Pseudococcus citri).................. 63

Hippodamia convergens, effect of fumigation thereon. . . . . . . . . . . . . . 77

Hydrochloric acid, action on hydrocyanic acid . . . . . . . . . . . . . . . . . . . 98-99

Hydrocyanic acid, action of hydrochloric acid thereon. . . . . . . . . . . . . . . 98-99

mineral acids thereon.................... . 96-99

sulphuric acid thereon................... . 97-98

gas (see also Fumigation).

cautions regarding use........................ 80

chemicals used for production, analyses........... . 91-93

distribution within a fumigating tent.............. 67

fumigation, chemistry thereof................ . . 91-105

summary............ 104-105

leakage through tents, allowance therefor under im-

proved system of fumigation................. . . 33-34

nature of residue from generation............. . . 50-51

proportion of cyanid of potassium, sulphuric acid, and

water for best yield of gas....................

yield as affected by presence of sodium chlorid in cya-

nids...... 99-102

nitrate in cya-

nids....... 103

Icerya purchasi, fumigation of citrus trees therefor.................... 1

Insect enemies of citrus fruits in California... . . . . . . . . . . . . . . . . $7-10$

"Jingler" attachment for sheet tents, purpose........ . . . . . . . . . . . 16

Labor for fumigation, cost..................................... 79

Ladybirds, effect of fumigation thereon. . . . . . . . . . . . . . . . . . . . . . 77

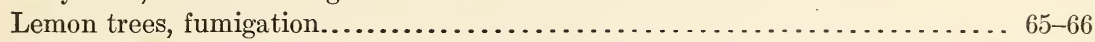

Lepidosaphes beckii. (See Scale, purple.)

Light, effects in fumigation of citrus trees. . . . . . . . . . . . . . . . . . . . . 71-72

Linseed oil, use for gas-proofing fumigating tents................... 16, 17-18

McDonnell, C. C., paper, "Chemistry of Fumigation with Hydrocyanic-Acid

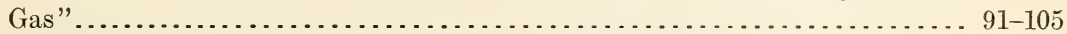

McFadden machine for placing fumigation tents on trees. . . . . . . . . . . . 21-22

supply wagon for use in fumigation of citrus trees. . . . . . . . . . . 23-24

Mealy-bug, enemy of citrus fruits in California. . . . . . . . . . . . . . . . . . . . . 10

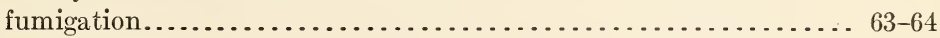

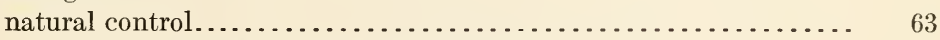

Meteorological elements (see also Climatic conditions).

effects on fumigation of citrus trees. . . . . . . . . . . 68-72

Mills, fumigation....................................... 2

Moisture, effects in fumigation of citrus trees. . . . . . . . . . . . . . . . . 68-69

Morrill method of measuring tented trees for dosage.. . . . . . . . . . . . . . . . 29-30

Nursery stock, fumigation..................................... . . 2

Opuntia engelmanni, use of concoction for gas-proofing fumigating tents...... 16

Oranges, decay in transit, causes................................. 2-3

Pepper tree. (See Schinus molle.)

Poles for fumigating tents.................................... 20-21

Potassium cyanid. (See Cyanid of potassium.)

Pseudococcus citri. (See Mealy-bug.)

Saissetia olex. (See Scale, black.) 
Scale, black, climatic Page.

enemy of citrus fruits in California.................... $7,8-9$

fumigation............................ $59-60$

dosages with potassium cyanid............... 59-60

sodium cyanid................. 89

introduction of parasite, Scutellista cyanea, into California....... 2 cottony-cushion. (See Icerya purchasi.)

insects affecting citrus, effect of climatic conditions thereon........ . 76-77

fumigation dosages with sodium cyanid....... 89-90

purple, climatic conditions most favorable................. 76

enemy of citrus fruits in California.................. 7,8

fumigation, difficulty of destroying scale on fruit............ 56-57

dosages with potassium cyanid................ 55-56

sodium cyanid................. $89^{\circ}$

length of exposure....................... 55

two successive treatments................... 57

red, climatic conditions most favorable.................... 76

enemy of citrus fruits in California.................. 7,9

fumigation..................................... $57-58$

dosages with potassium cyanid.............. 58

sodium cyanid.................... 89

San Jose, fumigation of trees therefor...................... 1

yellow, climatic conditions most favorable.................. 76

enemy of citrus fruits in California.................. 10

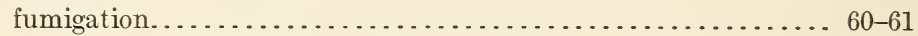

dosages with potassium cyanid................6 60-61

sodium cyanid................ 89

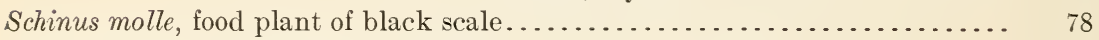

Scutellista cyanea, drawback to fumigation against black scale............ 60

effectiveness against black scale on pepper tree (Schinus

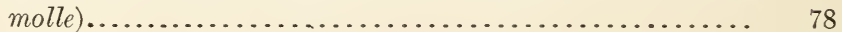

effect of fumigation thereon...................... $77-78$

parasite of black scale (Saissetia olex), introduction into

California.................................... 2

Sodium chlorid, action during generation of hydrocyanic-acid gas........... 87-88

effect of presence in cyanids on yield of hydrocyanic-acid gas

in fumigations.................... 49-50, 87-88, 99-102

cyanid. (See Cyanid of sodium.)

nitrate, effect of presence in cyanids on yield of hydrocyanic-acid gas

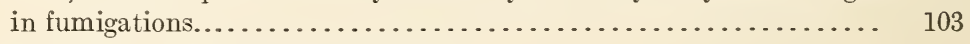

Sooty-mold fungus. (See Fungus, sooty mold.)

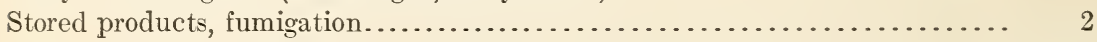

Sulphuric acid, action on hydrocyanic acid..................... 97-98

analyses of samples used for production of hydrocyanic-acid

gas......................................... 91-92

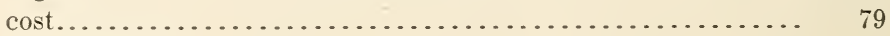

in fumigation............................ $41-43$

amount necessary................... 42-43

proportion with potassium cyanid for best yield of hydrocyanic-

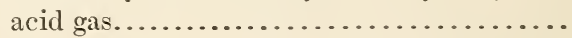

sodium cyanid for best yield of hydrocyanicacid gas...................... 85, 93-96 
$\begin{array}{ll}\text { Page. } & \\ 79 & \end{array}$

Supply cart for fumigation, cost................................. 79

equipment............................. 22-23

wagon for fumigation, equipment...................... 23-24

Syrphus fly, enemy of mealy-bug (Pseudococcus citri)................... 63

Tannin treatment for mildew-proofing fumigating tents............... 18-19

Temperature, effects in fumigation of citrus trees................ $69-71$

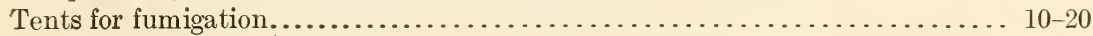

bell tents................................ 16

gas-proofing them................................. 18

marking them............................ 19-20

mildew-proofing them..................... 18-19

sheet tents....................................... 10

amount of cloth required for different sizes. . . 14-15

cloth to use....................... 12-13

construction........................ 13-14

experiments with new tent material......... 12

materials used....................... 11

new tenting material................ 11-12

ring attachments and reenforcements....... 15-16

sizes......................... 11

size to purchase..................... 15

Wagon. (See Supply wagon.)

Water as a factor in fumigation.............................. $44-47$

correct proportion with potassium cyanid in fumigation........... 47

sodium cyanid in fumigation.............. 85

in fumigation, effect of different proportions on amount of available gas. $45-47$

temperature of gas...... 45

proportion with potassium cyanid for best yield of hydrocyanic-acid gas. $\quad 93$

sodium cyanid for best yield of hydrocyanic-acid gas... 93-96

Winds, effects in fumigation of citrus trees......................... 72

Woglum, R. S., paper, "Fumigation of Citrus Trees"................ 1-81

"The Value of Sodium Cyanid for Fumigation Purposes" 83-90

ADITIONAL COPIES of this publication A. may be procured from the SUPERINTENDENT OF Documents, Government Printing Office, Washington, D. C., at 20 cents per copy 

1 



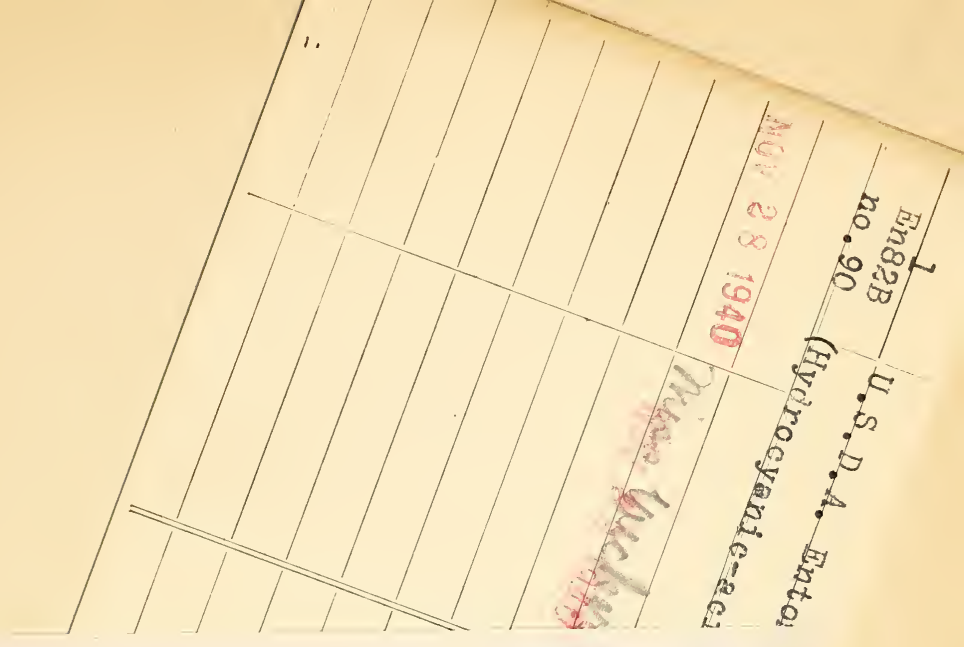

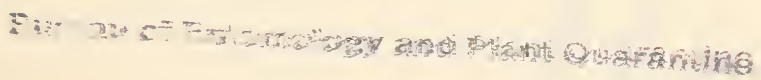


